\title{
WestVirginiaUniversity
}

THE RESEARCH REPOSITORY @ WVU

Graduate Theses, Dissertations, and Problem Reports

2005

\section{Staten Island Ferry emissions reduction}

John Nuszkowski

West Virginia University

Follow this and additional works at: https://researchrepository.wvu.edu/etd

\section{Recommended Citation}

Nuszkowski, John, "Staten Island Ferry emissions reduction" (2005). Graduate Theses, Dissertations, and Problem Reports. 1874.

https://researchrepository.wvu.edu/etd/1874

This Thesis is protected by copyright and/or related rights. It has been brought to you by the The Research Repository @ WVU with permission from the rights-holder(s). You are free to use this Thesis in any way that is permitted by the copyright and related rights legislation that applies to your use. For other uses you must obtain permission from the rights-holder(s) directly, unless additional rights are indicated by a Creative Commons license in the record and/ or on the work itself. This Thesis has been accepted for inclusion in WVU Graduate Theses, Dissertations, and Problem Reports collection by an authorized administrator of The Research Repository @ WVU. For more information, please contact researchrepository@mail.wvu.edu. 


\title{
Staten Island Ferry Emissions Reduction
}

\author{
John Nuszkowski
}

Thesis submitted to the

\author{
College of Engineering and Mineral Resources \\ at West Virginia University \\ in partial fulfillment of the requirements \\ for the degree of
}

\author{
Master of Science \\ in \\ Mechanical Engineering
}

Gregory J. Thompson, Ph.D., Chair

Nigel Clark, Ph.D.

Mridul Gautam, Ph.D.

Department of Mechanical and Aerospace Engineering

\section{Morgantown, West Virginia \\ 2005}




\section{ABSTRACT \\ Staten Island Ferry Emissions Reduction}

\section{John Nuszkowski}

Marine diesel engines are being investigated thoroughly since many engines in these vessels incorporate older technology that may not have been subjected to emissions regulations and hence produce a significant amount of pollution. The Staten Island Ferry Alice Austen was fitted with selective catalytic reduction (SCR) technology to reduce the emissions of oxides of nitrogen (NOx) to offset the dredging equipment emissions from the Harbor Deepening project. Data logging showed a repeatable route of vessel operation including an idle, acceleration, cruise, and maneuvering mode combined with vessel direction. The SCR system provided $34-64 \%$ NOx reduction for a round trip with less than 8ppm ammonia slip. Average NOx reductions during cruise mode were 47$75 \%$. Reductions for the cruise mode during urea injection typically exceeded $94 \%$. From modal analysis of onboard testing, idle, acceleration, and maneuvering produced $20 \%$ of the NOx. Cruise produced $80 \%$ of the NOx. The oxidation catalyst provided 80 $95 \%$ reduction in carbon monoxide. 


\section{TABLE OF CONTENTS}

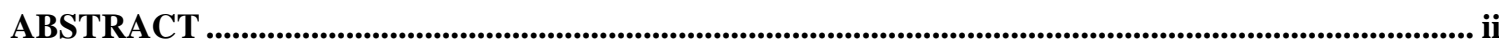

TABLE OF CONTENTS .....................................................................................................................................iii

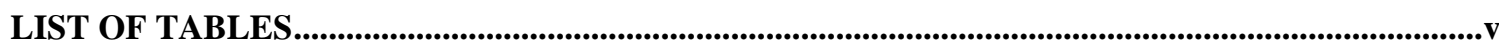

LIST OF FIGURES................................................................................................................................. vi

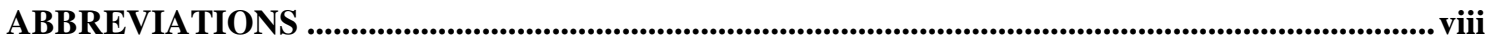

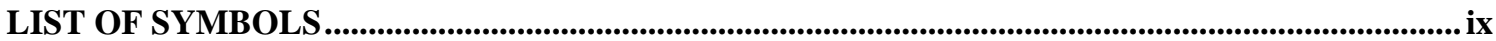

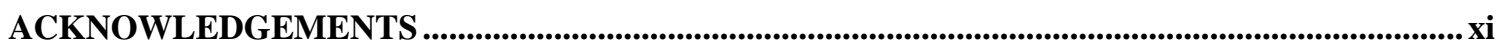

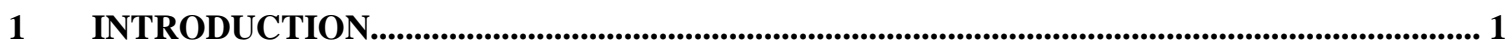

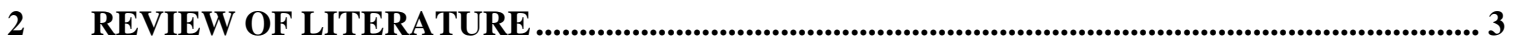

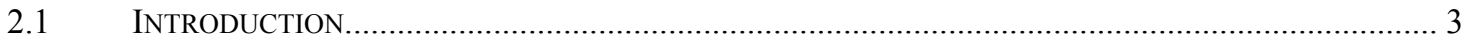

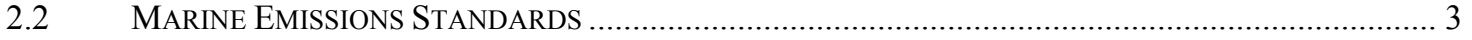

2.3 PRIOR IN-USE MARINE EMISSION MEASUREMENT STUDIES ..................................................... 4

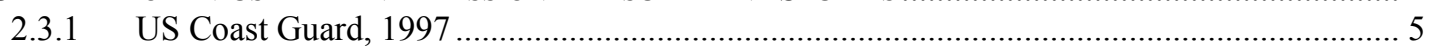

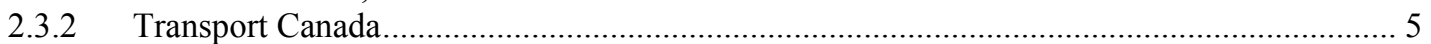

2.3.2.1 Field Testing of Water Injection System (WIS), 1999-2000 …………………...................... 5

2.3.2.2 Engine Exhaust Emissions Evaluation of the MV Cabot, 2000 .................................................. 6

2.3.2.3 Field Testing of WIS onboard MV Cabot, 2004 ............................................................. 6

2.3.3 Walther Engineering Services, Inc., 2001-2002 …….......................................................... 7

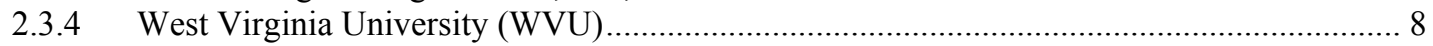

2.3.4.1 Hampton Road Transit Authority Ferry Boats, 2002 ……………………………………... 8

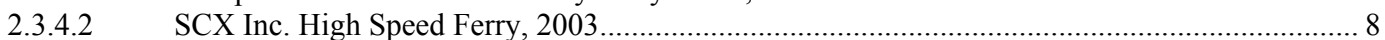

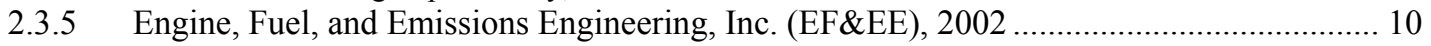

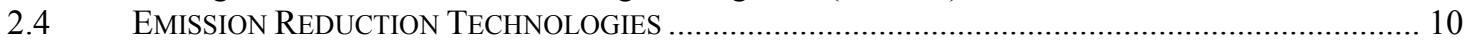

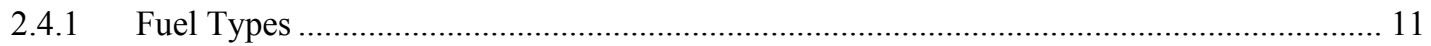

2.4.1.1 Ultra-Low Sulfur Diesel Fuel....................................................................................... 11

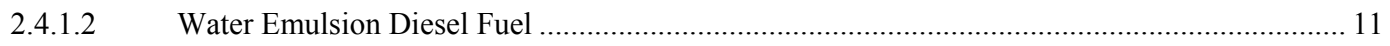

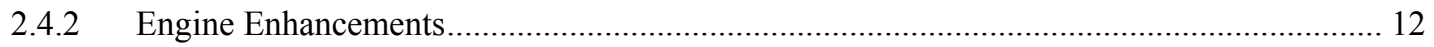

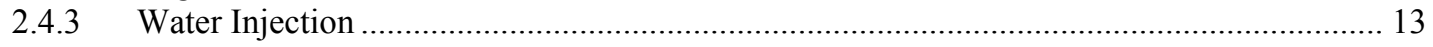

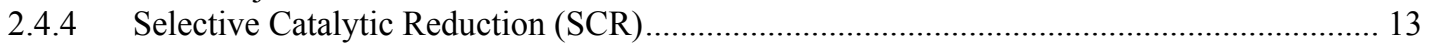

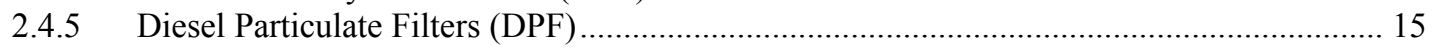

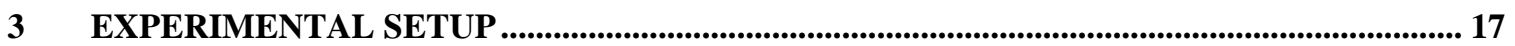

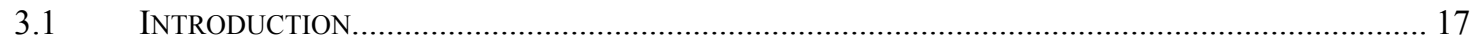

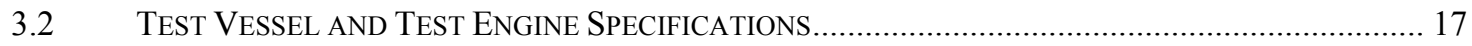

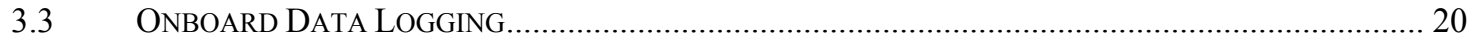

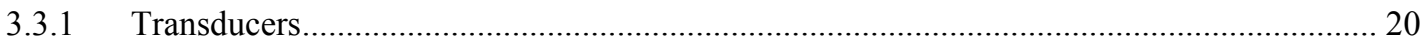

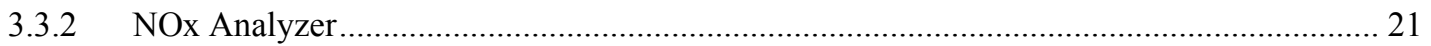

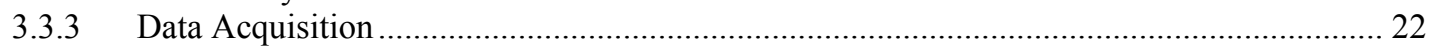

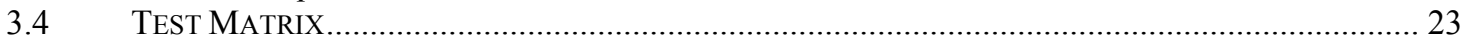

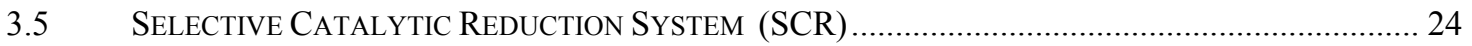

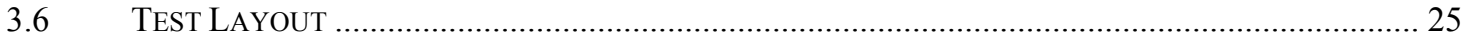

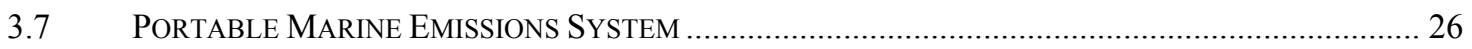

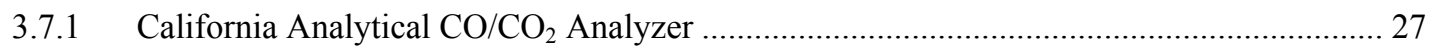

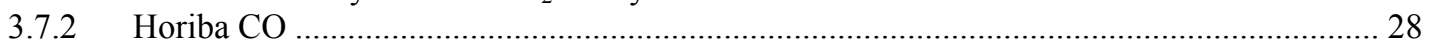

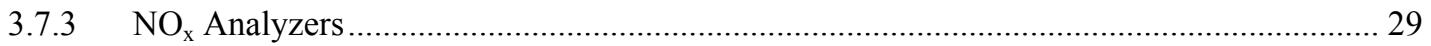

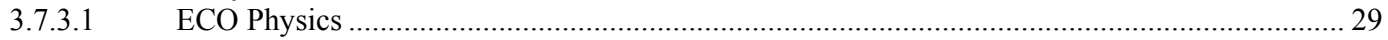

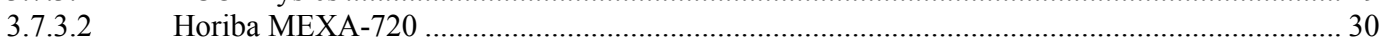

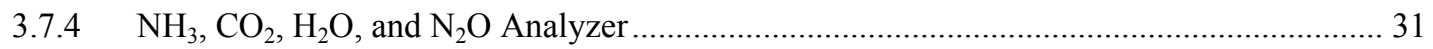

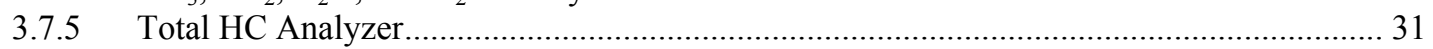




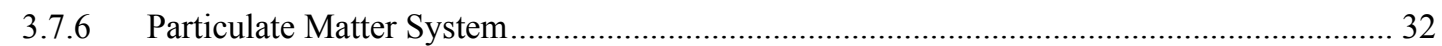

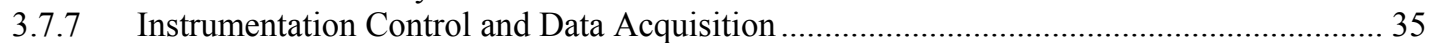

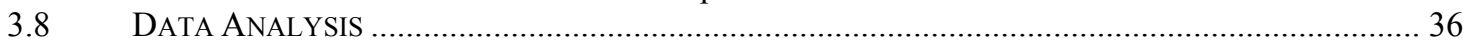

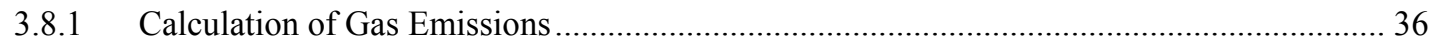

3.8.2 Calculation of Particulate Matter Emissions....................................................................... 40

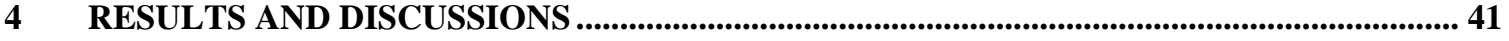

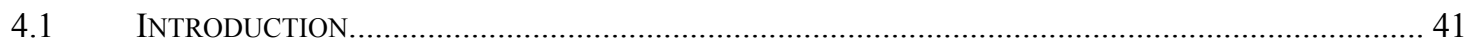

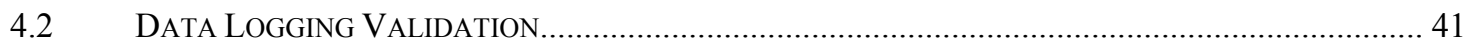

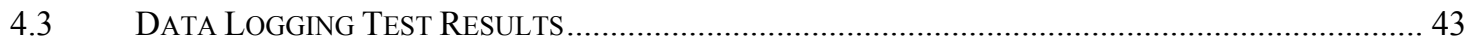

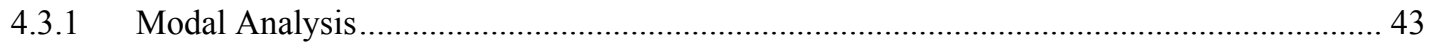

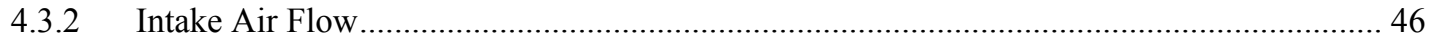

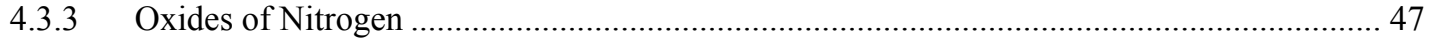

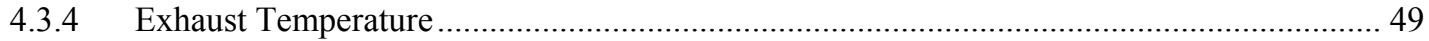

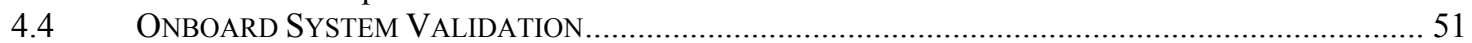

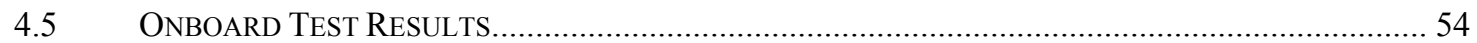

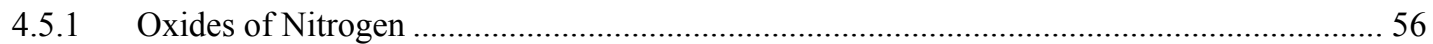

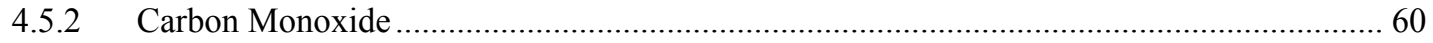

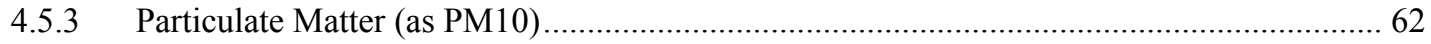

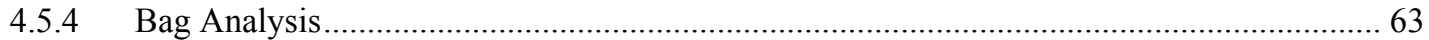

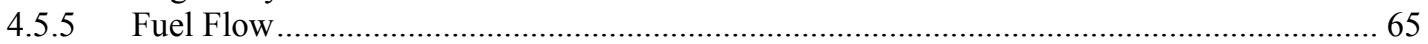

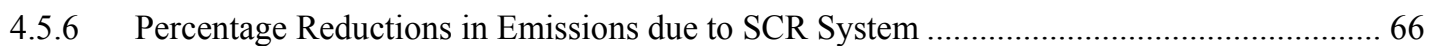

4.6 COMPARISON OF MODAL ONBOARD NOX TO PREVIOUS DATALOGGING NO.............................. 69

5 CONCLUSIONS AND RECOMMENDATIONS ......................................................................... 71

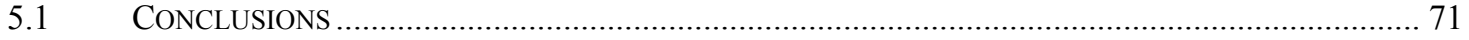

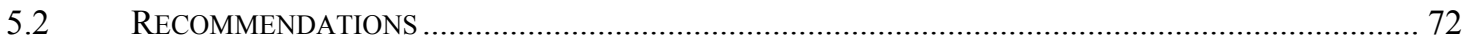

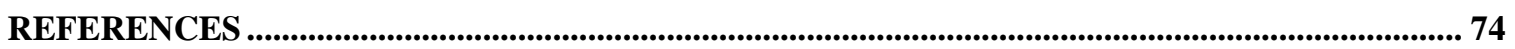

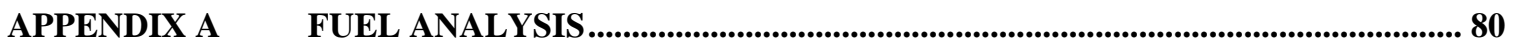

APPENDIX B DATALOGGER EXAMPLE PROGRAM …...................................................... 84

APPENDIX C GAS ANALYZER SPECIFICATIONS .................................................................. 88

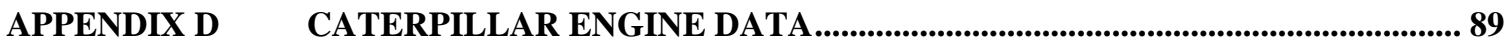

APPENDIX E INDIVIDUAL RUN RESULTS .................................................................................. 90 


\section{LIST OF TABLES}

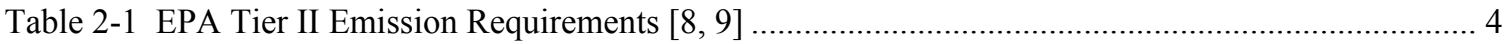

Table 2-2 Results of SCX ferry NOx emissions [15] .................................................................... 9

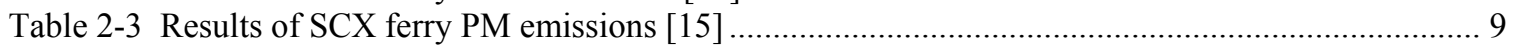

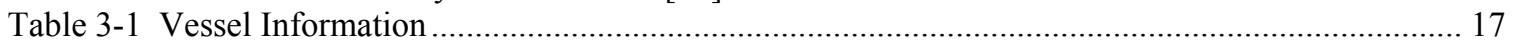

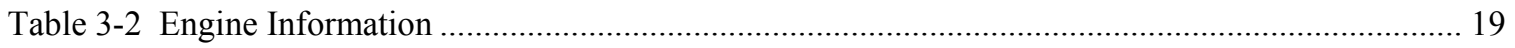

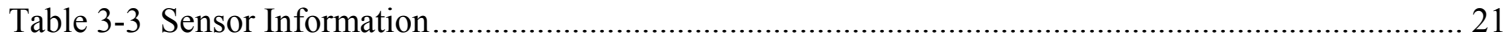

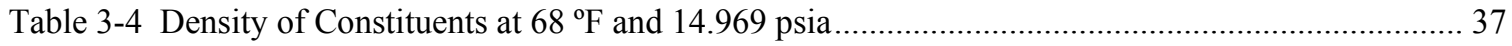

Table 4-1 Marine Measurement System Validation Gas Emissions Test Points ......................................... 52

Table 4-2 Average Percent Difference of Raw Analyzers Results to Lab Results ....................................... 54

Table 4-3 Time Based Weighting Factors used for Round Trip Calculation ................................................ 55

Table 4-4 Brake-Specific Emissions and Mass Emitted Test Results for a Compete Round Trip .............. 55

Table 4-5 Percent Reduction in Emissions for Each Engine: Average Brake-Specific Round Trip Data

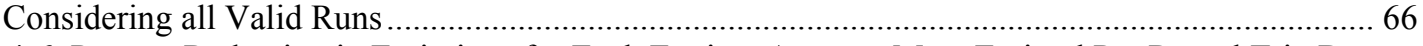

Table 4-6 Percent Reduction in Emissions for Each Engine: Average Mass Emitted Per Round Trip Data

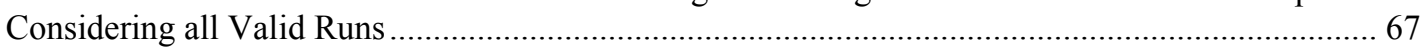

Table 4-7 Percent Reduction in NOx Emissions for Each Engine when Pre and post-aftertreatment was

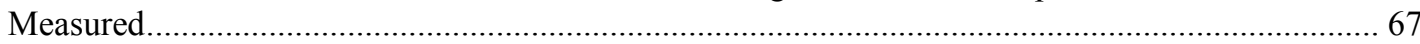




\section{LIST OF FIGURES}

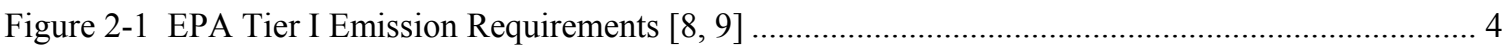

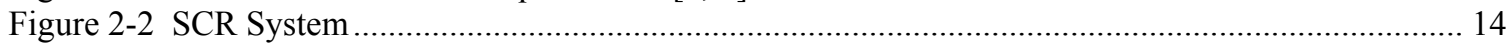

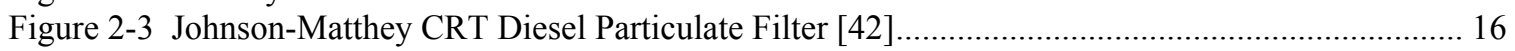

Figure 3-1 Staten Island Ferry Vessel, Alice Austen in the foreground [46] ............................................. 18

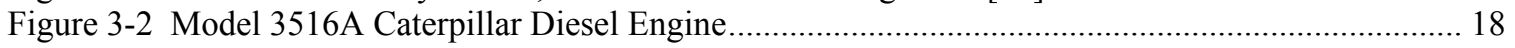

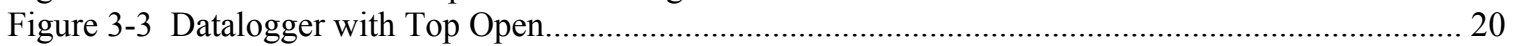

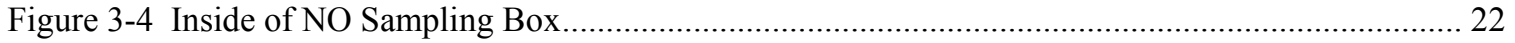

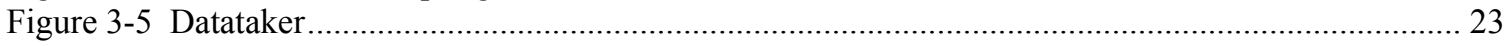

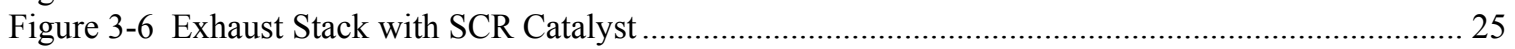

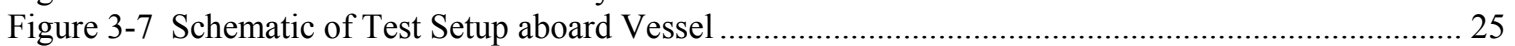

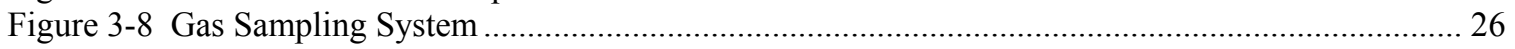

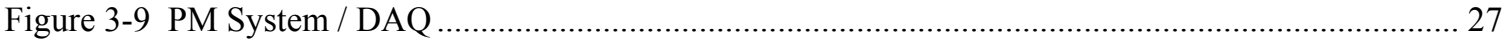

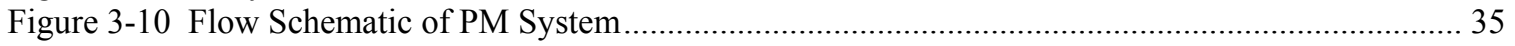

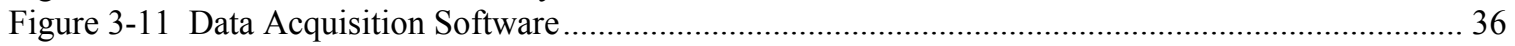

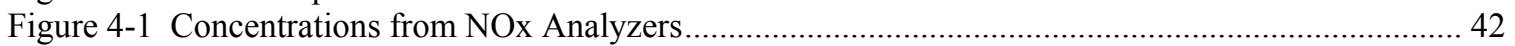

Figure 4-2 Percent Difference to Zirconia Oxide Sensor .......................................................................... 43

Figure 4-3 Alice Austen Location over a Single Day with 8 Round Trips [55] ......................................... 44

Figure 4-4 Mode Times Based on Direction and Engine ........................................................................ 45

Figure 4-5 Engine Speed of Route to Manhattan and back to Staten Island............................................... 46

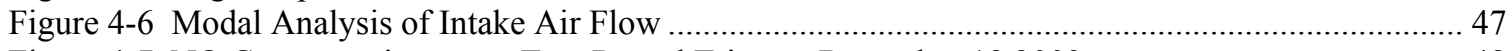

Figure 4-7 NO Concentrations over Two Round Trips on December 182003 ......................................... 48

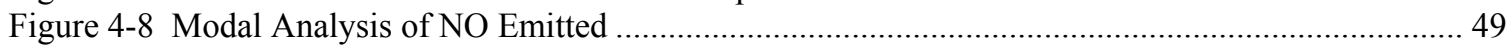

Figure 4-9 Engines Exhaust Temperatures during two trips ..................................................................... 50

Figure 4-10 Frequency and Cumulative of Exhaust Temperatures for Engine NY .................................... 51

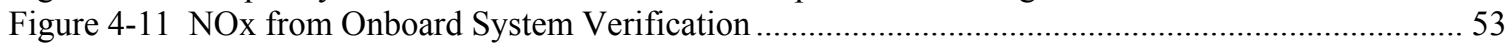

Figure 4-12 EPA 2007 Emission Requirements Compared to In-Use Emissions: Average Round-Trip Data

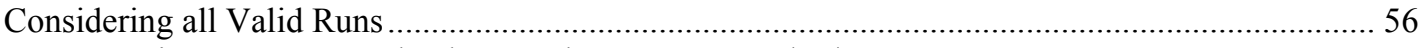

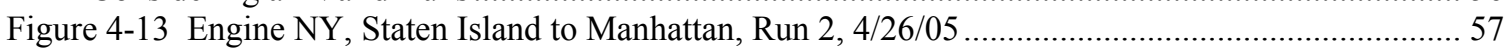

Figure 4-14 Engine SI, Manhattan to Staten Island, Run 1, 4/28/05 …….............................................. 58

Figure 4-15 Onboard Pre and post-aftertreatment NOx Modal Test Results: Average Modal Data Considering all Valid Runs ............................................................................................................ 59

Figure 4-16 Pre and post-aftertreatment with EPA Standards: Average Round-Trip Data Considering all

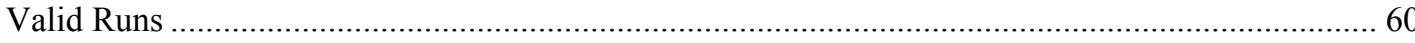

Figure 4-17 Concentration of CO in Engine NY from Staten Island to Manhattan Sampled Pre and postaftertreatment from Two Separate One-Way Time-Aligned Trips (The exhaust gas may be rich

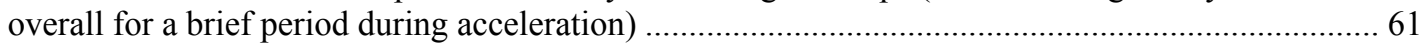

Figure 4-18 Onboard Pre and post-aftertreatment CO Modal Test Results: Average Modal Data

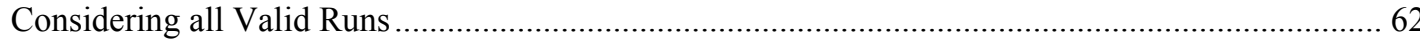

Figure 4-19 Onboard Pre and post-aftertreatment PM Modal Test Results: Average Modal Data

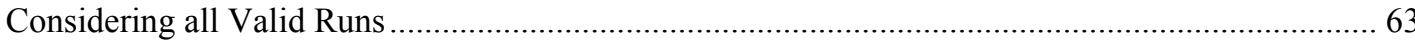

Figure 4-20 Onboard Pre-Aftertreatment $\mathrm{NH}_{3}$ Modal Test Results: Average Modal Data Considering all Valid Runs

Figure 4-21 Onboard Post-Aftertreatment $\mathrm{NH}_{3}$ Modal Test Results: Average Modal Data Considering all Valid Runs

Figure 4-22 Onboard Pre and post-aftertreatment Fuel Flow Modal Test Results: Average Modal Data

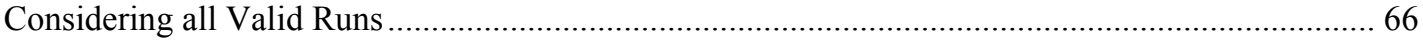

Figure 4-23 Percent Reduction of NOx during a One-Way Trip Based on Urea Injection Delay.................. 68 Figure 4-24 Percent Reduction of NOx Over One-Way Trip Based on Catalyst Turn-On Temperature

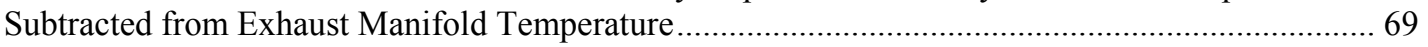

Figure 4-25 Comparison of Pre-Aftertreatment NOx from onboard testing and Datalogging .................... 70

Figure D - 1 Engine Manufacture Emission Values Based on Similar Engine ........................................... 89

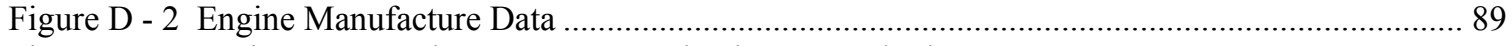

Figure E - 1 Engine NY, Manhattan to Staten Island, Run 2, 4/26/05 .................................................. 90 


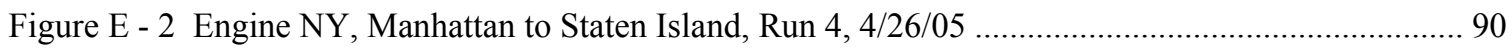

Figure E - 3 Engine NY, Staten Island to Manhattan, Run 5, 4/26/05 ................................................. 91

Figure E - 4 Engine NY, Manhattan to Staten Island, Run 5, 4/26/05 ............................................... 91

Figure E - 5 Engine SI, Staten Island to Manhattan, Run 2, 4/28/05 .............................................. 92

Figure E - 6 Engine SI, Manhattan to Staten Island, Run 2, 4/28/05 .............................................. 92

Figure E - 7 Engine SI, Staten Island to Manhattan, Run 3, 4/28/05 .............................................. 93

Figure E - 8 Engine SI, Manhattan to Staten Island and back, Run 3-4, 4/28/05 ............................... 93

Figure E - 9 Engine SI, Staten Island to Manhattan, Run 4, 4/28/05 .............................................. 94 


\section{ABBREVIATIONS}

\begin{tabular}{|c|c|}
\hline CARB & California Air Resources Board \\
\hline CFR & Code of Federal Regulations \\
\hline CI & Compression Ignition \\
\hline $\mathrm{CO}$ & Carbon Monoxide \\
\hline $\mathrm{CO}_{2}$ & Carbon Dioxide \\
\hline DPF & Diesel Particulate Filter \\
\hline EC & Electrochemical \\
\hline ECD & Emissions Control Diesel \\
\hline EERL & Engine and Emissions Research Laboratory \\
\hline EGR & Exhaust Gas Recirculation \\
\hline EPA & Environmental Protection Agency \\
\hline $\mathrm{HC}$ & Hydrocarbon \\
\hline HEPA & High Efficiency Particulate Air \\
\hline HFID & Heated Flame Ionization Detector \\
\hline IMO & International Maritime Organization \\
\hline ISO & International Organization for Standardization \\
\hline LFE & Laminar Flow Element \\
\hline LSD & Low Sulfur Diesel \\
\hline MARAD & Maritime Administration \\
\hline MEMS & Mobile Emissions Measurement System \\
\hline NDIR & Non Dispersive Infrared \\
\hline NO & Nitric Oxide \\
\hline $\mathrm{NO}_{\mathrm{x}}$ & Oxides of Nitrogen \\
\hline NREL & National Renewable Energy Laboratory \\
\hline $\mathrm{O}_{2}$ & Oxygen \\
\hline PM & Particulate Matter \\
\hline SAE & Society of Automotive Engineers \\
\hline SCR & Selective Catalytic Reduction \\
\hline SOF & Soluble Organic Fraction \\
\hline $\mathrm{SO}_{\mathrm{x}}$ & Oxides of Sulfur \\
\hline THC & Total Hydrocarbon \\
\hline ТPМ & Total Particulate Matter \\
\hline USDOE & United States Department of Energy \\
\hline WIS & Water Injection System \\
\hline WVU & West Virginia University \\
\hline $\mathrm{ZrO}_{2}$ & Zirconium Dioxide \\
\hline
\end{tabular}




\section{LIST OF SYMBOLS}

\begin{tabular}{|c|c|}
\hline$\lambda$ & Relative air/fuel ratio, Lambda, ( - ) \\
\hline$\left(\frac{A}{F}\right)_{\text {Actual }}$ & Actual Stoichiometric Air-to-Fuel Ratio, ( - ) \\
\hline$\left(\frac{A}{F}\right)_{\text {stoich }}$ & Stoichiometric Air-to-Fuel Ratio, ( - ) \\
\hline$\alpha$ & Hydrogen-to-Carbon Ratio, ( - ) \\
\hline$\rho_{\text {exh }}$ & Density of the Exhaust, $\left(\mathrm{g} / \mathrm{ft}^{3}\right)$ \\
\hline$[\mathrm{XX}]$ & Gas Concentration, Wet, (\%) \\
\hline$\{X X\}$ & Gas Concentration, Wet, (ppm) \\
\hline$\left(\mathrm{CO}_{2}\right)_{\text {raw }}$ & Concentration of $\mathrm{CO}_{2},(\%)$ \\
\hline$\left(\mathrm{CO}_{2}\right)_{\text {background }}$ & Concentration of $\mathrm{CO}_{2}$ in Background Air, (\%) \\
\hline$\left(\mathrm{CO}_{2}\right)_{\text {dilution }}$ & Concentration of $\mathrm{CO}_{2}$ in Diluted Exhaust, (\%) \\
\hline$B A R O$ & Barometric Pressure $(\mathrm{Pa})$ \\
\hline$B S_{i}$ & Brake-Specific Value of Exhaust Constituent i, (g/bhp-hr) \\
\hline BSFC & Brake Specific Fuel Consumption, (lbs/bhp-hr) \\
\hline$C_{E}$ & Engine Speed, (rpm) \\
\hline$C_{i, d}$ & Concentration of Exhaust Constituent, Dry, (ppm) \\
\hline$C_{i, w}$ & Concentration of Exhaust Constituent, Wet, (ppm) \\
\hline$D$ & Distance Traveled, (miles) \\
\hline$D R$ & Dilution Ratio, ( - ) \\
\hline DVOL Ratio & Ratio of Dry Intake Air to Dry Exhaust Air, ( - ) \\
\hline$H$ & Specific Humidity, ( $\mathrm{g} \mathrm{H}_{2} \mathrm{O} / \mathrm{kg}$ of dry air) \\
\hline K & Water Gas Equilibrium Constant, 3.5, ( - ) \\
\hline$K_{H}$ & Conversion Factor, $0.6220,\left(\mathrm{~g} \mathrm{H}_{2} \mathrm{O} / \mathrm{kg}\right.$ dry air) \\
\hline$K_{W}$ & Dry to Wet Conversion Factor, ( - ) \\
\hline$M_{i}$ & Mass Emitted of Exhaust Constituent i, (grams) \\
\hline$\dot{M}_{e x h, w}$ & Exhaust Mass Flow Rate, Wet, $(\mathrm{g} / \mathrm{sec})$ \\
\hline$\dot{M}_{i}$ & Mass Flow Rate of Exhaust Constituent $i,(\mathrm{~g} / \mathrm{sec})$ \\
\hline$\dot{M}_{\text {int ake, } w}$ & Mass Flow Rate of Intake, Wet, $(\mathrm{g} / \mathrm{sec})$ \\
\hline$\dot{M}_{\text {fuel }}$ & Mass Flow Rate of Fuel, $(\mathrm{g} / \mathrm{sec})$ \\
\hline MAP & Manifold Air Pressure, (psi) \\
\hline MAT & Manifold Air Temperature, $\left({ }^{\circ} \mathrm{F}\right)$ \\
\hline$M W_{\text {Air }}$ & Molecular Weight of Air, 28.96, (amu) \\
\hline$M W_{\text {Carbon }}$ & Molecular Weight of Carbon, 12.011, (amu) \\
\hline$M W_{\text {Hydrogen }}$ & Molecular Weight of Hydrogen, 1.008, (amu) \\
\hline$M W_{\text {Water }}$ & Molecular Weight of Water, 18.01, $(\mathrm{amu})$ \\
\hline
\end{tabular}




$\begin{array}{ll}n_{e f f} & \text { Volumetric Intake Efficiency, ( - ) } \\ P & \text { Engine Power, (bhp) } \\ P_{b f} & \text { Mass of Particulate Collected on Background Filters, (grams) } \\ P_{f} & \text { Mass of Particulate Collected on Filters per Mode, (grams) } \\ P_{\text {mass }} & \text { Mass of Particulate Matter Emitted per Mode, (grams) } \\ P_{V} & \text { Partial Pressure of Water Vapor, }(\mathrm{Pa}) \\ \dot{Q}_{\text {Intake }} & \text { Volumetric Intake Flow Rate, }\left(\mathrm{ft}^{3} / \mathrm{min}\right) \\ Q_{\text {tunnel }} & \text { Volumetric Flow Rate through PM Tunnel, }\left(\mathrm{ft}^{3} / \mathrm{min}\right) \\ Q_{\text {dilution }} & \text { Tunnel Dilution Air Volumetric Flow Rate, }\left(\mathrm{ft}^{3} / \mathrm{min}\right) \\ R_{S} & \text { Revolutions Per Cycle, }(-) \\ \mathrm{RH} & \text { Relative Humidity, }(\%) \\ t_{\text {Mode }} & \text { Length of Mode, }(\mathrm{secs}) \\ T F_{\text {Mode }} & \text { Weighted Time Factor for Mode, }(-) \\ V_{b f} & \text { Volume through Background Filters, }\left(\mathrm{ft}^{3}\right) \\ V_{D} & \text { Engine Displacement, (liters) } \\ V_{e x h} & \text { Volume of Exhaust during Test Mode, }\left(\mathrm{ft}^{3}\right) \\ V_{f} & \text { Volume through Filter per Mode, }\left(\mathrm{ft}^{3}\right)\end{array}$




\section{ACKNOWLEDGEMENTS}

I would like to thank Dr. Greg Thompson for giving me the opportunity to succeed. I appreciate the expertise and insight provided by my committee members, Dr. Nigel Clark and Dr. Mridul Gautam. Tom Spencer provided me incredible help in building and testing the system. I am grateful to Dan Carder, Andy Zimmerman, Mohan Krishnamurthy, and Hemanth Kumar Kappanna for the all night testing at Staten Island. Normally when you are somewhere that is $100^{\circ} \mathrm{F}$ for hours, you are getting a tan, not doing emissions testing in an engine room. The much-needed comic relief provided by everybody at the ERC brought a fun and enjoyable work environment.

I would like to dedicate my thesis to my parents. Without them, I would have never been able to follow my dreams. Lastly, to my fiancé (soon to be Mrs. Melanie Nuszkowski), thank you for the standing by me through my long work hours and I love you. 


\section{INTRODUCTION}

Off-road sources of pollution are becoming more of an interest to emissions regulations as on-road sources of pollution have been identified and regulated [1,2]. Marine diesel engines are being investigated thoroughly since many engines in these vessels incorporate older technology that may not have been subjected to emissions regulations and hence produce a significant amount of pollution. Marine engines encompass a great range of different engine sizes from small high-speed outboard engines to large low-speed freight engines. Marine engines vary in size and can be either two stroke or four stroke engines. EPA standards for diesel emissions are covering non-road and marine because of the health risks identified with engine emissions. In particular, oxides of nitrogen (NOx) and airborne particulate matter (PM) are among the most interest in regulating from diesel (compression ignition) engines. These pollutants have been associated with adverse health affects and many toxic air pollutants have been identified in diesel combustion sources [3]. The EPA

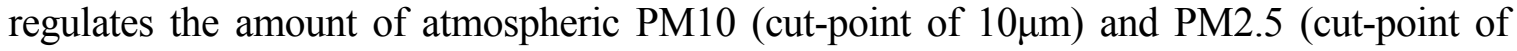
$2.5 \mu \mathrm{m})$.

Limited emissions testing (laboratory and/or in-use) have been done on marine engines used in existing vessels. Engine testing is required and performed in an engine testing laboratory on marine diesel engines, which does not test how the engine performs in the vessel's environment. The difficulty involved in onboard testing alone reduces available marine emission data. A constraint in performing in-use emissions testing of marine engines is the availability of the engine vessels since the majority of these vessels are in revenue service and it would be cost prohibitive to take the vessel out of service just to perform emissions testing. In addition, the operation of the engine, and the emissions 
produced, will be dependent on the vessel age (hull fouling), engine age, sea condition, weather condition, and other factors.

Several channels in the Port of NY \& NJ are to be deepened to roughly 50 feet for larger, more efficient, cargo vessels to be used [4]. The project, termed the Harbor Deepening Project, includes a ten-year dredging program. The dredging equipment will cause a significant impact on emissions. Reducing the emissions from the Staten Island Ferries is being used to offset the dredging equipment emissions. A project goal of $70 \%$ NOx reduction was chosen for the Alice Austen, as part of a pilot phase demonstration.

The objective of this project was to determine if retrofitting the Alice Austen with a selective catalytic reduction system would meet the requirement of $70 \%$ NOx reductions for a vessel round trip. West Virginia University (WVU) was subcontracted for this project by MJ Bradley and Associates. MJ Bradley and Associates was contracted by the Port Authority of NY \& NJ. 


\section{REVIEW OF LITERATURE}

\subsection{Introduction}

In this section, the current marine emissions standards for diesel engines are discussed. The major contributors to marine standards are the Environmental Protection Agency (EPA) and International Maritime Organization (IMO). The EPA in 40 CFR 94 [5] and International Organization for Standardization (ISO) in ISO8178 [6], discuss the regulations for emission testing. The regulations are limited in context to onboard marine testing and pertain more to engines tested in a test cell environment. This section also discusses the previous onboard marine testing and the potential technologies to reduce diesel emissions on marine vessels.

\subsection{Marine Emissions Standards}

The EPA has stages of emissions levels to meet called Tiers. The Tier I level encompasses all categories of marine engines and is based on rated power. The NOx level is depicted in Figure 2-1 and is equivalent to the IMO MARPOL Annex VI limits [7]. This standard applies to all engines manufactured or installed on a new vessel during or after the year 2004. The Tier I standards have emissions levels about 20 percent lower than uncontrolled levels. These new levels are achieved with available technology such as improved turbocharging, delayed timing, and higher compression ratios.

The Tier II standards for marine diesel engines are shown in Table 2-1. These standards include regulation for hydrocarbons (HC), PM, carbon monoxide (CO), and NOx. Category 3 engines, which are primarily ocean going vessels, do not have finalized Tier II levels provided by the EPA. 


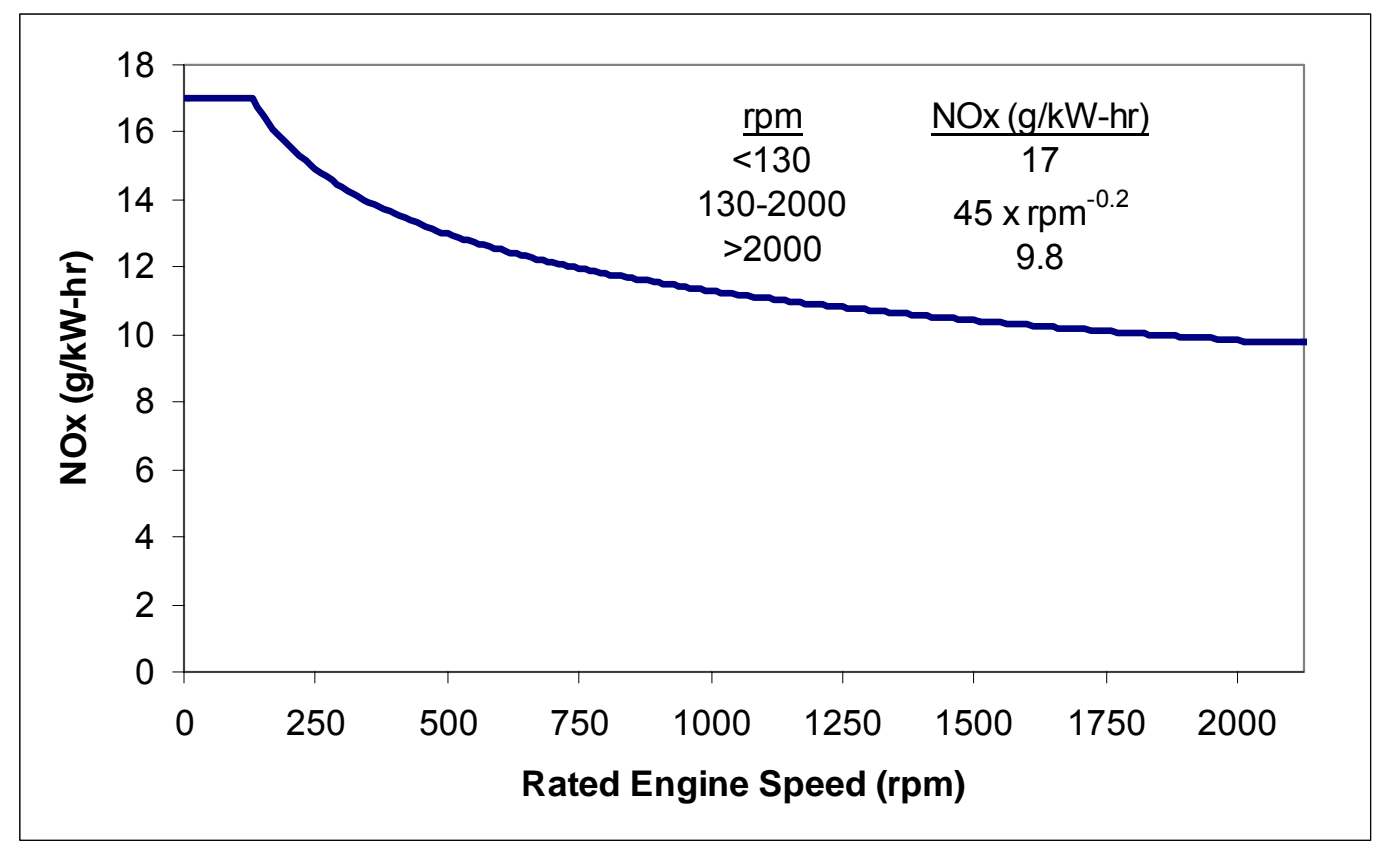

Figure 2-1 EPA Tier I Emission Requirements [8, 9]

Table 2-1 EPA Tier II Emission Requirements $[8,9]$

\begin{tabular}{|c|c|c|c|c|c|}
\hline Category & Displacement (D) & Effective Date & $\begin{array}{c}\text { NOx + } \\
\text { THC }\end{array}$ & $\mathbf{P M}$ & CO \\
\hline & $d m^{3}$ per cylinder & & $g / k W-h r$ & $g / k W-h r$ & $g / k W-h r$ \\
\hline \multirow[t]{4}{*}{1} & $\mathrm{D}<0.9 \&$ Power $<37 \mathrm{~kW}$ & 2005 & 7.5 & 0.4 & 5.0 \\
\hline & $0.9 \leq \mathrm{D}<1.2$ & 2004 & 7.2 & 0.3 & 5.0 \\
\hline & $1.2 \leq \mathrm{D}<2.5$ & 2004 & 7.2 & 0.2 & 5.0 \\
\hline & $2.5 \leq \mathrm{D}<5.0$ & 2007 & 7.2 & 0.2 & 5.0 \\
\hline \multirow[t]{5}{*}{2} & $5 \leq \mathrm{D}<15$ & 2007 & 7.8 & 0.3 & 5.0 \\
\hline & $15 \leq \mathrm{D}<20 \&$ Power $<3300 \mathrm{~kW}$ & 2007 & 8.7 & 0.5 & 5.0 \\
\hline & $15 \leq \mathrm{D}<20 \&$ Power $\geq 3300 \mathrm{~kW}$ & 2007 & 9.8 & 0.5 & 5.0 \\
\hline & $20 \leq \mathrm{D}<25$ & 2007 & 9.8 & 0.5 & 5.0 \\
\hline & $25 \leq \mathrm{D}<30$ & 2007 & 11.0 & 0.5 & 5.0 \\
\hline 3 & $\mathrm{D} \geq 30$ & \multicolumn{4}{|c|}{ Rulemaking to be completed by 2007} \\
\hline
\end{tabular}

\subsection{Prior In-use Marine Emission Measurement Studies}

This section discusses the previous in-use marine emissions testing focusing on the test matrix, test equipment, results, and reduction technology. The section encompasses testing from 1997 to 2004. 


\subsubsection{US Coast Guard, 1997}

The Maritime Administration and the US Coast Guard put together an effort to adapt a portable emissions system for marine use [10]. The testing consisted of three US Coast Guard Cutter vessels. Each boat had two Caterpillar D3412 Diesel engines with an output between $700-800 \mathrm{hp}$. The test protocol was based on the ISO 8178 procedure with modification for the actual speeds used by the vessel.

Two portable emissions systems were evaluated during testing, the Lancom 6500 (Land Combustion) and the ENERAC 2000E (Energy Efficiency Systems, Inc). The pollutants analyzed were NOx and CO. From this testing, the US Coast Guard showed that portable emission testing was capable onboard marine vessels.

\subsubsection{Transport Canada}

\subsubsection{Field Testing of Water Injection System (WIS), 1999-2000}

Environment Canada conducted emissions testing on the Queen of New Westminister with and without water injection in July 1999 and January 2000 [11]. This vessel was a ferryboat operating between Vancouver and Vancouver Island, Canada. The engine tested was a Wartsila model 9R32D with 9 cylinders in-line, turbocharged, and a rating of $4526 \mathrm{hp}$ at $750 \mathrm{rpm}$ operating on Diesel No. 2 fuel.

The emissions system consisted of a continuous emissions monitor (ECOM-AC) measuring $\mathrm{CO}, \mathrm{CO}_{2}, \mathrm{NOx}$, and $\mathrm{O}_{2}$ utilizing electrochemical sensors. Particulate matter was measured by gravimetric means with $47 \mathrm{~mm}$ diameter filters.

Environment Canada found NOx to reduce 10-22\% with the water injection system at varying water volumes injected. PM emissions reduced on averaged by about $20 \%$, while $\mathrm{CO}$ and $\mathrm{CO}_{2}$ did not show any variation. 


\subsubsection{Engine Exhaust Emissions Evaluation of the MV Cabot, 2000}

During October 2000, Transport Canada conducted an evaluation of the emissions on a vessel named the MV Cabot [11]. This vessel operated between Montreal and St. John's, Canada on a weekly basis. The engine tested onboard was a Pielstick $7300 \mathrm{hp} \mathrm{V-12}$ operating on blends of marine diesel oil and bunker $\mathrm{C}$ oil.

The testing method consisted of seven different sampling conditions based on engine power, engine speed, and fuel type. The exhaust sampling and analysis system sampled CO, $\mathrm{CO}_{2}, \mathrm{NOx}$, and $\mathrm{O}_{2}$ using electrochemical sensors and total particulate mass using $47 \mathrm{~mm}$ diameter filters. The electrochemical sensors were a bundled portable, commercial system called ECOM-AC manufactured by ECOM America Ltd.

The results of the exhaust emissions of the MV Cabot, a typical medium sized cargo vessel in service in Canadian waters showed NOx to be above the IMO standards (same as EPA Tier I) for 6 of the 7 different operating conditions sampled.

\subsubsection{Field Testing of WIS onboard MV Cabot, 2004}

Transport Canada conducted field testing of a water injection system onboard the MV Cabot in 2004 [12]. Testing was conducted to verify emission inventories and evaluate the performance of an inexpensive method for NOx reduction to meet the IMO Annex VI, which limits the emissions of NOx and SOx. Testing was conducted with marine diesel oil and intermediate fuel oil. The engines and vessel operation was described above in Section 2.3.2.2.

A portable SMART 2000 emissions analyzer, ECOM analyzer, and a Horiba MEXA-720 analyzer were used during this emissions testing. The measured emissions were $\mathrm{NOx}, \mathrm{THC}, \mathrm{CO}, \mathrm{CO}_{2}, \mathrm{O}_{2}, \mathrm{PM}$, and opacity. Water was injected into the intake system lowering the combustion temperature, thus decreasing the NOx. 
NOx reductions ranged from 10-30\%, while CO and PM increased. The water injection had no effect on fuel consumption and $\mathrm{CO}_{2}$. The effect of inadequate distribution of water in the intake manifold was noticeable.

\subsubsection{Walther Engineering Services, Inc., 2001-2002}

Walther Engineering Services conducted emissions testing on the $M / V$ OSKI passenger ferry operated by Blue \& Gold Fleet on San Francisco Bay, California [13]. The vessel was equipped with two identical Detroit Diesel 12V-71NA-7122-7000 engines with a power output of $360 \mathrm{bhp}$ at $1800 \mathrm{rpm}$.

Each engine was tested with normal off-road diesel fuel, $20 \%$ soybean based biodiesel, and $100 \%$ soybean based bio-diesel. The $100 \%$ diesel and $100 \%$ bio-diesel were tested with an inlet water injection system, injecting water when the engine operated above $1200 \mathrm{rpm}$.

An Enerac Model 3000 portable analyzer produced by Energy Efficiency Systems of Westbury, $\mathrm{NY}$ was used for testing. This analyzer consisted of an electrochemical $\mathrm{NO} / \mathrm{NO}_{2}$ sensor, an electrochemical $\mathrm{CO}$ sensor, and an electrochemical $\mathrm{SO}_{2}$ sensor. The analyzer calculated the concentrations of $\mathrm{CO}_{2}$ and THC.

This testing showed that with off-road diesel fuel as a basis, NOx increased $24 \%$ with pure bio-diesel fuel. NOx increased $11 \%$ with $20 \%$ bio-diesel / $80 \%$ off-road diesel. NOx decreased $26 \%$ with water injection using the base off-road diesel fuel. NOx was decreased $12 \%$ on the pure bio-diesel fuel with water injection. The pure bio-diesel fuel reduced particulate matter by $50 \%$. 


\subsubsection{West Virginia University (WVU)}

\subsubsection{Hampton Road Transit Authority Ferry Boats, 2002}

West Virginia University conducted emissions testing on two similar ferry boats operated by the Hampton Road Transit Authority [14]. One vessel, Elizabeth II, operated using two Detroit Diesel model 671 using diesel fuel. The other vessel, James C. Echols, operated using two Caterpillar model 3406 engines and several years earlier was retrofitted to use compressed natural gas.

The parameters collected were PM, NOx, $\mathrm{CO}, \mathrm{CO}_{2}$, THC, fuel mass flow rate, intake air flow rate, exhaust flow rate, shaft speed/torque, air temperature, air pressure, and air humidity. The emissions testing system from West Virginia University was a portable laboratory grade system (within $5 \%$ of laboratory CVS results).

Overall, the results showed that the natural gas powered ferry had 10 to 100 times less particulate matter, two to three times higher $\mathrm{THC}$ and $\mathrm{CO}$, and roughly the same $\mathrm{NOx}$ emissions as the diesel powered ferry. The significantly lower particulate matter was expected, but the natural gas engines should reduce NOx. The testing showed that the natural gas engines had poor control over the $\mathrm{A} / \mathrm{F}$ ratio. With a proper system, emissions could be reduced significantly, while still maintaining adequate performance.

\subsubsection{SCX Inc. High Speed Ferry, 2003}

Previous testing has been conducted by West Virginia University on a hydrofoil deployed high-speed passenger ferry on low-sulfur diesel (LSD) fuel (with and without intake air water injection), compared to operating the ferry on marine diesel fuel [15]. The testing was conducted onboard a high-speed ferry (hydrofoil) operated by SCX, Inc. between San Diego and Oceanside, California. The vessel was powered by four Detroit 
Diesel Corporation 12V92 engines retrofitted with an intake charge air water injection system.

The emissions sampling system, MEMS (Mobile Emissions Measurement Systems) [16 - 19], was developed in house at West Virginia University. This system recorded $\mathrm{CO}_{2}, \mathrm{NOx}, \mathrm{O}_{2}$, torque, intake flow, and fuel flow. A particulate matter sampling system was used, consisting of a mini-tunnel design.

The water injection systems (WIS) reduced NOx emissions $10-17 \%$. This is seen in a summary of the results in Table 2-2. The results of the PM emissions, displayed in Table 2-3, shows that LSD was the biggest contributor in the testing to a reduction in PM emissions. The water injection system did not influence particulate matter emissions when tested with marine diesel or low sulfur diesel fuel. From this testing, using lowsulfur diesel fuel instead of marine diesel, which lowers the sulfur content, can reduce particulate matter emissions between 30-40\% depending on the engine conditions.

Table 2-2 Results of SCX ferry NOx emissions [15]

\begin{tabular}{|c|c|c|c|c|}
\cline { 2 - 5 } \multicolumn{1}{c|}{} & \multicolumn{4}{c|}{ Brake - Specific NOx emissions (g/bhp-hr) } \\
\hline Mode & $\begin{array}{c}\text { LSD I } \\
\text { Without WIS }\end{array}$ & $\begin{array}{c}\text { LSD I } \\
\text { With WIS }\end{array}$ & $\begin{array}{c}\text { Marine Diesel I } \\
\text { Without WIS }\end{array}$ & \begin{tabular}{c} 
Marine Diesel \} $\\
{\text { With WIS }}$ \\
\hline $2100 \mathrm{rpm}$ & 6.72 & 5.92 & 7.14 & 6.43 \\
\hline $2000 \mathrm{rpm}$ & 6.5 & 5.61 & 6.5 & 5.69 \\
\hline $1900 \mathrm{rpm}$ & 5.97 & ----- & 5.91 & 4.93 \\
\hline
\end{tabular}
\end{tabular}

Table 2-3 Results of SCX ferry PM emissions [15]

\begin{tabular}{|c|c|c|c|c|}
\cline { 2 - 5 } \multicolumn{1}{c|}{} & \multicolumn{3}{|c|}{ Brake - Specific PM emissions (g/bhp-hr) } \\
\hline Mode & $\begin{array}{c}\text { LSD I } \\
\text { Without WIS }\end{array}$ & $\begin{array}{c}\text { LSD I } \\
\text { With WIS }\end{array}$ & $\begin{array}{c}\text { Marine Diesel I } \\
\text { Without WIS }\end{array}$ & $\begin{array}{c}\text { Marine Diesel I } \\
\text { With WIS }\end{array}$ \\
\hline $2100 \mathrm{rpm}$ & 0.1 & 0.1 & 0.17 & 0.17 \\
\hline $2000 \mathrm{rpm}$ & 0.12 & 0.11 & 0.19 & 0.19 \\
\hline $1900 \mathrm{rpm}$ & 0.17 & ---- & 0.26 & 0.25 \\
\hline
\end{tabular}




\subsubsection{Engine, Fuel, and Emissions Engineering, Inc. (EF\&EE), 2002}

The San Francisco Bay Water Authority contracted EF\&EE to develop a test protocol for ferry emissions testing and use this protocol in onboard ferry emissions testing [20]. Three diesel ferry boats which operated in San Francisco Bay were tested. The vessels, Mare Island, MV Peralta, and Golden Gate had two MTU 16V396 TE74L diesel engines rated at $2682 \mathrm{hp}$ each, two Cummins KTTA50 diesel engines rated at $1600 \mathrm{hp}$ each, and two Caterpillar 3412C rated at $671 \mathrm{hp}$ each, respectfully.

Whenever possible, each vessel was tested under high-speed cruise 90-100\% maximum passenger load, high-speed cruise 20-30\% of rated passenger load, low-speed cruise, transient maneuvering, idle-ahead, and idle in neutral. The Golden Gate was tested on regular California diesel fuel and a water emulsion fuel called PuriNOx.

The emission measurements system used was the Ride Along Vehicle Emissions Measurement (RAVEM) system developed in house by EF\&EE [21]. The RAVEM system, along with added analyzers, collected measurements for $\mathrm{NOx}, \mathrm{NO}, \mathrm{CO}_{2}, \mathrm{CO}, \mathrm{PM}$, methane and non-methane hydrocarbons, speciated non-methane hydrocarbons, speciated carbonlys, $\mathrm{SO}_{2}, \mathrm{NO}_{2}$, and $\mathrm{NH}_{3}$.

The results of testing showed that NOx and PM emissions which are of most concern compared closely with the marine standards in place in 2002 when the testing took place.

\subsection{Emission Reduction Technologies}

This section discusses the technologies for reducing emissions on diesel marine engines. Some technologies are easy to implement since minimal engine and/or infrastructure changes are required and include low-sulfur diesel fuel and intake water injection. SCR and DPF technology provides the most effective technology, but operating 
costs and difficulty of implementation inhibit this technology. Engine modification provides reduction to mostly new engines by optimization of engine components or during engine overhaul.

\subsubsection{Fuel Types}

This section discusses ultra-low sulfur fuel and water emulsion diesel. These fuels provide an easy implement for reducing emissions. Diesel engines can run on inexpensive "dirty" fuel and many marine vessels utilize this. This inexpensive fuel with high emissions hinders the implementation of these new cleaner fuel types.

\subsubsection{Ultra-Low Sulfur Diesel Fuel}

The use of a low-sulfur diesel fuel has been shown to reduce PM emissions in diesel engines $[22,23]$ by reducing the sulfates formed, which are a component of the PM emissions. The EPA has proposed to reduce PM emissions on large marine diesels (per cylinder displacement $>30$ liters), which are mostly used as ocean going vessels, by decreasing the sulfur content in the fuel [9]. The fuel used on these vessels can have greater than $15,000 \mathrm{ppm}$ of sulfur as opposed to on-road diesel fuel, which has less than $500 \mathrm{ppm}$. The sulfates produced by the sulfur in the fuel are measured as PM in the exhaust. The sulfur content can have a negative effect on aftertreatment devices and engine components.

\subsubsection{Water Emulsion Diesel Fuel}

Another type of fuel is water emulsion fuels [22, 24, 25]. These consist of water mixed with diesel fuel. Water particles are suspended in the diesel fuel, which poses problems since water and diesel have different densities and liquid properties. The emulsified fuel has a length of time before the mixture separates.

The water in the diesel creates lower temperatures in the cylinder of the engine, which decreases NOx. This specific type of fuel has been shown in previous testing to 
lower and increase PM emissions while NOx can decrease up to $20 \%$. More research on water emulsion diesel fuel needs to be conducted to determine the benefits if any for particulate emissions.

\subsubsection{Engine Enhancements}

There are numerous studies supplying information on innovative design changes in engine and associated parts. Optimization of piston-bowl arrangements, fuel spray patterns, timing arrangements, injection pressure, and fuel/air ratios have been some of the most researched subjects.

Engines with higher compression ratios have a smaller ignition delay period, however compression ratios are limited practically if the engine is highly turbocharged [23]. The high compression ratios increase the temperature of the cylinder thus reducing PM and white smoke. A smaller ignition delay provides increased injection timing, which decreases NOx.

Multiple injections have been shown to reduce PM by 40 percent and NOx by 15 percent [26]. Manufacturers are optimizing the fuel injection characteristics and combustion chamber for increased engine and emissions efficiency.

Hardware changes are a viable way of reducing emissions. This is done by the replacement of engine components with emission optimized components or even replacing the whole engine with a new model, which requires certification for the current emission standards. Current programs such as the Carl Moyer Program [27] provided by the state of California, help pay for this type of engine change out.

Work has shown that modern electronic fuel injection introduced in high power 2stroke and 4-stroke engines primarily used in marine applications can reduce emissions to comply with the upcoming EPA Tier 2 regulations [28]. The electronic control allows 
optimization of the fuel injection timing, fuel injection pressure, and intake and exhaust valve opening and closing for each speed and load.

\subsubsection{Water Injection}

Another method of emissions reduction is water injection in the intake air or directly in the cylinder. These methods reduce the peak combustion temperatures in the cylinder thus reducing NOx and increasing PM with reduced combustion quality.

Direct injection of water into the combustion chamber provides a method of NOx reduction with the benefit of having great control of the water injection. With optimizations in water injection timing, pressure, and amount, a reduction of upwards of 80-90\% NOx is possible $[29,30]$. The major drawback of direct water injection is the need for engine modification, and a greater installation cost than intake water injection.

Intake water injection injects water into the intake air stream, which increases the humidity of the intake air and decreases NOx 5-20\% [11, 15, 31]. Intake injection provides an inexpensive method of emissions reduction, which can have adverse effects on lube oil. Many different methods of intake water injection are available with the lowest cost method being a single point injection method. A multi-point injection system provides better control with an injector for each cylinder allowing control of injection when the intake valve is open.

\subsubsection{Selective Catalytic Reduction (SCR)}

A selective catalytic reduction (SCR) system is a NOx removal strategy [32]. This system is capable of NOx reduction up to $90+\%[33,34]$ with an ammonia based reductant, such as aqueous urea. Having aqueous urea onboard is much safer than using ammonia directly. The main issue involved with using an SCR system on a mobile system is the need 
for infrastructure for refilling the urea tanks onboard as well as the storage needed for the urea tanks.

An SCR works by the urea delivery system pumping a value of urea/water into the exhaust stream through the urea injector. The urea/water mixture then hydrolyzes to ammonia and water in the exhaust stream if the exhaust is at a high enough temperature. At the catalyst, the NOx is reduced to nitrogen and water. This is shown in Figure 2-2.

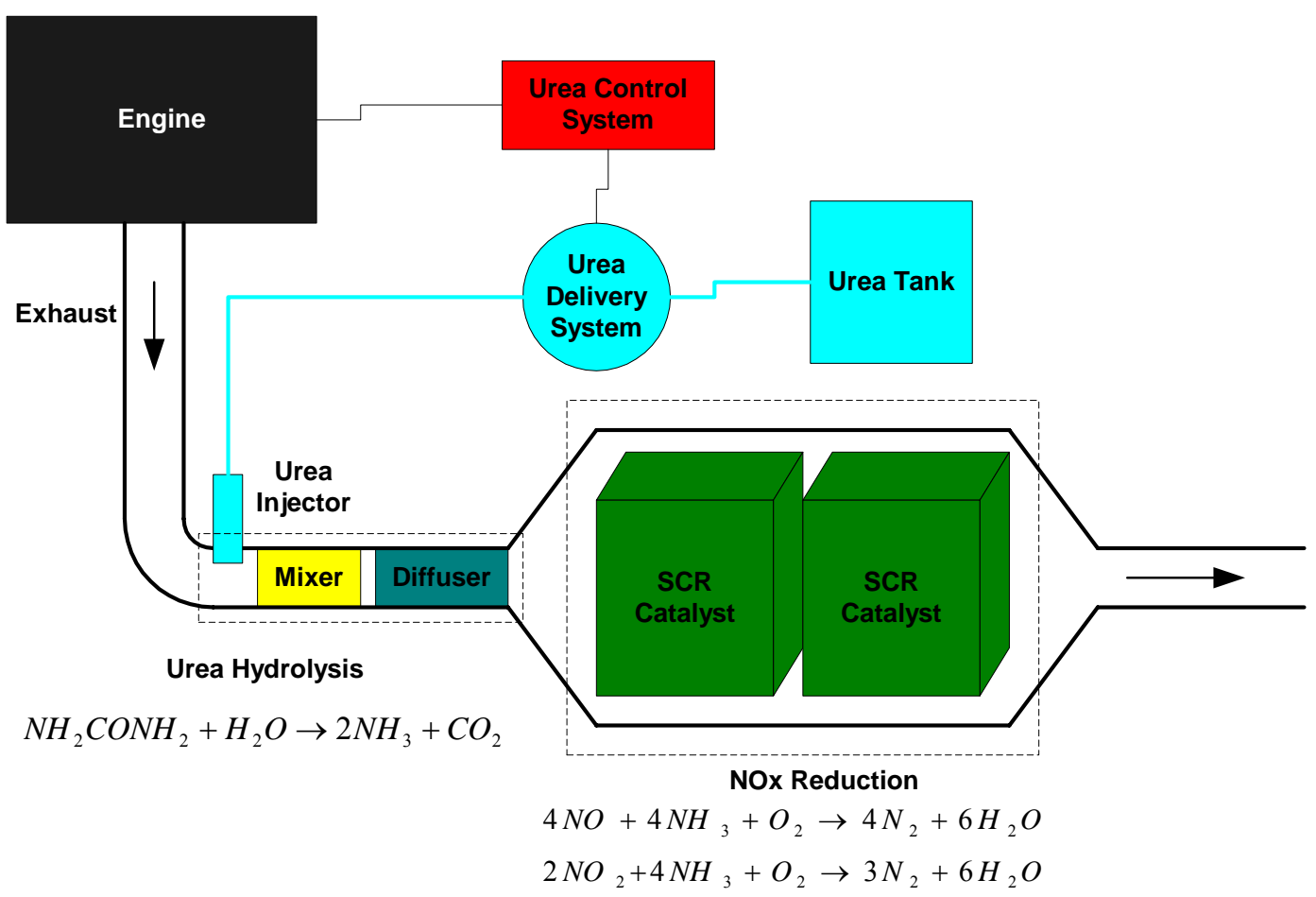

Figure 2-2 SCR System

A urea-SCR has been widely used as a NOx reduction system since the 1980s in stationary applications such as gas turbines, waste incineration, and diesel power generation. With the increasingly lower NOx limits being set by the EPA, SCR applications are gaining popularity in mobile applications as well [35].

The NOx reduction of the catalyst is a function of $\mathrm{NH}_{3}$ injected, inlet temperature of catalyst, space velocity of the exhaust through the catalyst, and the NOx in the exhaust. A 
catalyst has an optimal temperature range for reduction reactions. An SCR system combined with a particulate trap can provide a complete emissions reduction system [36].

A SCR system can include an oxidation catalyst before the SCR catalyst to convert $\mathrm{NO}$ to $\mathrm{NO}_{2}$. With more $\mathrm{NO}_{2}$ entering the catalyst, the SCR system can provide higher reduction of NOx at lower temperatures because the reaction of $\mathrm{NO}_{2}$ with ammonia takes place at lower temperatures. An oxidation catalyst can be placed after the SCR catalyst to oxidize any ammonia slip. An added effect of an oxidation catalyst is the oxidation of $\mathrm{CO}$, $\mathrm{HC}$, and SOFs by the reactions below.

$$
\begin{aligned}
& \mathrm{CO}+\frac{1}{2} \mathrm{O}_{2} \rightarrow \mathrm{CO}_{2} \\
& {[\text { Hydrocarbons }]+\mathrm{O}_{2} \rightarrow \mathrm{CO}_{2}+\mathrm{H}_{2} \mathrm{O}}
\end{aligned}
$$

\subsubsection{Diesel Particulate Filters (DPF)}

DPFs are devices that physically trap the PM emissions and prevent them from being emitted into the atmosphere [37, 38, 39]. A catalyzed DPF with high filtration efficiency is one of the most efficient technologies for the reduction of PM emissions from heavy-duty diesel engines.

One such type of particulate filter is the Johnson-Matthey CRT, displayed in Figure 2-3. The CRT particulate filter is a patented emission control technology that contains a platinum-coated catalyst and a particulate filter, engineered as a totally passive emission control system. The CRT particulate filter removes more than $85 \%$ of the PM, $\mathrm{CO}$ and $\mathrm{HC}$ emissions from diesel exhaust.

CRT particulate filters usually contain a combination of an oxidation catalyst and an uncatalyzed filter, which requires ultra low sulfur fuel. The CRT PM filter is mounted in the vehicle's exhaust system in the same location as the muffler or catalytic converter. The 
CRT is made up of two chambers where the oxidation step is separate from the particulate collection/combustion process. The exhaust passes through the first chamber where a portion of the $\mathrm{NO}$ is oxidized to $\mathrm{NO}_{2}$. The use of $\mathrm{NO}_{2}$ to combust the PM provides the lower exhaust temperatures needed to run efficiently on diesel engines. The second chamber of the DPF provides a filter, where PM is trapped and combusted by the previously produced $\mathrm{NO}_{2}$.

A DPF provides $>90 \%$ reduction in PM $[40,41]$ and $>90 \%$ reduction in particle count. The use of an ultra low sulfur fuel is needed by the DFP for efficient regeneration and reliability because sulfur poisons the catalyst. A negative attribute of these systems is the generation of $\mathrm{NO}_{2}$ by the catalytic reaction, although total $\mathrm{NOx}$ does not change.

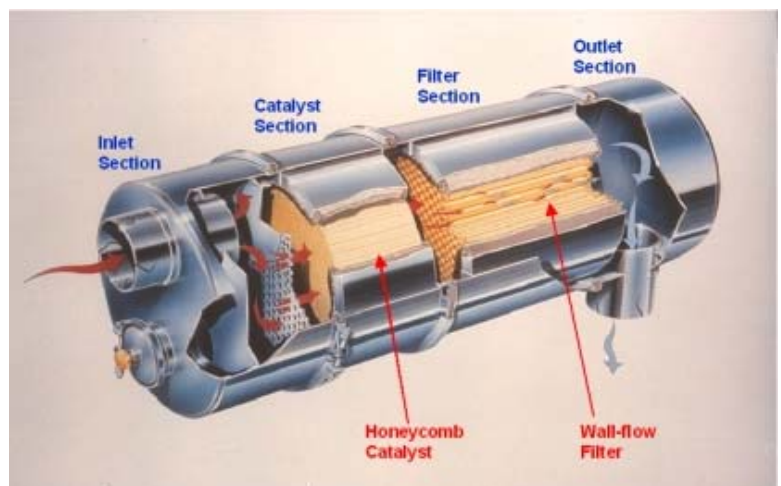

Figure 2-3 Johnson-Matthey CRT Diesel Particulate Filter [42] 


\section{EXPERIMENTAL SETUP}

\subsection{Introduction}

This section outlines the experimental equipment used in testing the vessel. System verification testing was conducted at the West Virginia University Engine and Emissions Research Laboratory (EERL), which was in accordance with the standards set by the Code of Federal Regulations (CFR) 40, Part 86 [43]. For information on the testing facility and the equipment used, see reference $[44,45]$. The test vessel is first discussed followed by the data logger setup. From the results of the data logger, a test matrix was constructed. The basic design of the SCR is covered. Lastly, the equipment used in the emission measurement is discussed.

\subsection{Test Vessel and Test Engine Specifications}

The data logger was installed in December 2003 and the emission testing was performed in April 2005 on the Staten Island Ferry boat named the Alice Austen, shown in Figure 3-1. Vessel information is provided in Table 3-1. Compared to the rest of the Staten Island Ferry fleet, the Alice Austen was one of two smaller vessels with two model 3516A Caterpillar engines, and held a maximum of 1280 passengers.

Table 3-1 Vessel Information

\begin{tabular}{|ll|}
\hline \multicolumn{2}{|c|}{ Vessel Information } \\
\hline Commission Date: & 1986 \\
\hline Passanger Capacity: & 1,280 \\
\hline Weight: & 499 gross tons \\
\hline Service Speed: & 16 knots \\
\hline Fuel Capacity: & 9,000 gallons \\
\hline
\end{tabular}




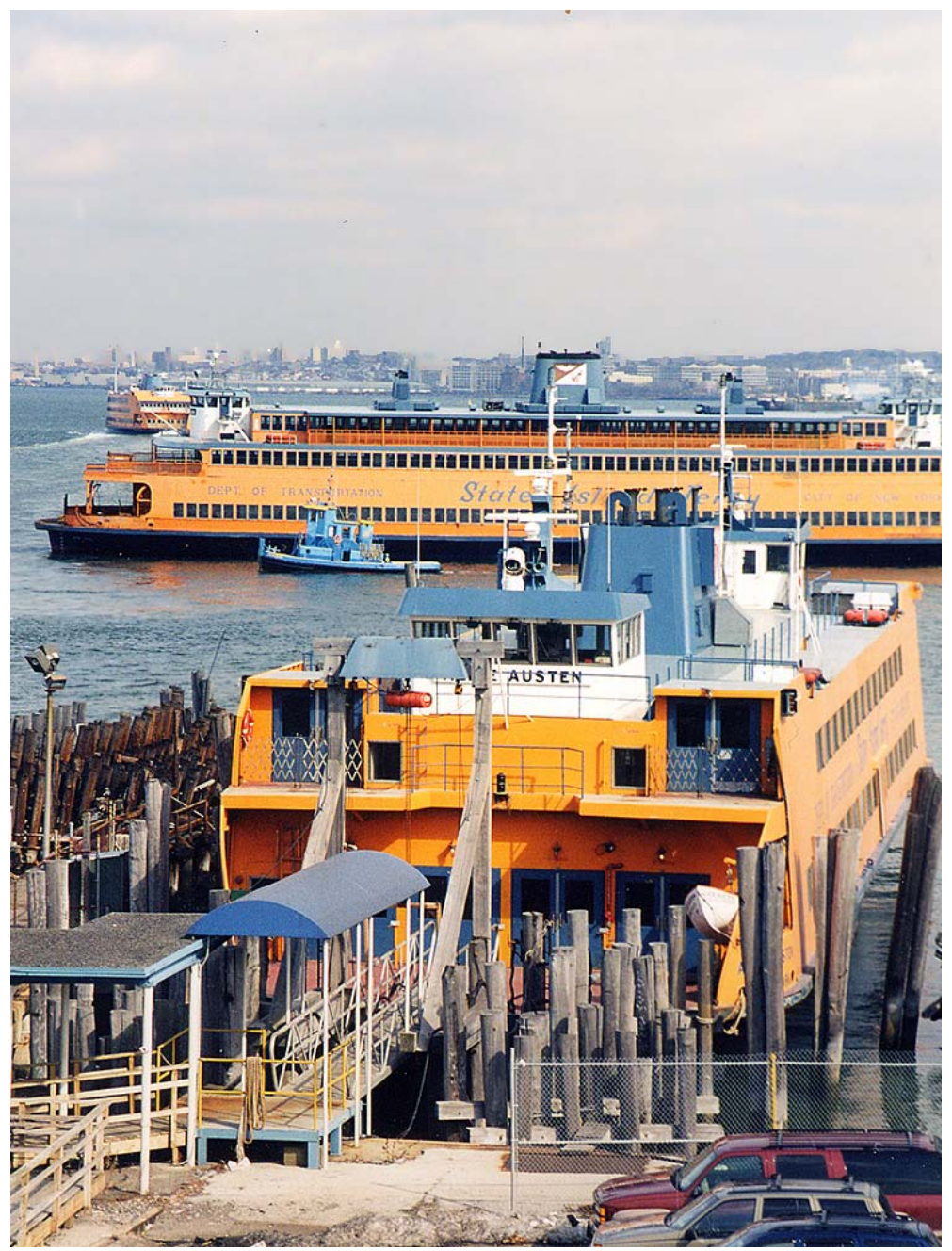

Figure 3-1 Staten Island Ferry Vessel, Alice Austen in the foreground [46]

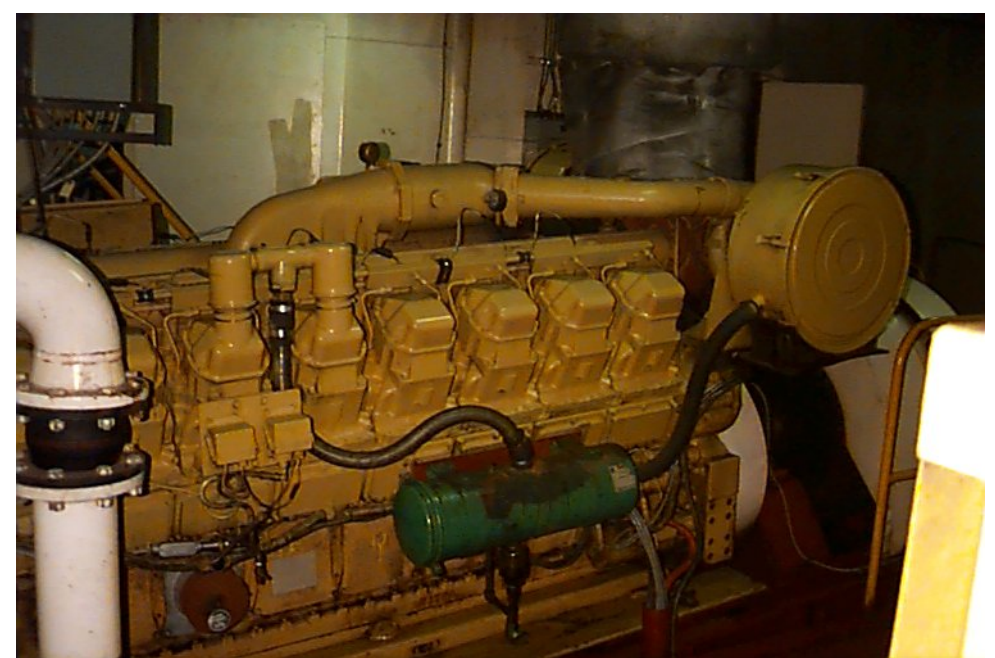

Figure 3-2 Model 3516A Caterpillar Diesel Engine 
There are two main engines onboard for propulsion and two auxiliary engines for electrical generation. The main engines were 16 cylinder caterpillar model 3516A with a displacement of 69.09 Liters. The main engines were situated at either end of the engine room. Because vessel orientation does not change with respect to Staten Island and Manhattan, the engines were identified by which island they were closest to (i.e. engine NY and engine SI). The auxiliary engines are six-cylinder caterpillar model 3406 . The auxiliary engines each power a $1600 \mathrm{rpm}, 248 \mathrm{hp}(185 \mathrm{~kW})$ generator. The main engines were the concern of this study with only the exhaust stack temperature of the auxiliary engines being measured. Table 3-2 summarizes the main and auxiliary engine information.

Table 3-2 Engine Information

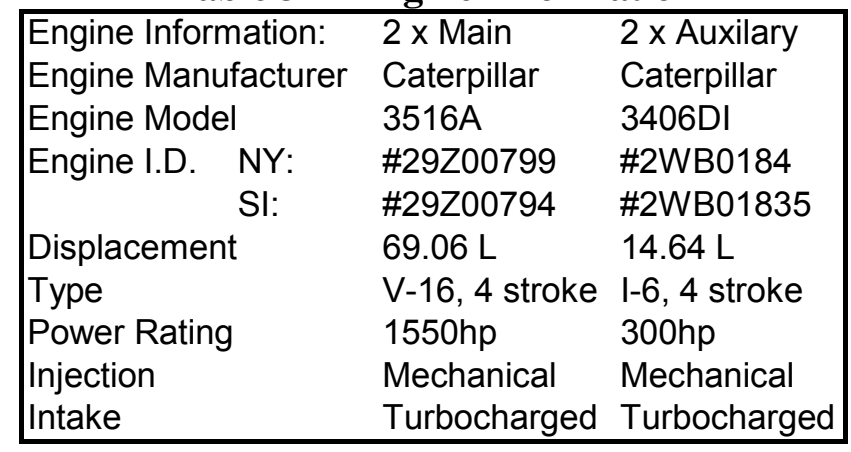

The propulsion system of the vessel consisted of two Voith Schneider propellers [47], one located at each end of the vessel. Each propeller consisted of a number of profiled blades projecting below the ship hull, rotating constantly in one direction with rotation around a vertical axis. By changing the angle of certain blades, the vessel can be caused to move in any direction. The greater the angle of these blades, the more power was provided by the propeller. The Voith Schneider propellers allowed greater maneuverability than would be afforded by screw propellers.

During emission testing, daily samples of the fuel onboard were taken for analysis. The fuel analysis is attached as APPENDIX A. The first report is of three fuel samples, 
with one from each day of testing. While testing was conducted, the fuel was never refilled. The second report is of an equally mixed fuel sample from the three other samples. The average sulfur content of the fuel was just over $900 \mathrm{ppm}$, with an individual variation from the mean of less than 5 percent.

\subsection{Onboard Data Logging}

WVU and MJ Bradley \& Associates outlined an onboard marine vessel data logging protocol for implementing emissions reduction strategies [48]. The data collected was used by WVU to produce a test matrix for emissions testing and modal analysis that provided MJ Bradley \& Associates with knowledge for implementing the appropriate emissions reduction strategy. The emission testing was done after the vessel was fitted with a SCR.

The data logger system consisted of a 24"x18"x12" (L x W x H) enclosure containing the data logger, sensor power supply, signal conditioning, connectors, battery backup system, and wiring, shown in Figure 3-3. Cables ran from the various sensor locations to the designated connector on the outside of the enclosure.

\subsubsection{Transducers}

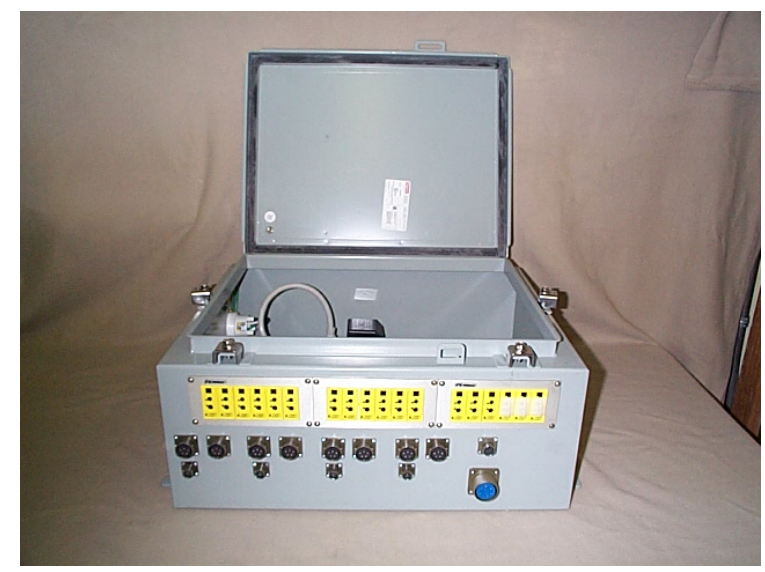

Figure 3-3 Datalogger with Top Open

The parameters needed to provide an overview of engine performance characteristics and exhaust characteristics is shown in Table 3-3 below. The parameters 
needed were defined by WVU and MJ Bradley \& Associates. These specific sensors were chosen to be within an individual sensor accuracy of $2 \%$ of full scale, except NOx, which required an accuracy of $20 \%$ of actual value.

Table 3-3 Sensor Information

\begin{tabular}{|l|l|l|l|}
\hline Location & Parameter & Sensor & Placement \\
\hline \multirow{4}{*}{ Per Main Engines } & Intake Temperature & K-Type Thermocouple & Intake Manifold (post turbo) \\
\cline { 2 - 4 } & Intake Pressure & Omega PX215-030GI (0-30 psig) & Intake Manifold (post turbo) \\
\cline { 2 - 4 } & Exhaust Manifold Temperature & K-Type Thermocouple & Exhaust Manifold (post turbo) \\
\cline { 2 - 4 } & Exhaust Attenuator Temperature & K-Type Thermocouple & Exhaust Stack Insulation (post turbo) \\
\cline { 2 - 4 } & Exhaust Backpressure & Omega PX215-015GI (0-15 psig) & Exhaust Stack (post turbo) \\
\cline { 2 - 4 } & Speed & Hall Effect Sensor (0-7000Hz) & Bell Housing (using starter gear teeth) \\
\cline { 2 - 4 } & NOx (ppm) & Electrochemical Sampling Box & Probe in Exhaust Stack (post turbo) \\
\hline \multirow{2}{*}{ Per Aux Engines } & Exhaust Temmperature & K-Type Thermocouple & Exhaust Stack (post turbo) \\
\hline \multirow{2}{*}{ Vessel } & Global Positioning Data / Speed & GPS module & Upper Deck \\
\cline { 2 - 4 } & Date and Time & Internal to Datalogger & Internal to Datalogger \\
\hline
\end{tabular}

\subsubsection{NOx Analyzer}

With the datalogger being installed, WVU used this opportunity to install a basic NO analyzer on each engine. The analyzer installed was an electrochemical NO sensor that provided an approximation of the NOx emitted.

An electrochemical sensor works on the principle of a micro fuel cell. The sample migrated through a porous membrane and reacted with the sensing electrode by either oxidation or reduction. With two electrodes, a chemical reaction took place at each electrode. The concentration of gas was proportional to the current flow between the electrodes in the sensor.

The two NO sensors installed, one for each engine, used the exhaust pressure from the engine for flow rate. The response time of the sensors, because of the sample method, was between 30 seconds to 2 minutes depending on engine exhaust flow rate. This sample method did not require a sample pump. With the electrochemical sensor sampling principle being independent of the exhaust humidity, a sensor for remote monitoring of NO in the exhaust was possible. The inside of a NO sampling box built for this project is displayed in Figure 3-4. The NO sampling method provided a simple drain for water in the exhaust with 
a needle valve allowing a small portion of the flow through for water drainage. Directly before the electrochemical sensor, inside the sampling box, a 0.5 micron inline filter was placed for particulate filtration. It is noted that the sampling system was at ambient temperature and that $\mathrm{NO}_{2}$ may have been removed with any condensed moisture. However, the EC used only respond to $\mathrm{NO}$ and this was not a concern for this measurement.

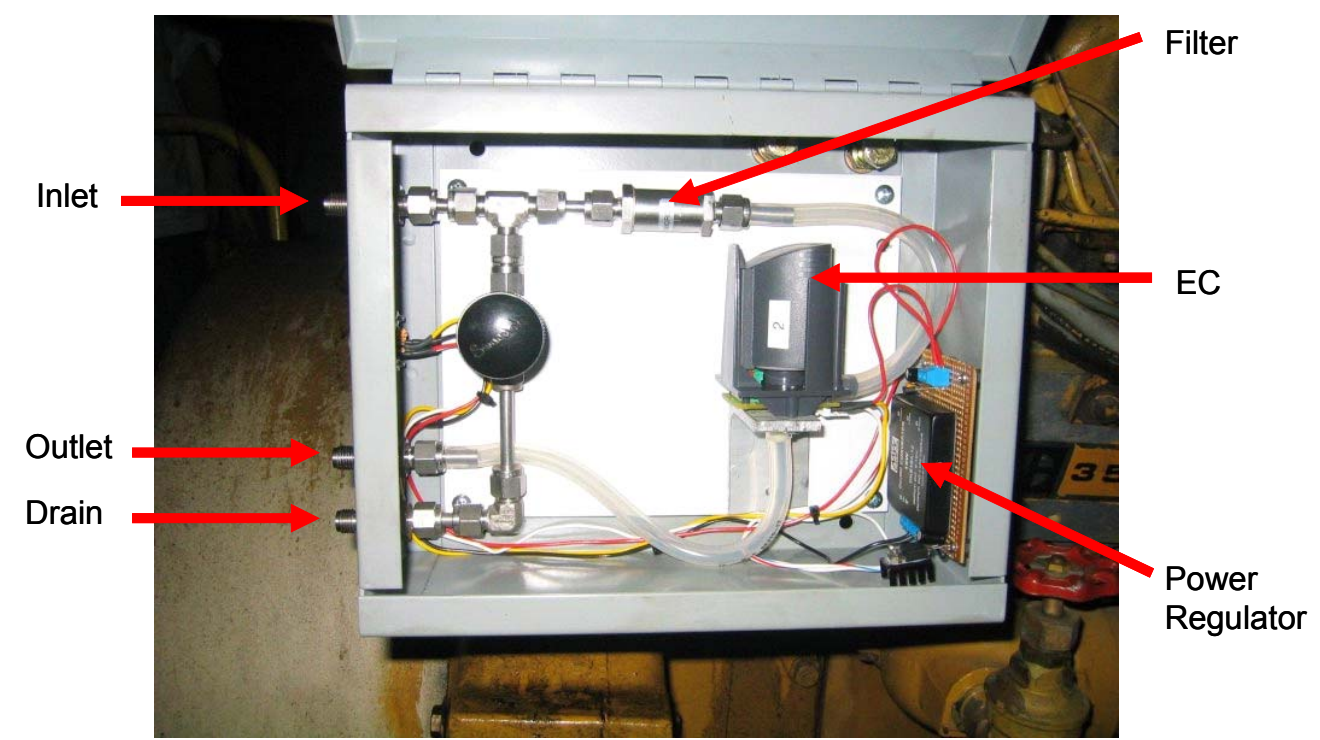

Figure 3-4 Inside of NO Sampling Box

\subsubsection{Data Acquisition}

The data acquisition system was a DT800 manufactured by Datataker, which provided 12 to 42 sensor channels with 16-bit resolution as well as a serial sensor channel, shown in Figure 3-5. The DT800 included a Flash PC card for removable data storage, which allowed weeks of data to be logged before data was downloaded. DataTaker had its own programming language for its products. A simple program was written for the DT800 to log channels, the type of channel (frequency, voltage, thermocouple), when to log data (only when engines running), scaling (sensor input to engineering units), and to log GPS data. Each sensor was calibrated to the DT800 input and the calibration curve was used for the scaling in the program. An example of the program is included in APPENDIX B. 


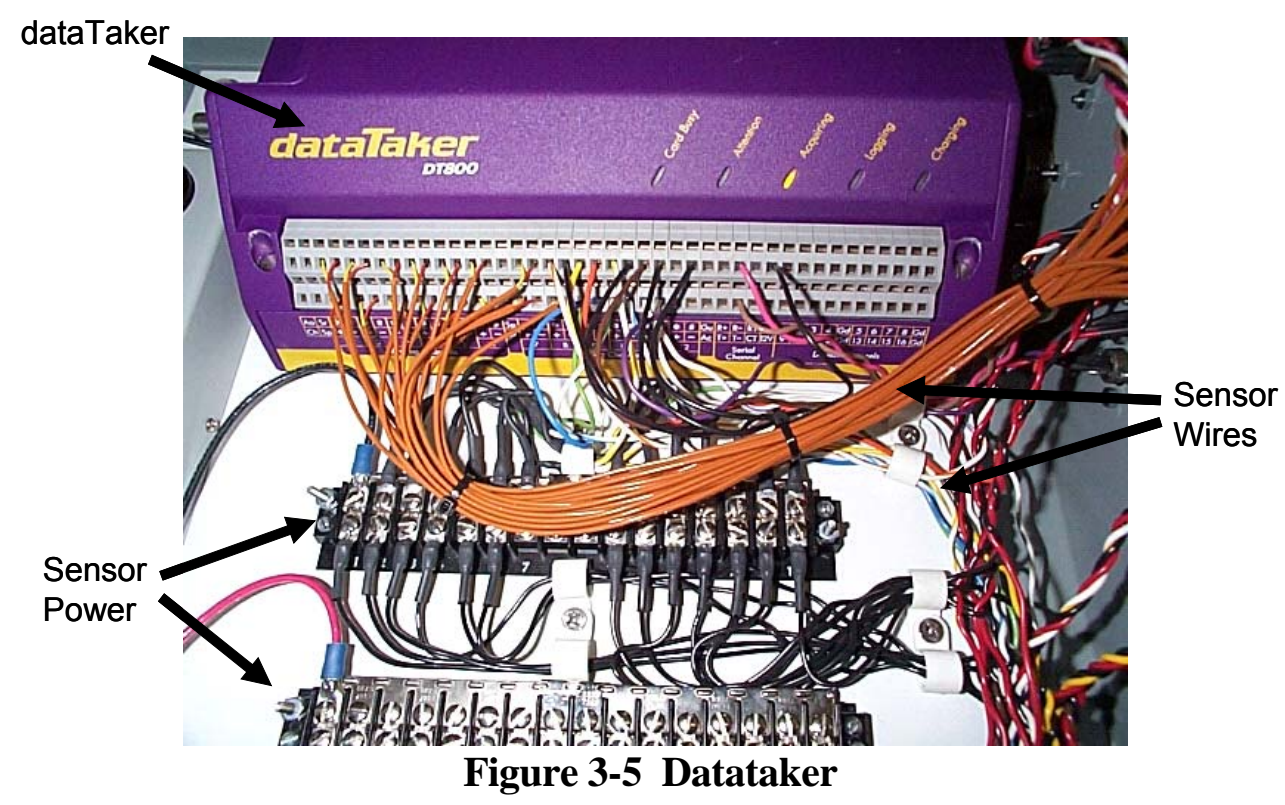

\subsection{Test Matrix}

During normal passenger service, the Alice Austen traveled from the St. George Terminal on Staten Island, NY to the Whitehall Terminal on Manhattan, NY. The passengers were unloaded and new passengers come onboard while the engines were at idle. The vessel then returned to the dock at Staten Island, NY without turning around.

The datalogger collected data continuously at $1 \mathrm{~Hz}$ whenever at least one engine was running. From this data, explained later in Section 4.3, and knowledge of normal operation, a test plan for testing all the exhaust gases with a portable emissions system was established.

The vessel was tested during normal operation hours with passengers onboard. Each run was categorized as having an idle, acceleration, cruise, and maneuvering mode. Each engine had a pre-and post-SCR condition and whether the route was Staten Island to Manhattan or Manhattan to Staten Island. Since the vessel did not turn around, the route determined whether the engine was the front engine or the rear engine. Each engine was tested separately for pre and post-aftertreatment and the direction the vessel was running. Gaseous emissions were collected continuously while the vessel traveled in one direction, 
either Staten Island to Manhattan (SM) or Manhattan to Staten Island (MS). During the beginning of idle, each analyzer zero and span was checked and adjustments were made accordingly. A bag sample for ammonia and PM sample was collected for a single mode, idle, acceleration, cruise, or maneuvering at a time. The time needed to change a filter or prepare for a new bag required that two modes were skipped during each trip. Both idle and cruise were collected or acceleration and maneuvering for a single trip. With the pre and post-aftertreatment, vessel direction, vessel modes, and both engines needing to be tested at least once for every condition, PM and bag data did not have repeat runs.

\subsection{Selective Catalytic Reduction System (SCR)}

The SCR system installed in the Alice Austen was produced and installed by Argillon [49]. Each engine stack included an oxidation catalyst and SCR catalyst. The oxidation catalyst was placed after the SCR catalyst. This location provided a means of removing ammonia slip. The system used manifold air pressure as a basis for the load of the engine to control urea injection. This control assumed that at higher load the exhaust has a higher pressure, which drove turbocharger to increase the boost pressure in the intake manifold. A catalyst brick temperature measurement was also used as a means of controlling urea injection. The catalyst had to be above a threshold temperature before injection could begin. The system was designed to inject urea while the vessel was cruising at full speed and the SCR catalyst reached the required temperature. 


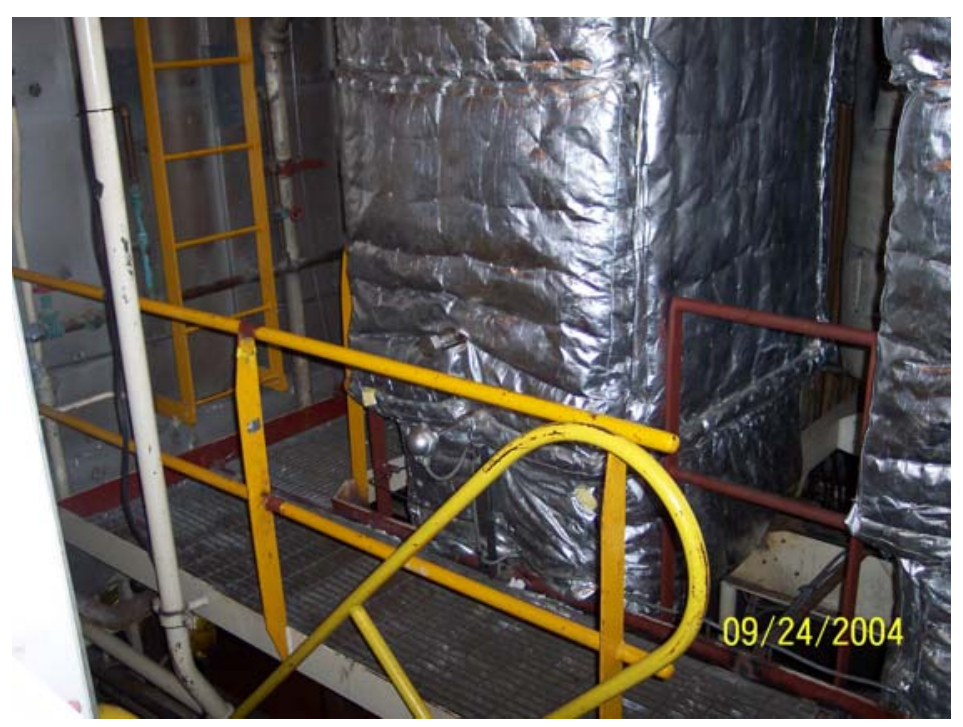

Figure 3-6 Exhaust Stack with SCR Catalyst

\subsection{Test Layout}

The emissions characterization employed a portable analyzer box, the data logger, PM system, and fuel flow meters. A diagram of the flow between components and electronic equipment is shown in Figure 3-7 below.

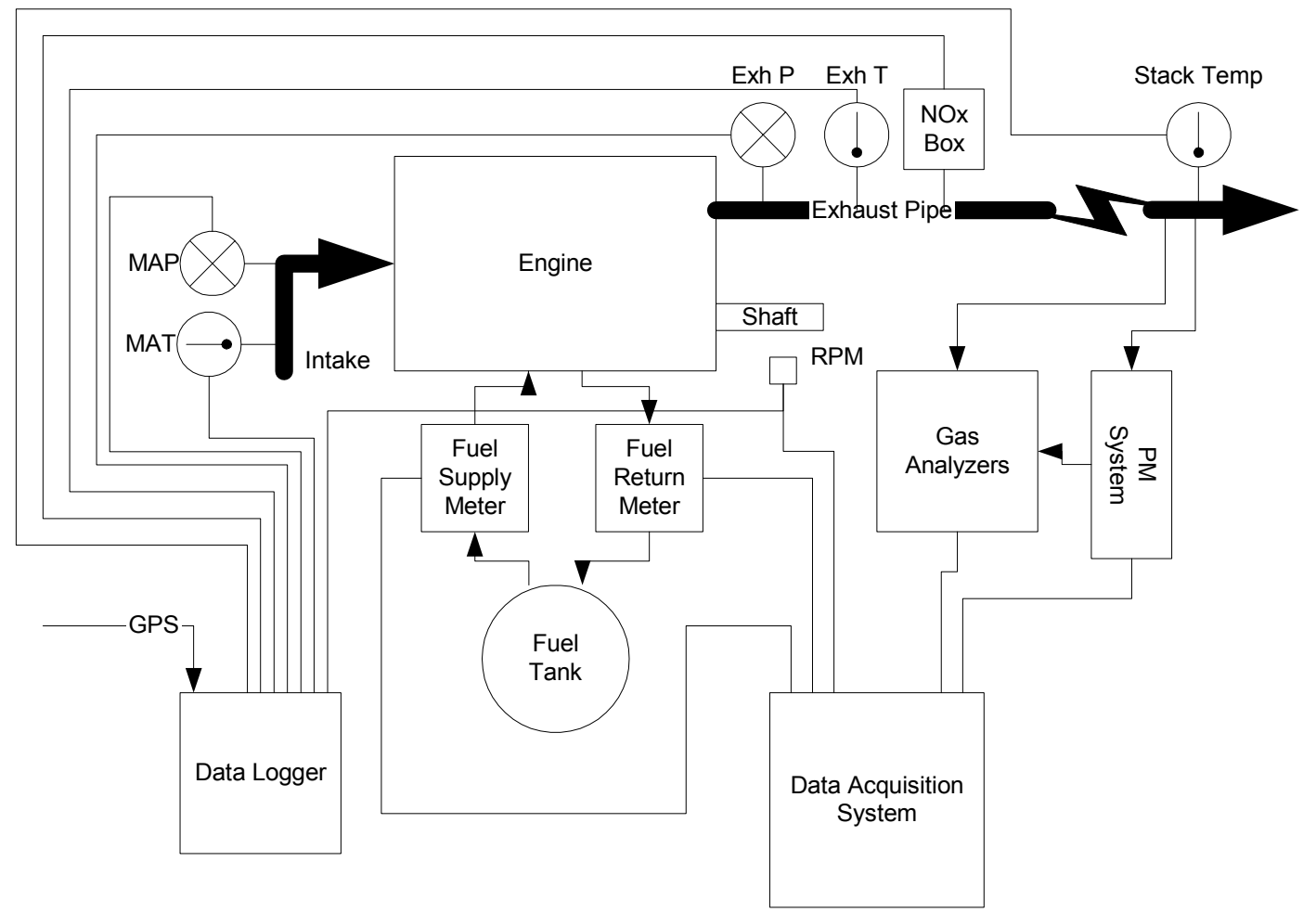

Figure 3-7 Schematic of Test Setup aboard Vessel 


\subsection{Portable Marine Emissions System}

A gas analysis bench was designed for this project to determine the levels of exhaust gases. The system was designed with portability and vessel characteristics in mind. The vessel was fitted with the SCR system to reduce the amount of NOx in the exhaust. Because of the usage of urea, a means to measure ammonia slip from the SCR was incorporated in the sample system in addition to $\mathrm{NOx}, \mathrm{HC}, \mathrm{CO}, \mathrm{CO}_{2}$, and $\mathrm{PM}$ from the propulsion engines. The $\mathrm{O}_{2}$ concentration was measured in the exhaust for purposes of calculating an air-fuel ratio to relate exhaust flow with intake air flow and fuel flow. The gas sampling system can be seen in Figure 3-8 and the PM system and data acquisition are shown in Figure 3-9.

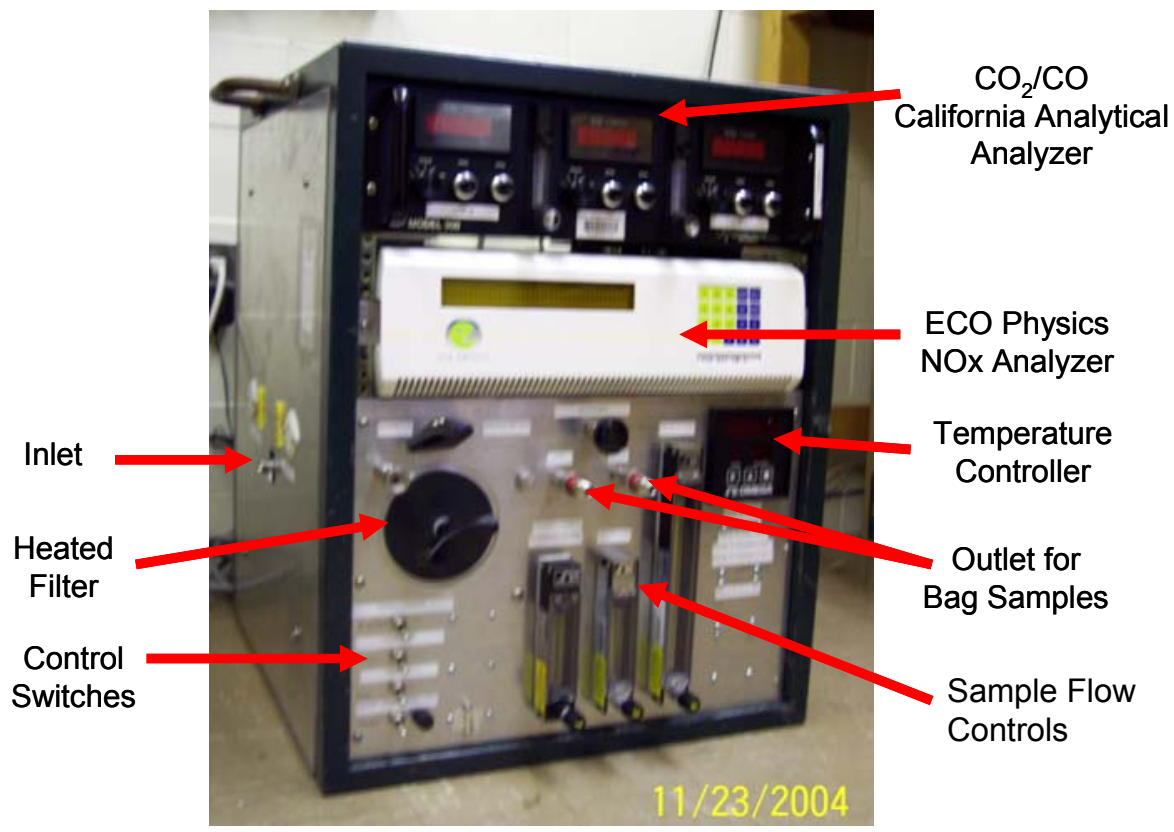

Figure 3-8 Gas Sampling System 


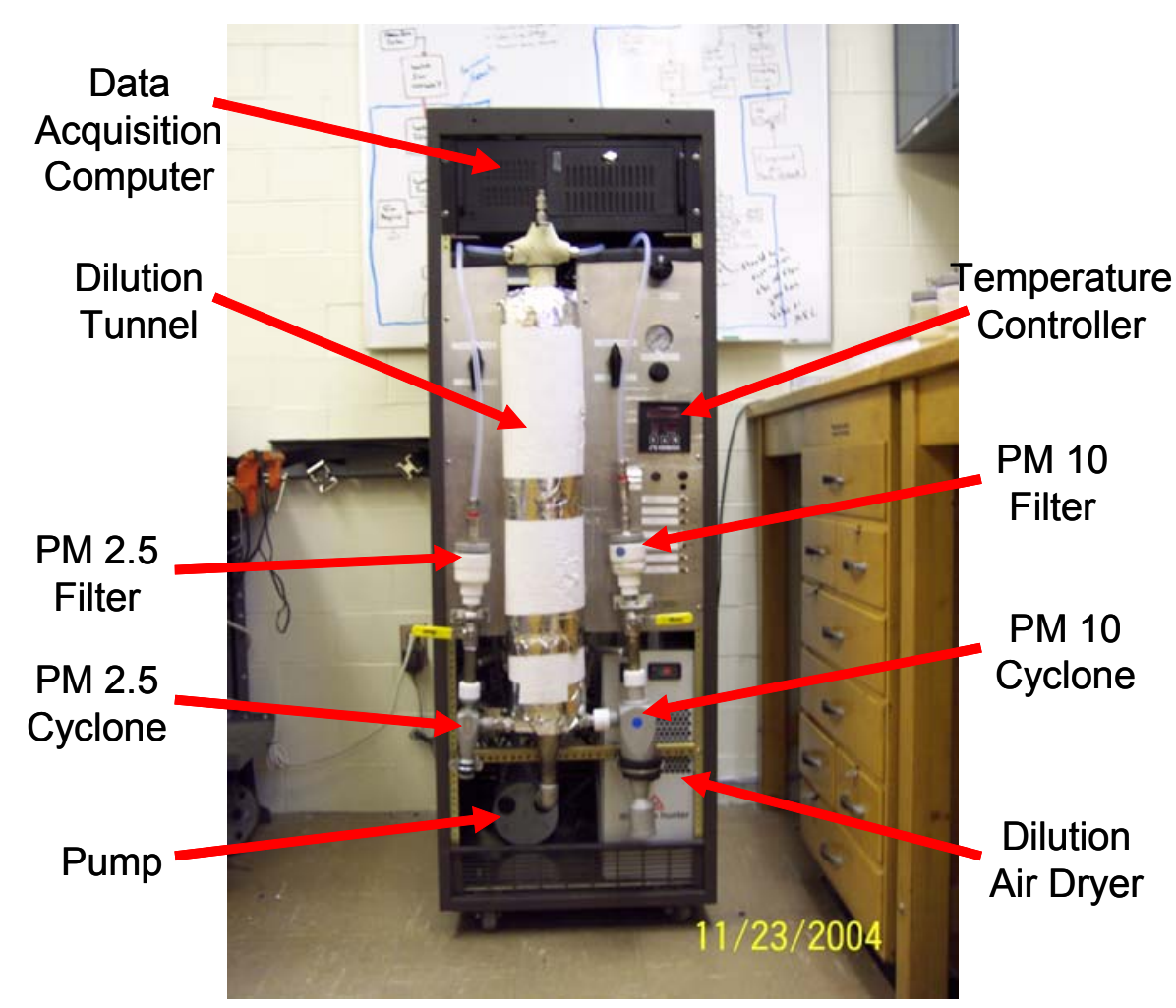

Figure 3-9 PM System / DAQ

The system included three main components, namely the PM sampling system, gas sampling, and data acquisition. The PM sampling and data acquisition combined into one 5 foot rack. The gas sampling system installed in a 3 foot rack system. Each analyzer accuracy is attached in APPENDIX C.

\subsubsection{California Analytical $\mathrm{CO} / \mathrm{CO}_{2}$ Analyzer}

A three component model 300 California Analytical gas analyzer capable of measuring a high $\mathrm{CO}_{2}$ of $15 \%$, low $\mathrm{CO}_{2}$ of $5 \%$, and $\mathrm{CO}$ of 5000 ppm was utilized for testing. The analyzer worked on the principle of infrared light absorption of gases at certain frequencies.

Each component had an infrared light source emitting into the sample chamber. A mirror directed all the emitted light into the chamber. A chopper wheel rotated and broke up the light causing the emitted light to pulse into the sample chamber. The light then passed 
through the sample chamber into a primary chamber of the sample gas being measured, then a secondary chamber of the sample gas. The primary chamber and secondary chamber were linked only by a small channel with a micro-flow sensor. The gas being measured absorbed the light, which increased the pressure in its chamber. The primary chamber absorbed most of the sample and the secondary chamber absorbed the rest. The pressure difference between these two chambers caused a flow from the primary chamber to the secondary chamber that was related to the concentration of the measured gas. As the concentration of the gas being measured increased in the sample chamber, light is absorbed and less light reached the primary and secondary chambers. The use of the primary and secondary chamber pressure difference helped to cancel out any interference gas near the sample gas infrared frequency.

\subsubsection{Horiba CO}

Another $\mathrm{CO}$ analyzer was used in the emissions testing performed. This CO analyzer was a single component high CO Horiba model AIA-210 non-dispersive infrared analyzer. The analyzer worked on the same principle as the three component model 300 California Analytical gas analyzer described above, the infrared light absorption of gases at certain frequencies.

A rotating chopper wheel created a pulsating light from the infrared light source inside the analyzer. Two cells, one with the gas sample and another reference gas were in parallel. One pulsating light passed through the sample cell into a detector cell. The gas being measured absorbed a portion of the light based on concentration. Another pulsating light passed through the reference cell into another detector cell. The two detector cells shared a membrane wall. This membrane wall vibrated based on the concentration of the 
measured gas. The changing capacity of the electrodes connected to the membrane produced an electrical current proportional to the $\mathrm{CO}$ concentration.

\subsection{3 $\quad \mathrm{NO}_{\mathrm{x}}$ Analyzers}

This section discusses the two types of NOx analyzers used during emissions testing. The ECO Physics analyzer was based on the chemiluminescent principle and was the required analyzer type for certification testing. The Horiba MEXA-720 is a zirconium oxide sensor that measures $\mathrm{NOx}$ and $\mathrm{O}_{2}$. This analyzer was smaller but less accurate as a chemiluminescent analyzer.

\subsubsection{ECO Physics}

The emissions testing system utilized an ECO Physics model CLD $822 \mathrm{CM} \mathrm{h}$ chemiluminescent analyzer. Chemiluminescent analyzers provide a fast response and accurate system for even low concentrations of NO. The NO concentration was determined by the infrared energy emitted when $\mathrm{NO}$ was converted to $\mathrm{NO}_{2}$. For measurement of $\mathrm{NOx}$, $\mathrm{NO}_{2}$ in the sample was first converted to $\mathrm{NO}$ by use of a converter. The $\mathrm{NO}$ was then reacted with ozone $\left(\mathrm{O}_{3}\right)$ to form $\mathrm{NO}_{2}$. About $10 \%$ of the converted $\mathrm{NO}_{2}$ was in an excited state, which produced infrared energy proportional to the concentration of NO.

The ECO Physics analyzer used by WVU had dual converters and dual detectors. The exhaust sample was split, allowing a portion of the sample to pass through a low temperature converter, converting $\mathrm{NO}_{2}$ to $\mathrm{NO}$, which then passed through a detector giving a NOx concentration. The other portion of the sample passed through a higher temperature converter, converting $\mathrm{NO}_{2}$ and amines (ammonia) to NO. The NO passed through a detector providing a concentration reading of NOx plus amines (ammonia). Subtracting the two outputs of the analyzers gave an ammonia concentration. The other output was already the NOx concentration. The two converters can be bypassed to allow only a reading of NO. 
The ECO Physics analyzer can have a portion of the sampling through without a converter. As a result, this detector would only read the NO concentration. The other portion of the sample passed through a converter, converting $\mathrm{NO}_{2}$ to $\mathrm{NO}$, which then passed through a detector giving a NOx concentration. These two readings can be subtracted to give a $\mathrm{NO}_{2}$ concentration. WVU elected to use this method to have a $\mathrm{NO}_{2}$ reading and use bag sampling to measure ammonia slip.

\subsubsection{Horiba MEXA-720}

With simultaneous NOx required for pre-and post-SCR gas characterization, a Horiba MEXA-720 was installed pre-and post-SCR. This provided a real time NOx reduction and a quality check on the measurement from the ECO physics analyzer.

The Horiba MEXA-720 used a zirconium oxide sensor. This sensor had two chambers. The first chamber converted $\mathrm{NO}_{2}$ to $\mathrm{NO}$ at a constant high temperature. In this chamber, oxygen was pumped out through an ion pump to keep the concentration of oxygen low. The concentration of oxygen in the sample was proportional to the current used by the ion pump. The sample then continued into the second chamber, where NO was split into nitrogen and oxygen. In this chamber, the oxygen pumped out by an additional ion pump was proportional to the concentration of NO. Since $\mathrm{NO}_{2}$ was converted to $\mathrm{NO}$ in the first chamber, the value of NO from the second chamber correlated to NOx.

The zirconium oxide sensor required a high temperature, which rendered the sensor susceptible to ammonia in the sample. This caused a concentration reading for ammonia and NOx. However, if the SCR system worked properly, the concentration of ammonia will be very low with respect to NOx. 


\subsection{4 $\mathrm{NH}_{3}, \mathrm{CO}_{2}, \mathrm{H}_{2} \mathrm{O}$, and $\mathrm{N}_{2} \mathrm{O}$ Analyzer}

Bag sampling was used during testing for ammonia. The measurement of ammonia was done using an integrated bag because of limited ammonia analyzers. Each sample bag was filled over the entire sampling mode into a heated box with a temperature of $150^{\circ} \mathrm{F}$. This kept water from condensing.

The ammonia slip, water vapor, nitrous oxide, and QC/QA on carbon dioxide were measured using a Bruël \& Kjær 1302 multi-gas monitor. This analyzer was based on the photoacoustic infrared detection principle. The analyzer drew a sample into its sample cell and closed the inlet and outlet. An infrared light source was passed through a rotating chopper wheel, which pulsated the light. The light passed through an optical filter, then through an optical window, and into the sample cell. The pulsated light from the optical filter was selectively absorbed by the gas being monitored. This in turn, caused a pressure wave inside the cell. This pressure wave was monitored by microphones recording a signal directly proportional to the concentration of the monitored gas. The optical filter was then changed in an automated cycle, providing the signal for the next gas being measured. This procedure continued throughout the gases setup to be monitored. The inlet and outlet to the sample chamber was then opened and a new sample was pulled into the sample cell. The 1302 analyzer was therefore batchwise rather than continuous in its function.

\subsubsection{Total HC Analyzer}

The total hydrocarbons was not sampled because the flame ionization detector (FID) fuel and zero air gas bottles needed to run the FID was a safety liability to have onboard with passengers. Off-board total hydrocarbon was not tested due to the distance from the 
vessel to the analyzer cooling the heated boxes. The heavy hydrocarbons and water condense at low temperatures, producing incorrect results.

\subsubsection{Particulate Matter System}

MJ Bradley \& Associates required measurement of PM10 and PM2.5 from the exhaust to show the impact on the environment. It is noted that this is a deviation from certification testing requiring total PM. The particulate matter measurement system is shown in Figure 3-9. A schematic of the design is shown below in Figure 3-10. The pump at the exit constantly pulled about 90 liters of air through the system. The system utilized compressed air, which supplied the dilution air. The compressed air, with a coalescing filter to remove coarse particles, served as the first filter. The air then entered an air dryer to remove any remaining water in the compressed air. The air was further filtered with a HEPA filter, removing $99.9 \%$ of all particulates. The amount of dilution air entering the dilution tunnel was controlled by a mass flow controller (MFC). Dilution air and exhaust mixed inside the dilution tunnel. The diluted sample split between the PM10, PM2.5, and bypass line. The bypass line filtered and supplied a back pressure by means of a needled valve, so that enough flow diverted to the PM10 and PM2.5 lines.

The PM10 line flowed out of the dilution tunnel and through the PM10 cyclone to remove any particles at the $10 \mu \mathrm{m}$ cut-point. Larger particles in diesel exhaust are created by the collection of particles in the sampling system. After passing through the cyclone, the sample traveled through either the PM10 filter or a bypass filter. The flow path was dependent on the position of the 3-way valve. The PM10 line had an on-off ball valve and the PM10 bypass line did not. This valve was closed when changing filters, to prevent the pull of ambient air into the system. Next, sample traveled through the 3-way valve, and was 
then controlled by a MFC to the 16.7 liters per minute required by the cyclone The PM2.5 line consisted of the same setup as the PM10, except the cyclone had a cut-point of $2.5 \mu \mathrm{m}$. The three lines: bypass, PM10, and PM2.5 met and flowed through a mass flow meter before flowing through the pump.

The system was controlled by setting a dilution ratio, which was the volumetric flow rate of the dilution tunnel to the volumetric flow rate of the exhaust sampled. The dilution ratio was controlled by using a PID control algorithm with the calculated real-time dilution ratio as the input and the voltage for the solenoid in the dilution air mass flow controller as the output to control the set dilution ratio.

Each cyclone was designed for an actual flow rate, not a standard flow rate. The actual flow rate was calculated by converting the standard flow rate from the mass flow controller with the line pressure and temperature. A PID control algorithm was used with the calculated actual flow rate as the input and the voltage for the mass flow controller solenoid as the output to control the required cyclone flow rate.

The upstream filter temperature was monitored to remain below the 40 CFR, Part 86, required limit of $125^{\circ} \mathrm{F}$, simulating the effect of exhaust mixing with ambient air. Below $125^{\circ} \mathrm{F}$, the soluble organic fraction (SOF) in PM converts from vapor to liquid form and collects on the filter. If the temperature was above the limits, the dilution ratio was increased, to obtain the desired temperature. Dual $47 \mathrm{~mm}$ Pallflex filters were used in the PM10 and PM2.5 filter holder. Test filters were pre-and post-weighed at the EERL after being conditioned in an environmentally controlled chamber, which was maintained at approximately $70{ }^{\circ} \mathrm{F}$ and $50 \%$ relative humidity, in compliance with requirements of 40 CFR Parts 86 and 89. Each filter pair in a glass Petri dish was packaged in a shipping envelope and transported to the testing site. After each test run, each filter was repackaged 
for transport back to EERL to be post-weighted. The pre-weighing to testing and testing to post-weighting time limits per 40 CFR Parts 86 and 89 were exceeded since an environmental chamber was not taken onboard. A pair of background filters was run for the PM10 and PM2.5 each day of testing to account for the dilution air particulates and tunnel shedding.

A pair of reference filters was pre-weighted at the EERL and shipped with the test filters. These filters were not used in testing. The filters were then post-weighted at the EERL to determine the effect of shipping on the filters used for testing. 


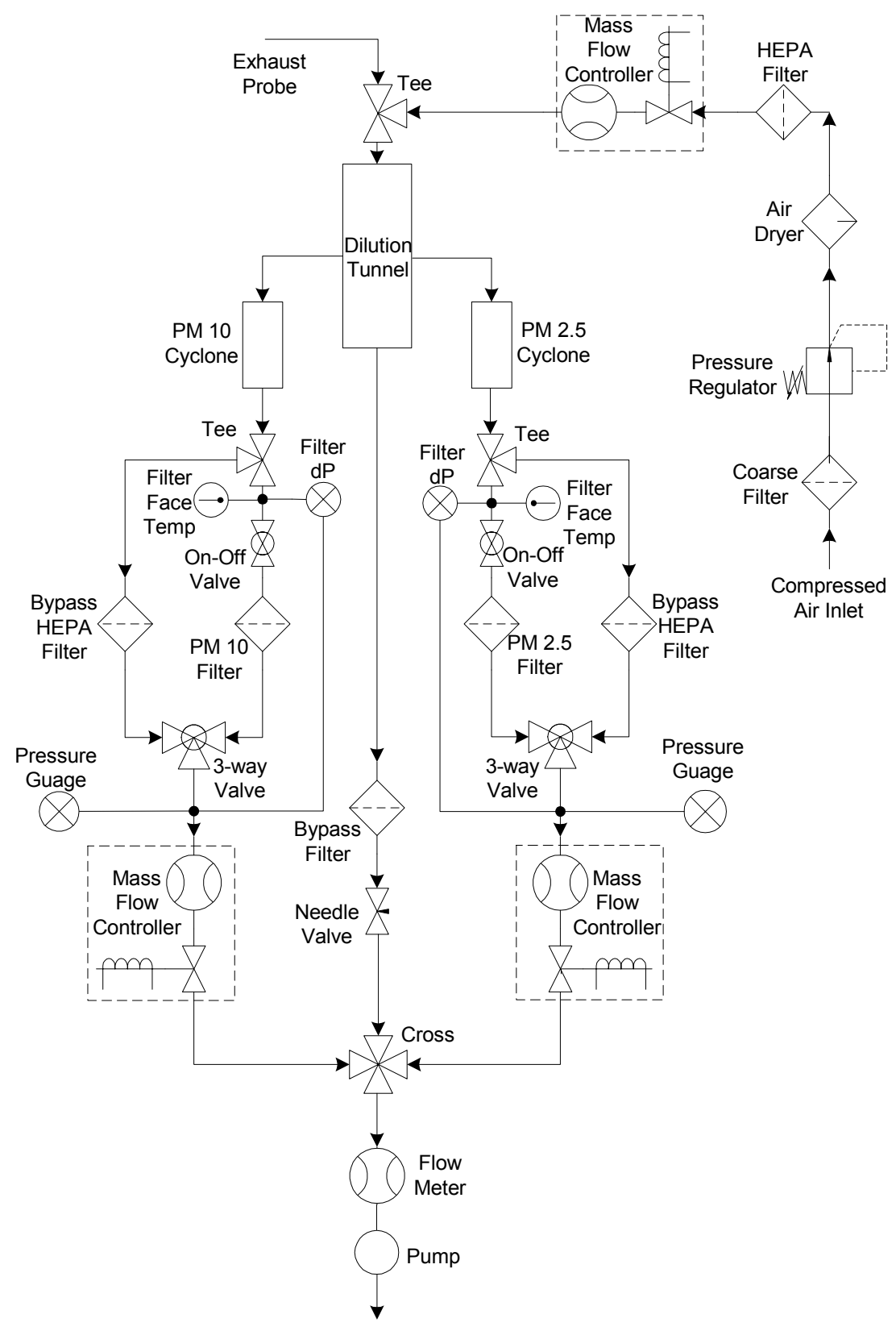

Figure 3-10 Flow Schematic of PM System

\subsubsection{Instrumentation Control and Data Acquisition}

The software used for this testing equipment was based upon the software used for Mobile Emission Measurement System, MEMS, designed by WVU [14, 15, 44]. This software acquired data through Analog Devices 3B modules signal conditioning to a National Instrument acquisition board or through serial ports on the computer onto which it was installed. The software controlled the PM system with the use of the PID algorithms 
mentioned earlier in Section 3.7.6. Within the DAQ, one graph showed the gas analyzer values and another graph displayed the PM real time system flows and the flow set points. A screenshot of this software is shown in Figure 3-11.

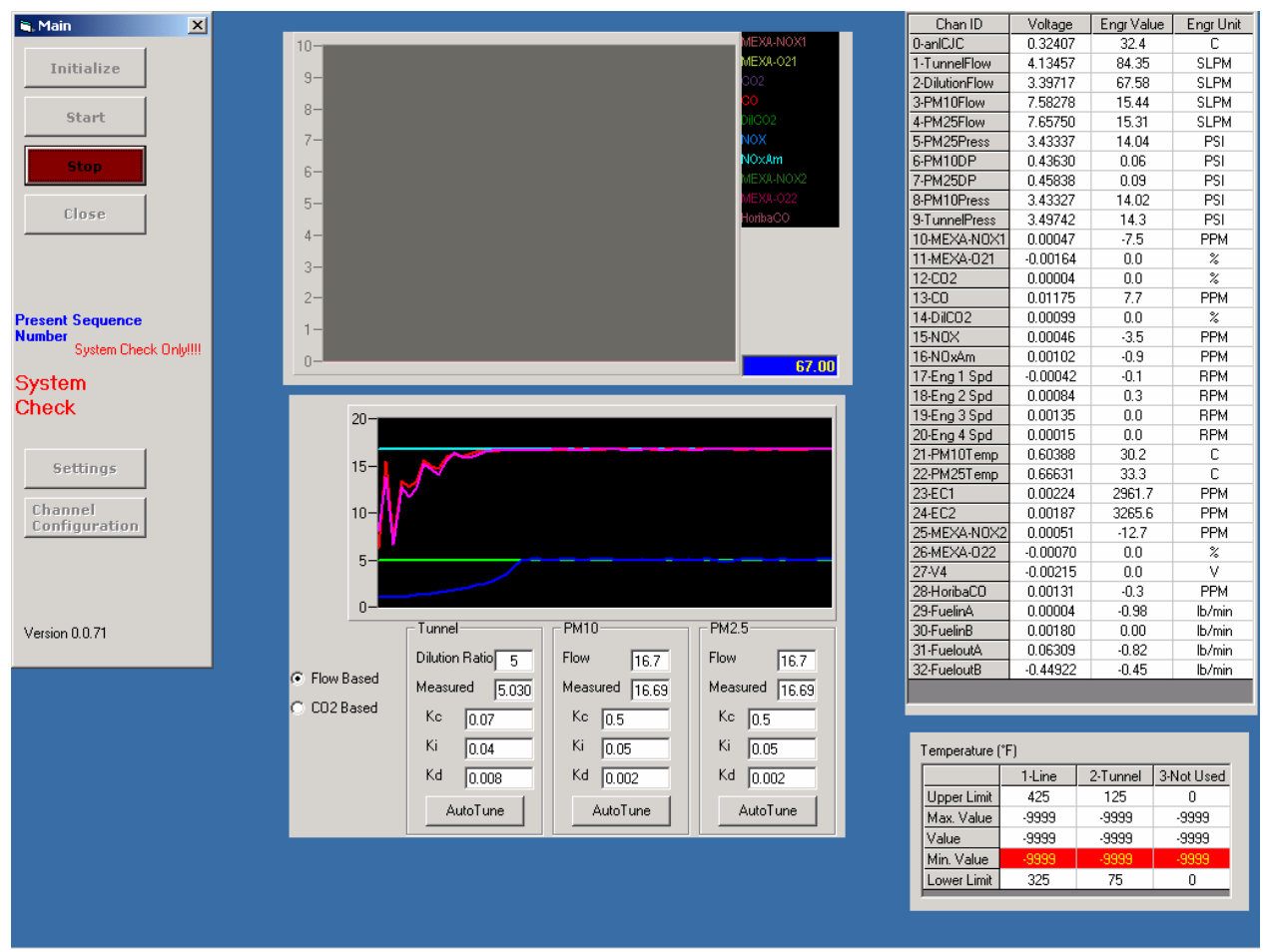

\subsection{Data Analysis}

Figure 3-11 Data Acquisition Software

Limited marine in-use testing has been done previously. With large onboard marine diesel engines, approximately 70 liters displacement each on the Alice Austen, specific testing procedures have not been administered. The equations used for testing were derived based on other regulations in Title 40 CFR 86 [5], Title 40 CFR 89 [43], Title 40 CFR 92 [50], Title 40 CFR 94 [51], ISO8178 [6], and SAE J177 [52].

\subsubsection{Calculation of Gas Emissions}

The mass flow rate of each exhaust constituent from the concentration value from the analyzer, volumetric flow of exhaust, and density of the constituent at $68^{\circ} \mathrm{F}$ and 14.696 psia can be written as, 


$$
\dot{M}_{i}=C_{i} * Q_{e x h} * \rho_{i}
$$

Equation 3-1

Table 3-4 Density of Constituents at $68^{\circ} \mathrm{F}$ and 14.969 psia

\begin{tabular}{|c|c|}
\hline Gas & Density, $\left(\frac{g}{f t^{3}}\right)$ \\
\hline $\mathrm{NOx}$ & 54.16 \\
\hline $\mathrm{CO}$ & 32.97 \\
\hline $\mathrm{HC}$ & 16.27 \\
\hline $\mathrm{CO}_{2}$ & 51.81 \\
\hline $\mathrm{NH}_{3}$ & 19.958 \\
\hline $\mathrm{N}_{2} \mathrm{O}$ & 51.81 \\
\hline
\end{tabular}

The exhaust flow was calculated from,

$$
Q_{e x h}=\rho_{e x h} * \dot{M}_{e x h}
$$

Equation 3-2

The exhaust flow rate of engine was given as,

$$
\dot{M}_{\text {exh,w }}=\dot{M}_{\text {int ake,w }}+\dot{M}_{\text {fuel }}
$$

Equation 3-3

The air-to-fuel ratio, to measure only fuel flow or intake flow was given as,

$$
\left(\frac{A}{F}\right)_{\text {actual }}=\frac{\dot{M}_{\text {int ake }}}{\dot{M}_{\text {fuel }}}
$$

Equation 3-4

The air-to-fuel ratio was also give as,

$$
\left(\frac{A}{F}\right)_{\text {actual }}=\lambda *\left(\frac{A}{F}\right)_{\text {stoich }}
$$

\section{Equation 3-5}

The stoichiometric air-to-fuel ratio from the molecular weight of carbon and hydrogen and the hydrogen-to-carbon ratio from fuel analysis were given as,

$$
\left(\frac{A}{F}\right)_{\text {stoich }}=\frac{M W_{\text {Carbon }}+\alpha * M W_{\text {Hydrogen }}}{138.18 *(1+0.25 * \alpha)}
$$

\section{Equation 3-6}

The relative air-to-fuel ratio, lambda, neglecting oxygen in the fuel and hydrocarbons, based on Brettschneider equation [53], is given below. The fuel analysis resulted in the hydrogen 
plus carbon in the fuel to represent $99.35 \%$ of the fuel by weight. The hydrocarbon content in diesel exhaust is negligible in comparison to carbon dioxide and carbon monoxide.

$$
\lambda=\frac{\left[\mathrm{CO}_{2}\right]+\frac{[\mathrm{CO}]}{2}+\left[\mathrm{O}_{2}\right]+\frac{\{\mathrm{NO}\} / 10,000}{2}+\left(\frac{\alpha}{4} * \frac{3.5}{3.5+\frac{[\mathrm{CO}]}{\left[\mathrm{CO}_{2}\right]}}\right) *\left(\left[\mathrm{CO}_{2}\right]+[\mathrm{CO}]\right)}{\left(1+\frac{\alpha}{4}\right) *\left(\left[\mathrm{CO}_{2}\right]+[\mathrm{CO}]\right)} \text { Equation 3-7 }
$$

The constituents of $\mathrm{CO}$ and $\mathrm{CO}_{2}$ were measured dry and $\mathrm{NOx}$ and $\mathrm{O}_{2}$ were measured wet. The dry concentrations of $\mathrm{CO}$ and $\mathrm{CO}_{2}$ were converted to wet from this equation,

$$
C_{i, w}=\frac{C_{i, d}}{K_{w}}
$$

Equation 3-8

The wet-to-dry conversion factor was given by,

$$
K_{w}=1+\mathrm{DH}_{2} \mathrm{O}
$$

\section{Equation 3-9}

The value of $\mathrm{DH}_{2} \mathrm{O}$ can be approximated by,

$$
\mathrm{DH}_{2} \mathrm{O}=\left[\alpha *\left(\frac{\frac{C_{\mathrm{CO}_{2}, d r y}}{10^{2}}+\frac{C_{C O, d r y}}{10^{6}}}{2}\right)+Y^{*} \mathrm{DVOL}_{\mathrm{Ratio}}\right] *\left[\frac{1}{1+\frac{C_{\mathrm{CO}, \text { dry }}}{C_{\mathrm{CO}_{2}, d r y} * K^{*} 10^{4}}}\right] \text { Equation 3-10 }
$$

The $D V O L_{\text {Ratio }}$ was obtained from,

$$
D V O L_{\text {Ratio }}=1-\frac{C_{\mathrm{CO}_{2}, \text { dry }}}{10^{2}} * \frac{\alpha}{4}-\frac{C_{\mathrm{CO}, \text { dry }}}{10^{6}} *\left(\frac{\alpha}{4}+0.5\right) \quad \text { Equation 3-11 }
$$

Solving for $Y$ using,

$$
Y=\frac{H^{*} M W_{\text {air }}}{M W_{\mathrm{H}_{2} \mathrm{O}}}-\frac{P_{v}}{B A R O-P_{v}}
$$


The value of specific humidity, $H$, from the partial pressure of the water in the air and the barometric pressure, was given as,

$$
H=\frac{K_{H} * P_{v}}{\left(B A R O-P_{v}\right)}
$$

The mass fuel rate in pounds, derived from Title CFR 86 Subpart N, neglecting hydrocarbons, was written as,

$$
\dot{M}_{\text {Fuel }}=\left[\frac{0.429 * \dot{M}_{\mathrm{CO}}+0.273 * \dot{M}_{\mathrm{CO}_{2}}}{\frac{12.011}{12.011+\alpha(1.008)}}\right] *\left(\frac{1}{453.6}\right)
$$

Each emission constituent in brake-specific terms was given as,

$$
B S_{i}=\frac{\dot{M}_{i}}{P}
$$

Equation 3-15

Each emission constituent, in mass emitted per mode, was given as,

$$
M_{i}=\dot{M}_{i} * t_{\text {mode }}
$$

Equation 3-16

Each vessel round trip consisted of Staten Island to Manhattan (SM) and Manhattan to Staten Island (MS). Each direction was broken up into modes of idle, acceleration, cruise, and maneuvering. Each direction was completed in a time very close to 30 minutes in length and a round trip was therefore 60 minutes. Based on the average time in each mode, a time factor was the average time for the mode over 60 minutes. The idle time in each direction was determined by adding the acceleration, cruise, and maneuvering time and subtracting that from 30 minutes. The time weighted factors provided a method of determining an average round-trip based on multiple runs of data when round-trip and mode times vary. Each mode's brake-specific emissions were calculated and multiplied by the 
mode's time factor. Summing the emission contribution from each mode based on time was written as,

$$
\left(B S_{i}\right)_{\text {Round-Trip }}=\sum_{S M}\left\{T F_{\text {Mode }} *\left(B S_{i}\right)_{\text {Mode }}\right\}+\sum_{M S}\left\{T F_{\text {Mode }} *\left(B S_{i}\right)_{\text {Mode }}\right\} \text { Equation 3-17 }
$$

\subsubsection{Calculation of Particulate Matter Emissions}

The mass of particulate matter emitted per mode based on the exhaust volumetric flow rate, dilution ratio, mass on filters, and the volume of air through filters, was given as,

$$
P_{\text {mass }}=V_{\text {exh }} *\left(\frac{P_{f}}{V_{f}} * D R-\frac{P_{b f}}{V_{b f}} *(D R-1)\right) \quad \text { Equation 3-18 }
$$

The total exhaust volumetric flow rate was given as,

$$
V_{e x h}=\frac{\dot{M}_{e x h} * t}{\rho_{e x h}}
$$

Equation 3-19

The dilution ratio, DR, using the total tunnel volumetric flow rate from the tunnel mass flow meter and the dilution air volumetric flow rate from the dilution mass flow controller, was written as,

$$
D R=\frac{Q_{\text {tunnel }}}{Q_{\text {tunnel }}-Q_{\text {dilution }}}
$$

The DR was also defined using the wet $\mathrm{CO}_{2}$ raw exhaust concentration, wet $\mathrm{CO}_{2}$ diluted exhaust concentration from the dilution tunnel, and $\mathrm{CO}_{2}$ background air concentration as,

$$
D R=\frac{\left(\mathrm{CO}_{2}\right)_{\text {raw,wet }}-\left(\mathrm{CO}_{2}\right)_{\text {background,wet }}}{\left(\mathrm{CO}_{2}\right)_{\text {dilution,wet }}-\left(\mathrm{CO}_{2}\right)_{\text {background,wet }}}
$$

Equation 3-21 


\section{RESULTS AND DISCUSSIONS}

\subsection{Introduction}

The main goal of this study was to quantify in-use marine emissions from this vessel based on regular service. This section discusses the results of experimentation involved in the data logging and marine emissions performed onboard as well as the validation results of the equipment.

\subsection{Data Logging Validation}

Steady state validation testing was performed on the data logger at the EERL prior to installation on the Alice Austen. The data logger was tested to check that each sensor read simultaneously in an engine environment. The testing was performed on a 2001 Cummins 5.9L B-series engine with \#2 diesel fuel. The testing consisted of four set points lasting ten minutes at different engine speed and torque to have different exhaust flow. The flow through the NO EC analyzer boxes depended upon exhaust flow and exhaust pressure. The five set points were $1500 \mathrm{rpm} / 65 \mathrm{ft}-\mathrm{lbs}, 1501 \mathrm{rpm} / 100 \mathrm{ft}-\mathrm{lbs}, 1700 \mathrm{rpm} / 125 \mathrm{ft}-\mathrm{lbs}, 1899$ rpm / $145 \mathrm{ft}-\mathrm{lbs}$, and $2100 \mathrm{rpm} / 210 \mathrm{ft}-\mathrm{lbs}$. This Cummins engine should produce lower NOx concentration in the exhaust and lower PM loading on the $0.5 \mu \mathrm{m}$ filter inside the NO boxes than the Alice Austen's Caterpillar engines.

The raw concentrations of NOx were compared between the NO boxes and the MEMS systems values. The accuracy of the NO analyzer required $20 \%$ of value for the preliminary testing. An awareness of NOx emitted was needed because there were no emissions standards when the engines were produced. The concentration of three analyzers is displayed below in Figure 4-1. The MEMS MEXA analyzer was a zirconia oxide sensor, Horiba model MEXA-120, similar to the MEXA-720 previously described, with $3 \%$ accuracy of full scale. The MEMS EC analyzer was the same electrochemical analyzer as in 
the NO boxes except, MEMS has its own flow system with a NOx converter, constant flow rate, and constant pressure. The two NO boxes (NO box 1 and NO box 2) were the two analyzers used onboard the Alice Austen vessel. The MEMS EC analyzer was used as quality check and quality control for the MEMS MEXA analyzer.

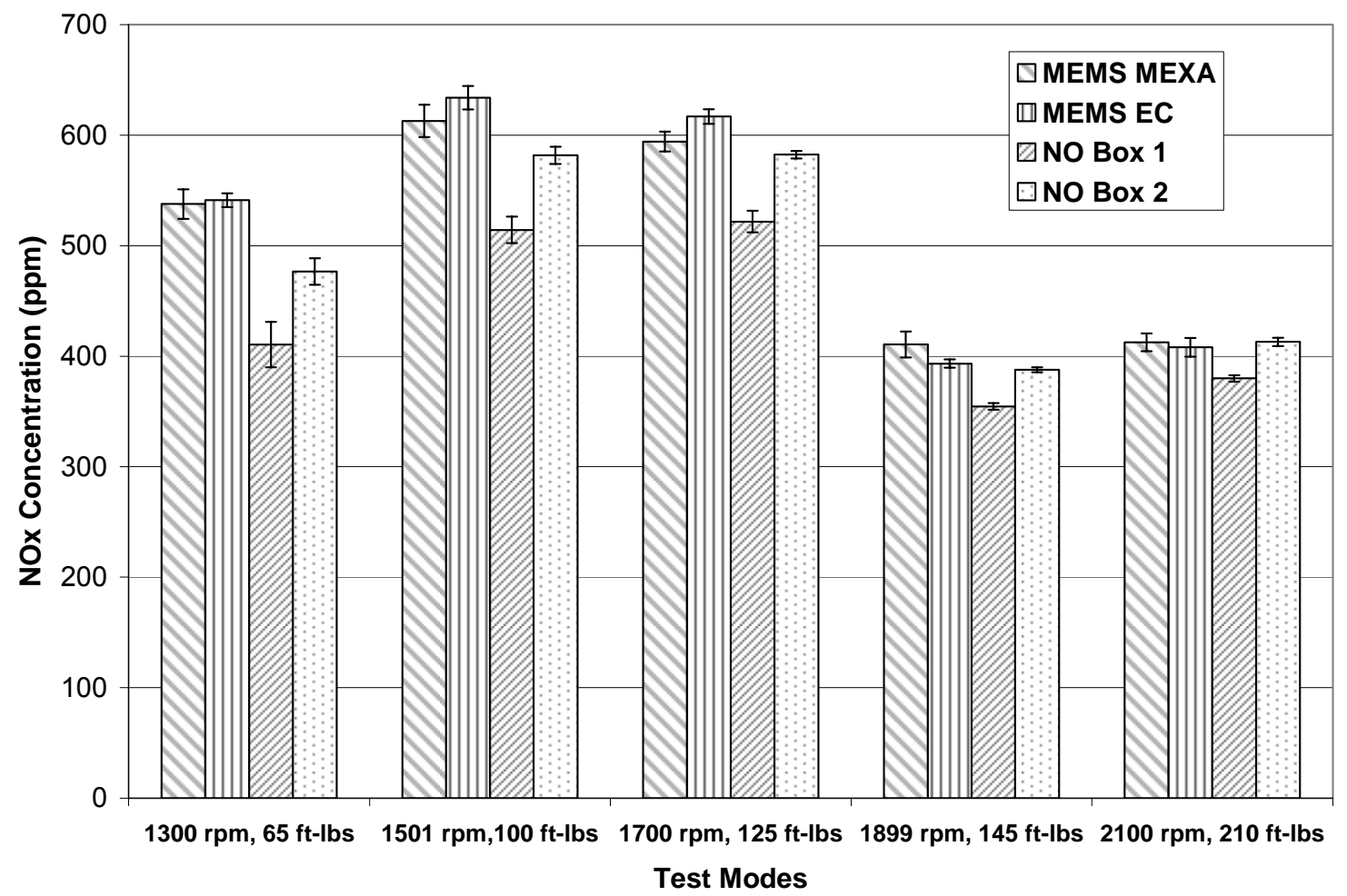

Figure 4-1 Concentrations from NOx Analyzers

NO box 1 and NO box 2 was within $25 \%$ of the MEXA-120 at low engine speed and within $10 \%$ at higher engine speeds, shown in Figure 4-2, which corresponds to higher flow rate through the NO box which takes a slipstream from the engine exhaust flow. The bars show one standard deviation from the mean value during the test mode for each analyzer. The MEMS system had a converter prior to the MEXA-120 and EC analyzer inside the system. The NO boxes were without this converter. The converter works by 
changing the $\mathrm{NO}_{2}$ in the exhaust to NO. The NOx in the exhaust usually consists of 5-10\% $\mathrm{NO}_{2}[54]$.

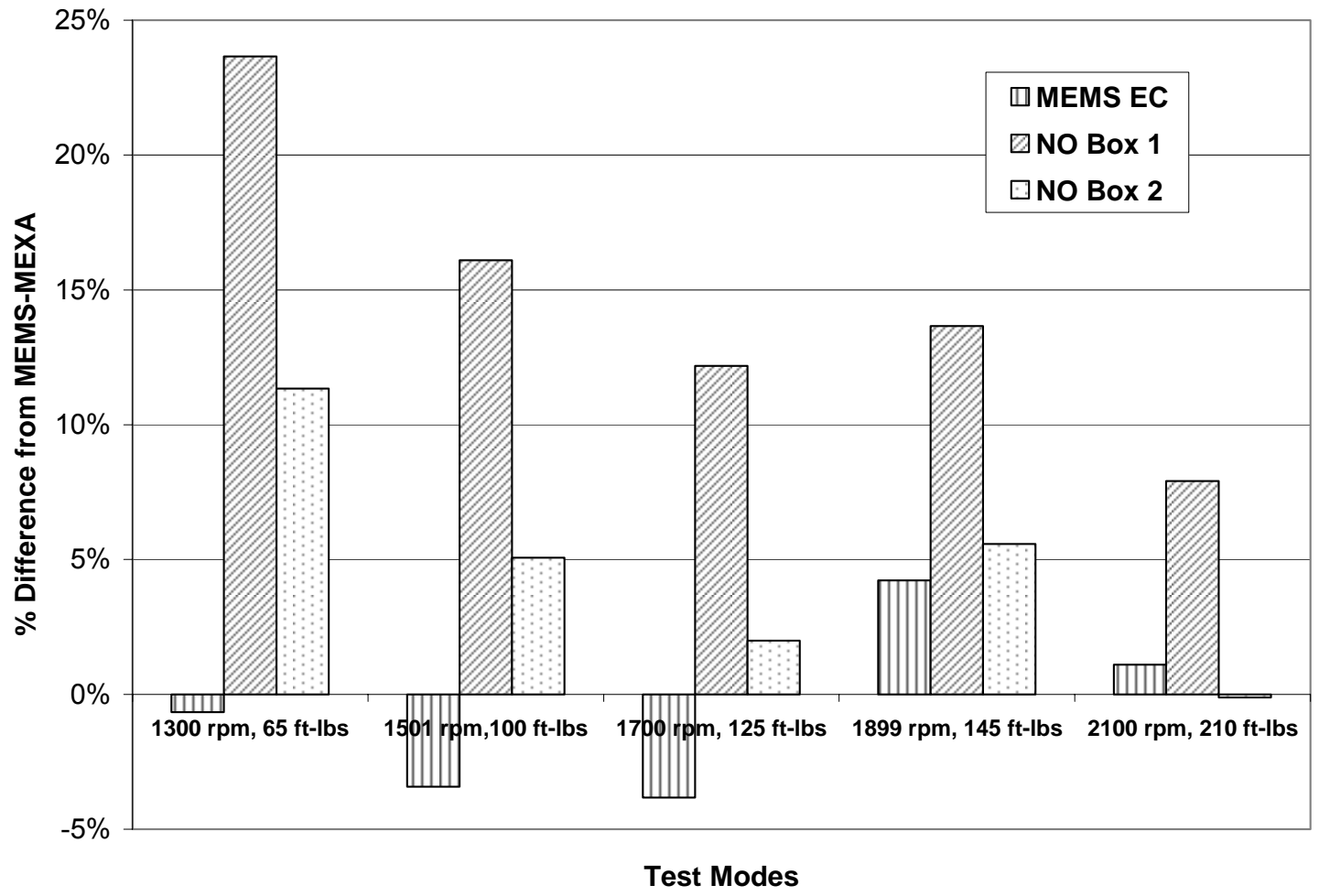

Figure 4-2 Percent Difference to Zirconia Oxide Sensor

\subsection{Data Logging Test Results}

This section discusses the results of testing using the datalogger and NO boxes. This data was used to obtain engine information for aftertreatment selection and emissions test procedures. The results are broken down in a modal analysis.

\subsubsection{Modal Analysis}

From GPS data, the Alice Austen had a repeatable route. This route can be seen in Figure 4-3. The Alice Austen started the day at St. George Terminal on Staten Island picked up passengers. The vessel then traveled northeast to the Whitehall Terminal in Manhattan. After unloading and loading passengers, the vessel then traveled back southwest to the Whitehall terminal without turning around. This route was repeated while the vessel was in 
service. This was usually from 10 PM until 6 AM during the week. The line of travel over the water was approximately repeated thus allowing the use of comparing one passenger run to another, but with route variability.

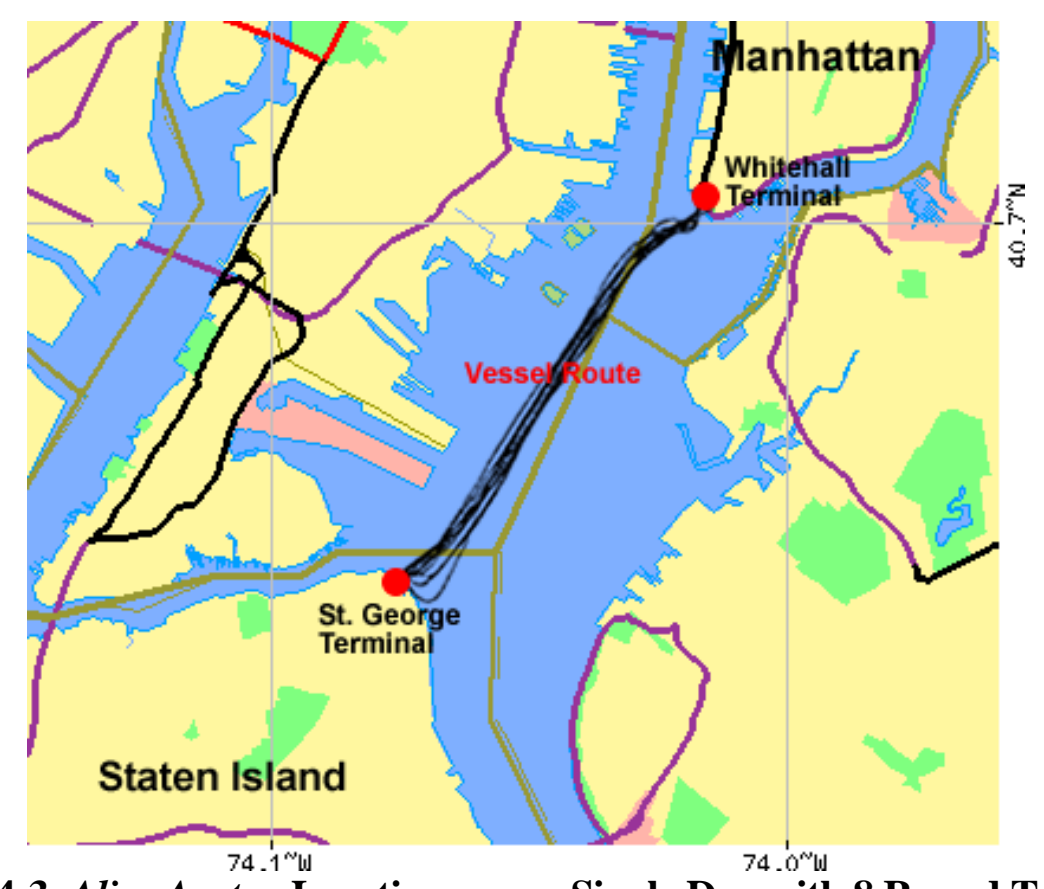

Figure 4-3 Alice Austen Location over a Single Day with 8 Round Trips [55]

Using the engine speed and GPS speed, a clear picture of the engine modes was determined. The vessel, while in dock unloading and loading passengers, sat at idle for approximately ten minutes. As the Alice Austen left dock, the vessel accelerated to full speed for approximately 2 minute. The vessel then cruised at full speed for approximately 17 minutes until approaching the dock. The maneuvering at the dock took 2 minutes. The run times in each mode is shown in Figure 4-4. The Alice Austen showed much greater idle times at dock on Staten Island because the vessel warmed up everyday for about an hour before passenger service. The bars in the graph show one standard deviation from the mean for that mode. The idle times had the largest variation from passenger drop off and pickup time variation. 


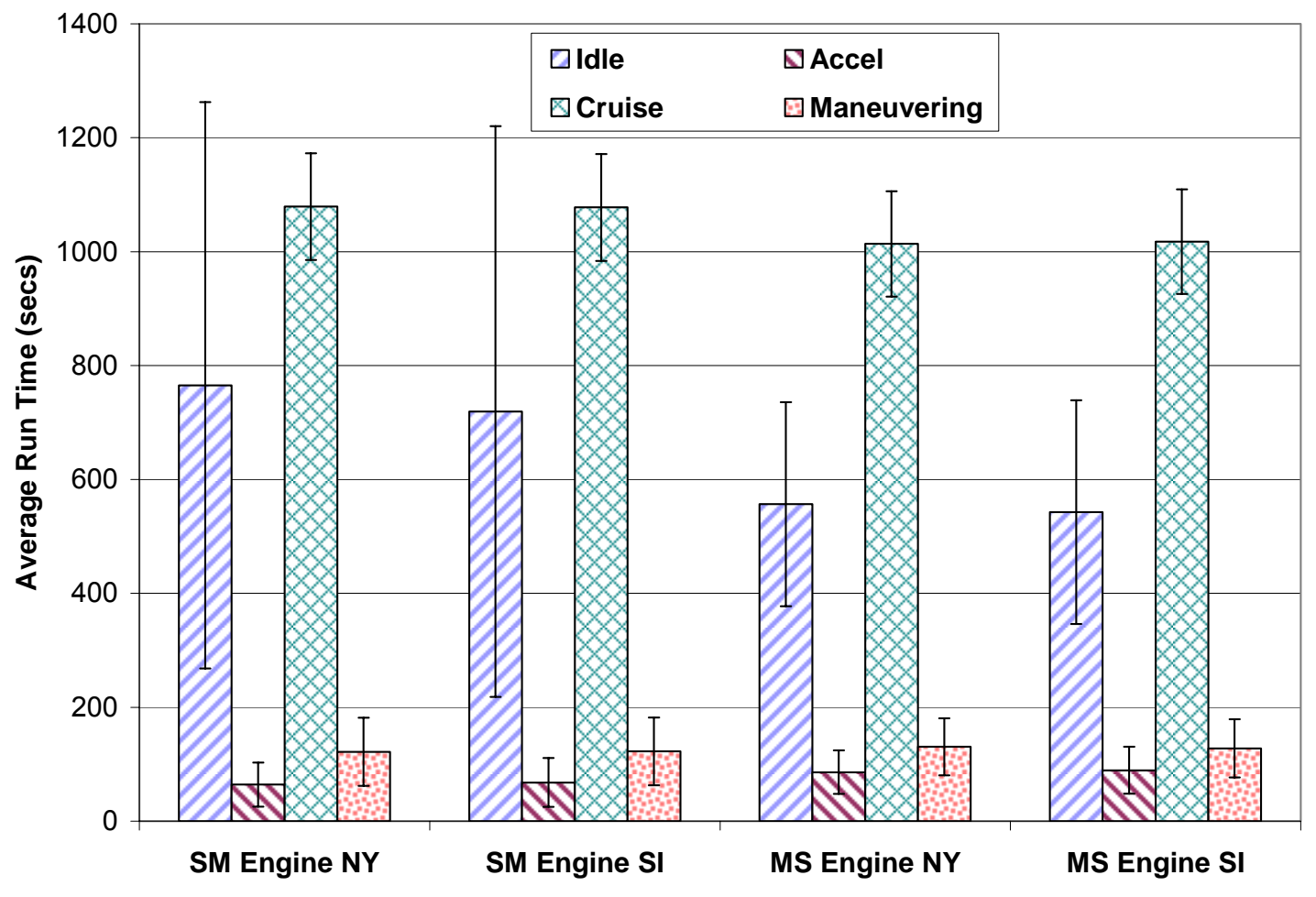

Figure 4-4 Mode Times Based on Direction and Engine

With the vessel not turning around, the front and rear engine of the vessel changed based on the route. This can easily be seen in Figure 4-5 with the small variation of engine speed for the rear engine at cruise and the larger variation of engine speed for the front engine. Engine SI was the rear engine first, then on the trip back, the rear engine changed to engine NY. This could be attributed to the water being rougher at the front of the vessel than the rear. The vessel speed was approximately 14 to 16 knots at cruise. 


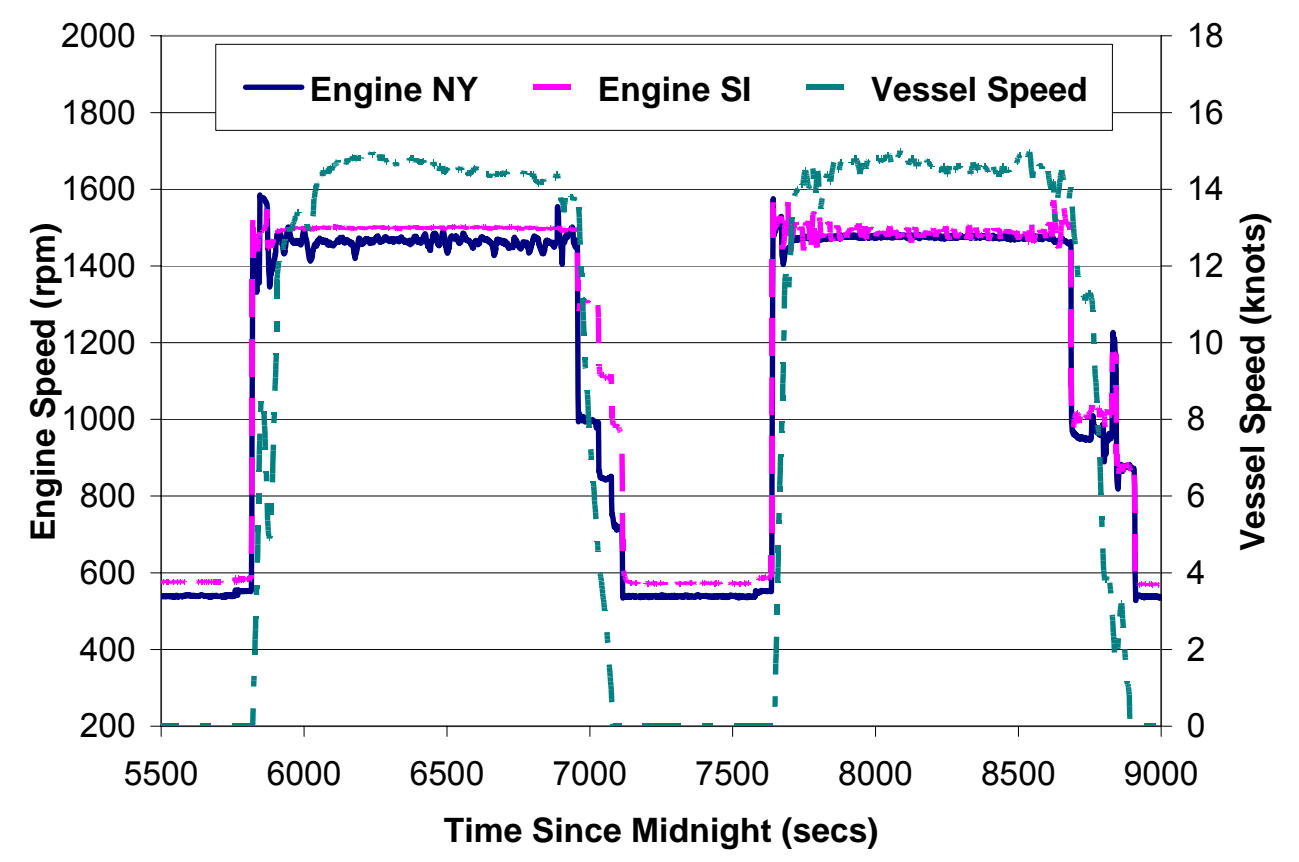

Figure 4-5 Engine Speed of Route to Manhattan and back to Staten Island

\subsubsection{Intake Air Flow}

The engine intake flow was calculated, assuming intake efficiency $\left(n_{\text {eff }}\right)$, with engine speed $\left(C_{E}\right)$, engine displacement $\left(V_{D}\right)$, manifold air pressure $(M A P)$, manifold air temperature $(M A T)$, and revolutions per cycle $\left(R_{S}\right)$ using the equation below. Engine NY showed a higher intake flow at cruise during SM and MS routes, displayed in Figure 4-6. The intake flow around idle was approximately $550 \mathrm{scfm}$ and the flow at cruise was approximately $2600 \mathrm{scfm}$. For the purposes of preliminary testing, the exhaust flow was assumed the intake flow for calculating the NO mass flow rate.

$$
\dot{Q}_{\text {intake }}=\frac{n_{\text {eff }} * C_{E} * V_{D}}{R_{S}} *\left(\frac{M A P+14.696}{14.696}\right) *\left(\frac{459.67+68}{M A T+459.67}\right) \quad \text { Equation 4-1 }
$$




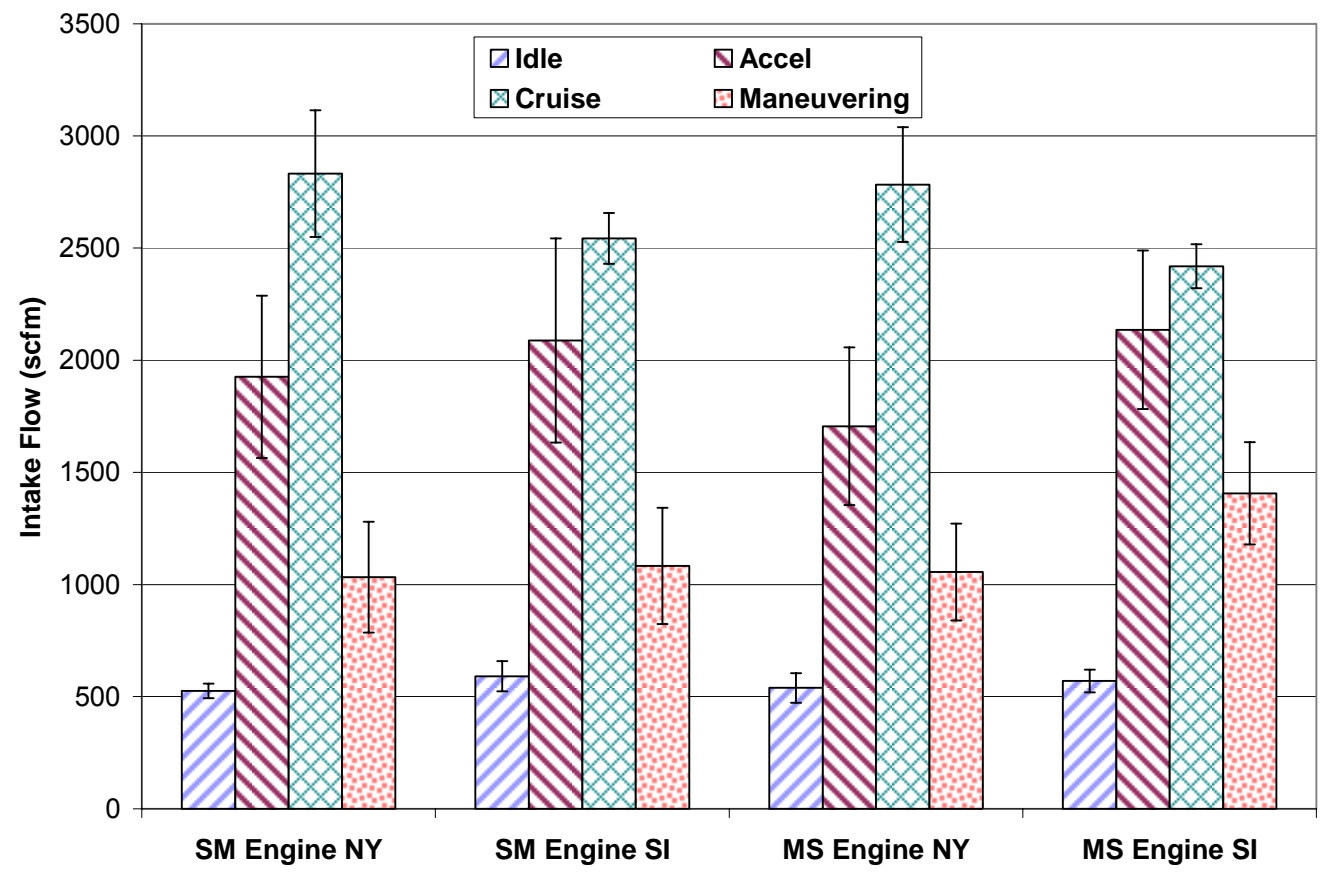

Figure 4-6 Modal Analysis of Intake Air Flow

\subsubsection{Oxides of Nitrogen}

From the installed EC sensor onboard for each engine a reading of NO concentration was obtained. The NO concentrations for two round trips of SM to MS on December 18, 2003 are depicted in Figure 4-7. Engine SI was consistently higher at cruise. The reduced flow through the NO sample box at idle caused the concentration value from reaching a steady value, thus rendered a higher reading than actual at idle. The less variation at cruise for the rear engine and higher variation for the front engine are again noticeable. 


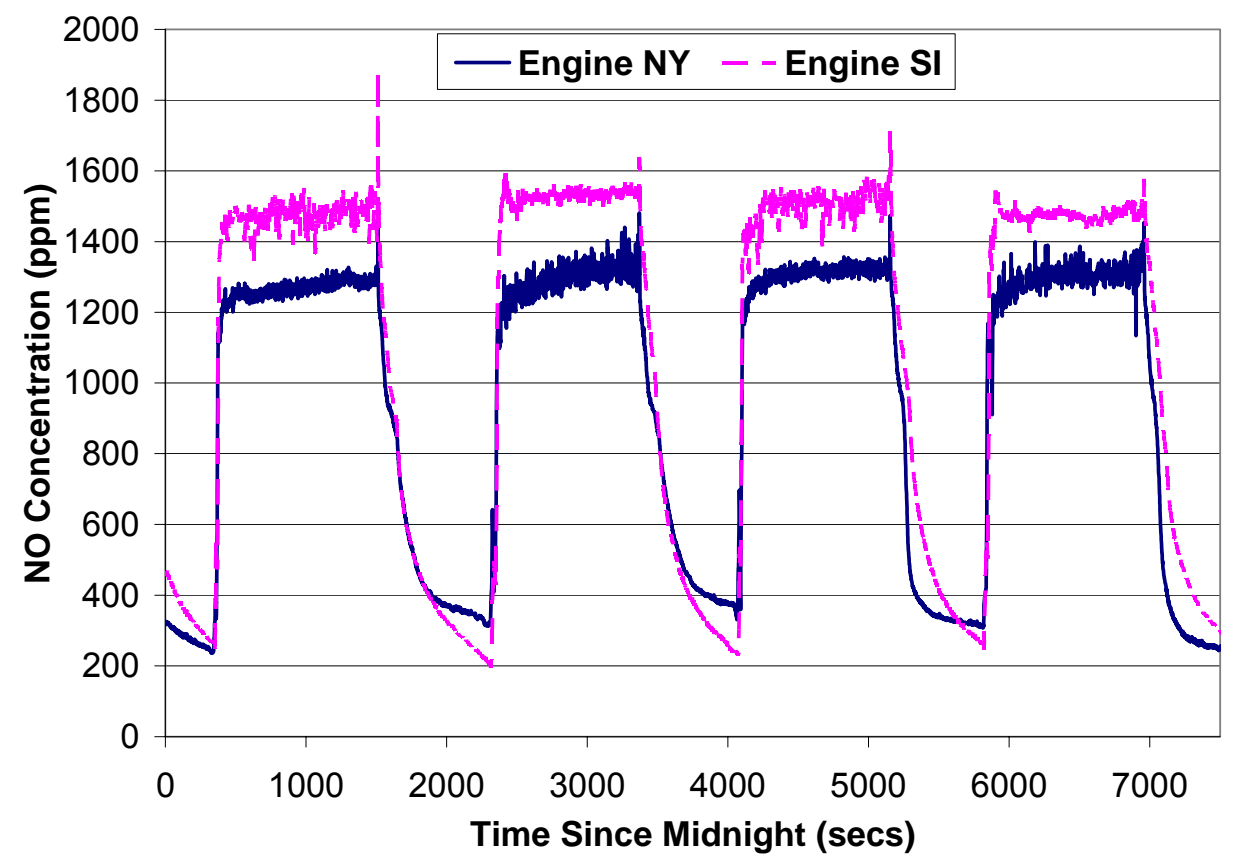

Figure 4-7 NO Concentrations over Two Round Trips on December 182003

Using the intake flow rate as the exhaust flow rate, a rough estimation of NO mass rate was determined. The modal output for engine NY and engine SI is shown in Figure 4-8. The bars show one standard deviation from the mean. The bars show that idle had the least variation from run to run and acceleration had the highest variation with the largest bars. Acceleration mode can capture part of idle at the beginning of the mode and part of cruise at the end of the mode depending on the determination of the start and end of acceleration. Engine SI showed a higher NO output than engine NY during cruise. The mass flow rate of NO during cruise was approximately 12-13 times higher than idle. During each run, idle was approximately 10 minutes and cruise was approximately 18 minutes. Thus, for one round trip, idle contributed $3 \%$, acceleration accounted for $2 \%$, maneuvering $4 \%$, and cruise accounted for $91 \%$ of the NOx loading to the atmosphere. For NOx, the cruise mode was the most beneficial place for reduction. 


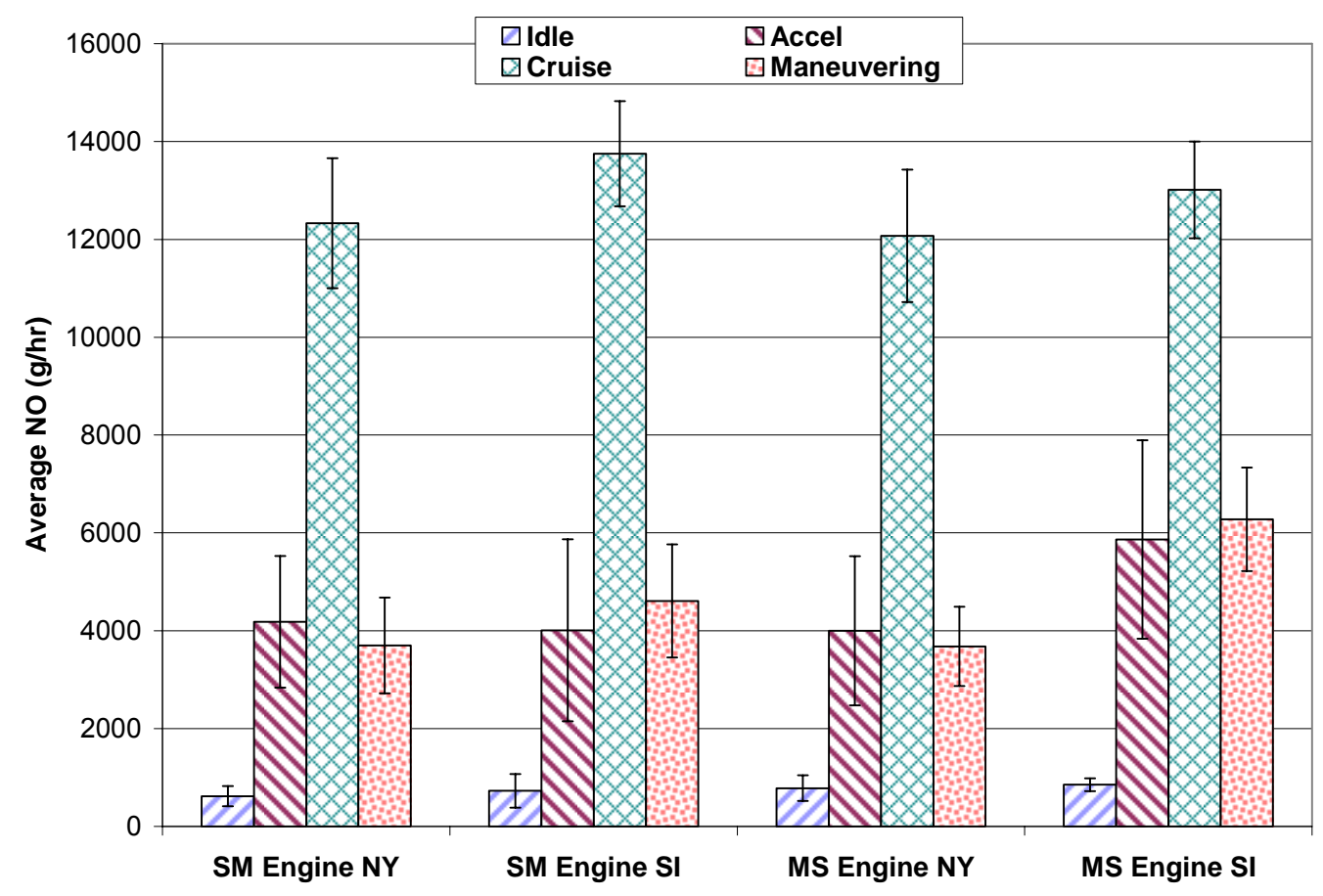

Figure 4-8 Modal Analysis of NO Emitted

\subsubsection{Exhaust Temperature}

The exhaust manifold temperature of engine NY averaged to approximately $340{ }^{\circ} \mathrm{C}$ with the minimum temperature of $140{ }^{\circ} \mathrm{C}$ and a maximum of $440{ }^{\circ} \mathrm{C}$, while engine $\mathrm{SI}$ averaged around $250{ }^{\circ} \mathrm{C}$ with the minimum temperature of $140{ }^{\circ} \mathrm{C}$ and a maximum of 360 ${ }^{\circ} \mathrm{C}$. A round trip of the Alice Austen exhaust manifold and exhaust stack temperature is shown in Figure 4-9. The exhaust manifold temperature was post-turbocharger with the thermocouple in the exhaust stream and the exhaust stack temperature was located at the muffler with the thermocouple below the insulation. During cruise, the engine NY exhaust manifold temperature of Alice Austen was above $400^{\circ} \mathrm{C}$ and engine SI was above $300^{\circ} \mathrm{C}$. From the frequency analysis for all the exhaust manifold temperatures of engine NY on December 26, 2003, shown in Figure 4-10, the exhaust manifold temperature was over 300 ${ }^{\circ} \mathrm{C} 50 \%$ of the day. 
An SCR system requires the use of catalysts that require a high enough temperature for the NOx reduction reactions to take place. A SCR system can operate with at temperatures of $200{ }^{\circ} \mathrm{C}[56,57]$, but with reduced NOx conversion efficiency. The Alice Austen engine NY and engine SI had a high enough temperature for an SCR system to work. Engine SI had a much lower exhaust manifold temperature then engine NY, which might hinder the performance of the SCR.

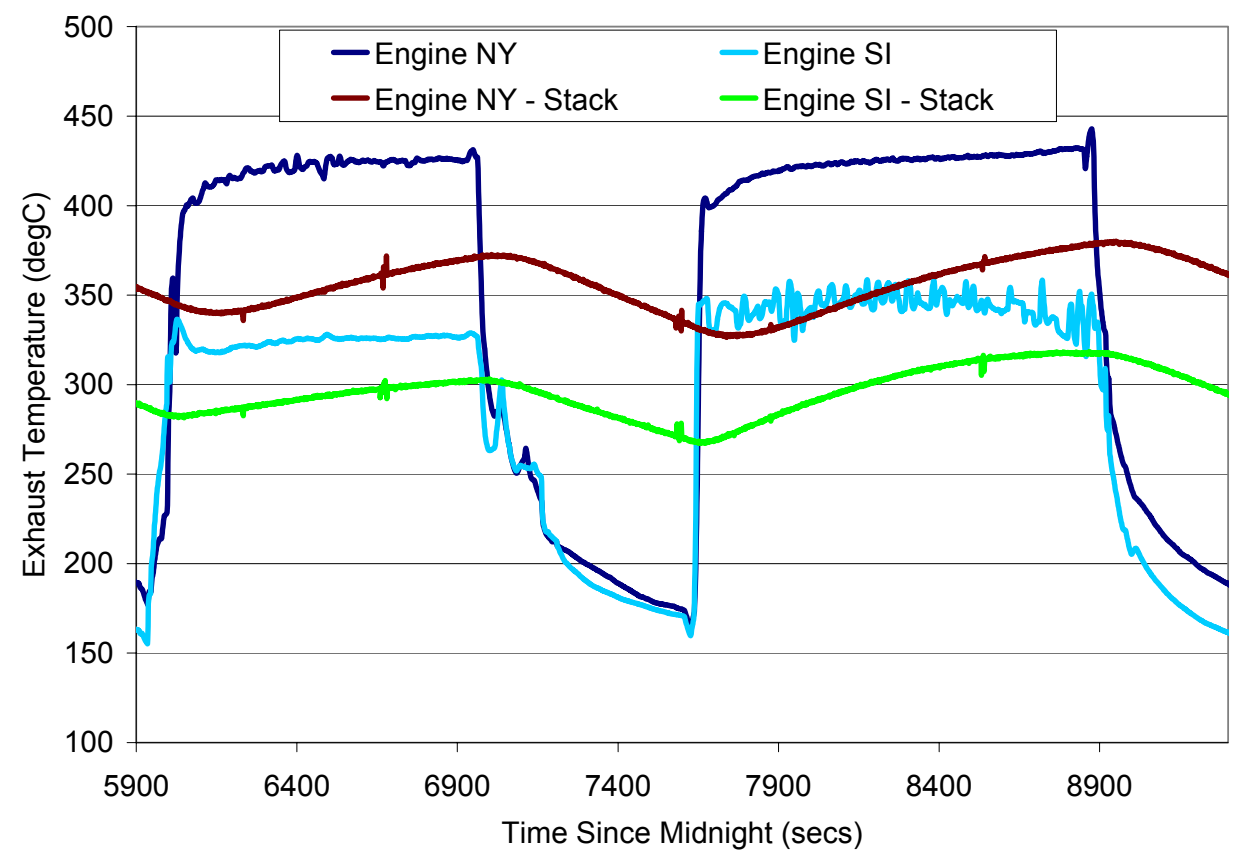

Figure 4-9 Engines Exhaust Temperatures during two trips 


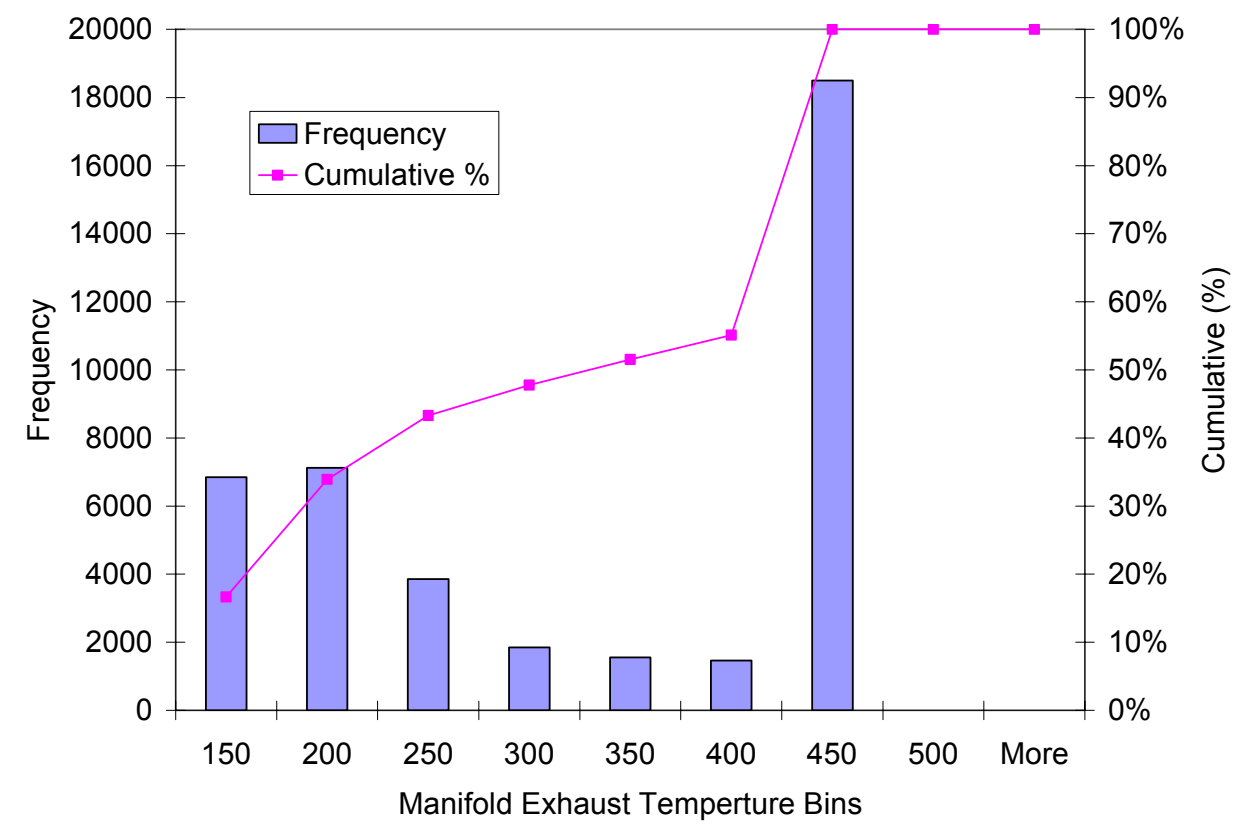

Figure 4-10 Frequency and Cumulative of Exhaust Temperatures for Engine NY

\subsection{Onboard System Validation}

The onboard marine measurement system explained in Section 3.7 was validated by performing steady state comparison testing to the EERL CVS system. For more information on EERL, see references [44, 45]. The system was tested on a 1992 Detroit Diesel, series 60 diesel engine. Although this engine was 4-stroke, turbocharged, intercooled, and electronically controlled, this was the only engine available that mimicked the Alice Austen exhaust stream concentration of NOx and PM. For the gaseous emissions, ten tests were performed at a pre-selected engine speed and torque for two minutes to reach steady state, then the next 3 minutes for collected data. The test modes are displayed in Table 4-1 below. For PM validation, the system was tested at $1200 \mathrm{rpm} / 800 \mathrm{ft}-1 \mathrm{bs}$ for 5 minutes to reach steady state, and then the next 20 minutes PM data was collected. This mode was repeated four times to determine the repeatability. 
Table 4-1 Marine Measurement System Validation Gas Emissions Test Points

\begin{tabular}{|c|c|c|}
\hline Test & $\begin{array}{c}\text { Engine } \\
\text { Speed } \\
\text { (rpm) }\end{array}$ & $\begin{array}{c}\text { Torque } \\
\text { (ft-lbs) }\end{array}$ \\
\hline 1 & 1200 & 700 \\
\hline 2 & 1200 & 1000 \\
\hline 3 & 1800 & 560 \\
\hline 4 & 1800 & 1130 \\
\hline 5 & 1200 & 700 \\
\hline 6 & 1800 & 560 \\
\hline 7 & 1800 & 1130 \\
\hline 8 & 1200 & 700 \\
\hline 9 & 1200 & 350 \\
\hline 10 & 1200 & 350 \\
\hline
\end{tabular}

Five NOx analyzers were used during the validation testing. Two Rosemount Analytical Model 955 NO/NOx analyzers for the laboratory were used. An ECO Physics analyzer with one channel reading NOx and the second channel reading NO and two Horiba Mexa-720 NOx analyzers were used for the raw system. The raw system used fuel flow from two Coriolis meters, one for supply and another for return to provide exhaust flow using the air-to-fuel ratio, calculated using Equation 3-2 to Equation 3-7. The results for the average NOx over the test mode for each analyzer is shown below in Figure 4-11. The ECO Physics correlates quite well with the EERL laboratory results. The Mexa-NOx analyzers were slightly lower which can be attributed to inadequate $\mathrm{NO}_{2}$ to $\mathrm{NO}$ conversion as well as accuracy of the analyzer. 


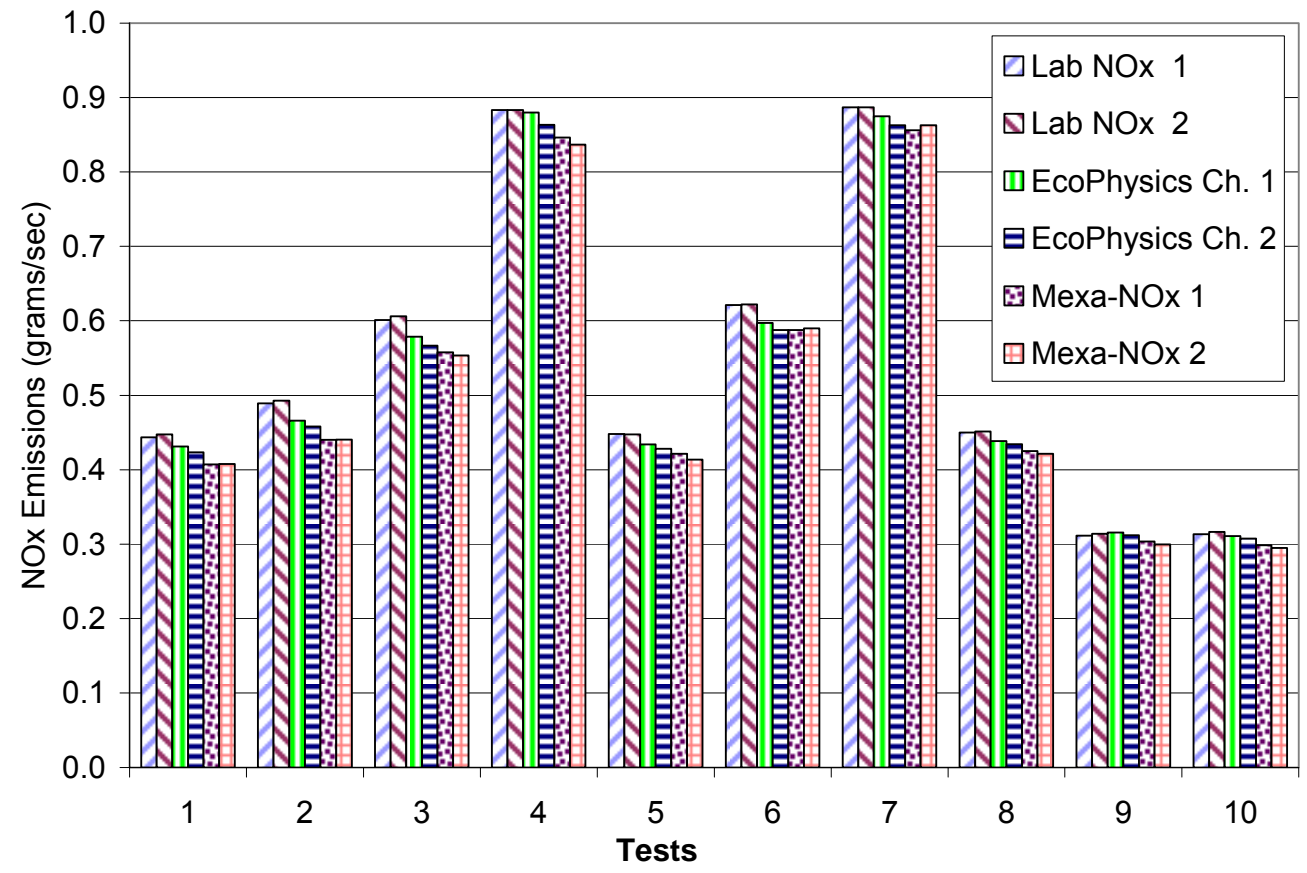

Figure 4-11 NOx from Onboard System Verification

The average percent difference of each raw analyzer to the laboratory results is shown below in Table 4-2. The Eco Physics NOx analyzer was on average within $2.5 \%$ for the NOx channel and within $3.7 \%$ on the NO channel. The NO channel was compared to the NOx from the laboratory. The two Mexa-120 NOx analyzers were within $5.7-6.3 \%$. The Horiba CO model AIA-210 was within $2.2 \%$, but the California Analytical analyzer was only within $13.4 \%$. From these results, the California Analytical was only used as QA/QC device for the Horiba CO during testing onboard the Alice Austen. The raw $\mathrm{CO}_{2}$, raw PM10, coriolis fuel flow, and emissions fuel flow were within $2.5 \%, 7.8 \%, 2.7 \%$, and $3.9 \%$, respectfully. The coriolis fuel meter was not used during the testing on the Alice Austen because of over ranging, so fuel flow from emissions was determined to be sufficient. The PM results utilized dilution ratio from $\mathrm{CO}_{2}$ because this was determined to be more accurate than using flows. The PM10 correlates much closer to the laboratory PM 
than PM2.5 since the laboratory does not utilize a cyclone to remove larger particulates created from the tunnel shedding.

Table 4-2 Average Percent Difference of Raw Analyzers Results to Lab Results

\begin{tabular}{|l|l|c|}
\hline \multirow{3}{*}{ Emission } & \multicolumn{1}{|c|}{ Analyzer } & $\begin{array}{c}\text { Average Percent } \\
\text { Difference from } \\
\text { Laboratory }\end{array}$ \\
\hline $\mathrm{NOx}$ & EcoPhysics Ch. 1 & $2.5 \%$ \\
& EcoPhysics Ch. 2 & $3.7 \%$ \\
& Mexa-NOx 1 & $5.7 \%$ \\
& Mexa-NOx 2 & $6.3 \%$ \\
\hline $\mathrm{CO}$ & California Analytical & $13.4 \%$ \\
& Horiba CO & $2.2 \%$ \\
\hline $\mathrm{CO}_{2}$ & California Analytical & $2.5 \%$ \\
\hline $\mathrm{PM}$ & PM10 - Flow-based DR & $19.6 \%$ \\
& PM10 - CO ${ }_{2}$-based DR & $7.8 \%$ \\
& PM2.5 - Flow-based DR & $26.0 \%$ \\
& PM2.5 - CO ${ }_{2}$-based DR & $15.0 \%$ \\
\hline Fuel Flow & Coriolis & $2.7 \%$ \\
& Emissions & $3.9 \%$ \\
\hline
\end{tabular}

\subsection{Onboard Test Results}

Testing was performed onboard the Alice Austen for three consecutive nights from 10 PM until 6 AM the next morning from April 26 to 29, 2005. The power of the vessel's engine was calculated by linear interpolation using manifold air pressure of the engine test data provided by the manufacturer in APPENDIX D. The data was collected one-way, part of idle was collected and all of acceleration, cruise, and maneuvering mode. The analyzers were rezeroed and spanned at the end of each one-way trip. The gaseous emissions were broken down into integrated values for each mode. From the average time for each mode and the requirement that each one-trip be an average of 30 minutes, time weighted factors were calculated, Table 4-3. The time-weighted factors were used to calculate the average round trip from idle, acceleration, cruise, and maneuvering modal gaseous data, Equation 317. 
Table 4-3 Time Based Weighting Factors used for Round Trip Calculation

\begin{tabular}{|c|c|c|c|c|c|c|}
\hline Direction & Idle & Accel & Cruise & Maneuvering & Total & $\begin{array}{l}\text { Fraction of } \\
\text { Round Trip }\end{array}$ \\
\hline SM & 0.27 & 0.07 & 0.56 & 0.10 & 1.00 & 0.50 \\
\hline MS & 0.29 & 0.07 & 0.51 & 0.14 & 1.00 & 0.50 \\
\hline
\end{tabular}

From this testing the results are shown in Table 4-4. Each engine was tested pre and post-aftertreatment. The results shown indicate a complete round trip in both brake-specific emissions and mass emitted per round trip. Engine NY was found to produce higher power than engine SI. This was indicated from the greater fuel consumption and higher $\mathrm{CO}_{2}$ levels. The PM without values designate that PM was not collected for idle, acceleration, cruise, or maneuvering for both directions at least once and an average round-trip could not be calculated. Engine SI operating characteristics changed when collecting data for postaftertreatment to pre-aftertreatment. This was seen in mass emitted per round trip emissions for fuel consumption changing approximately $20 \%$. This can be attributed to water current or pilot characteristic changes.

Table 4-4 Brake-Specific Emissions and Mass Emitted Test Results for a Compete Round Trip

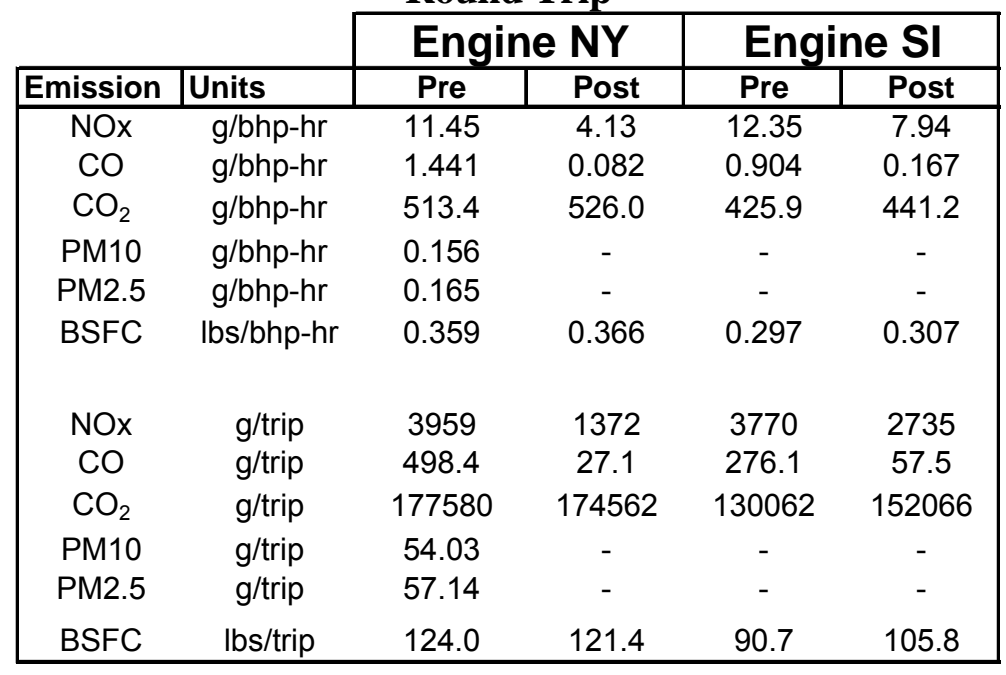

Under the current operating cycle and without an SCR, the Alice Austen did not meet the NOx + THC requirements for new engines after 2007, shown in Figure 4-12. The Alice 
Austen was a category 1 engine with a 4.375 liter displacement per cylinder, Table 2-1. The test cycle used by the EPA for category 1 engines was an 8-mode cycle consisting of rated speed and intermediate speed at different torque values and an idle point. The in-use cycle for the Alice Austen cycle was much different. Engine NY met the NOx requirements postSCR while engine SI did not. The carbon monoxide emissions were below the requirements pre-SCR and well below the limits post-SCR. The PM was approximately at the limit of the 2007 requirements in pre-and post-SCR conditions.

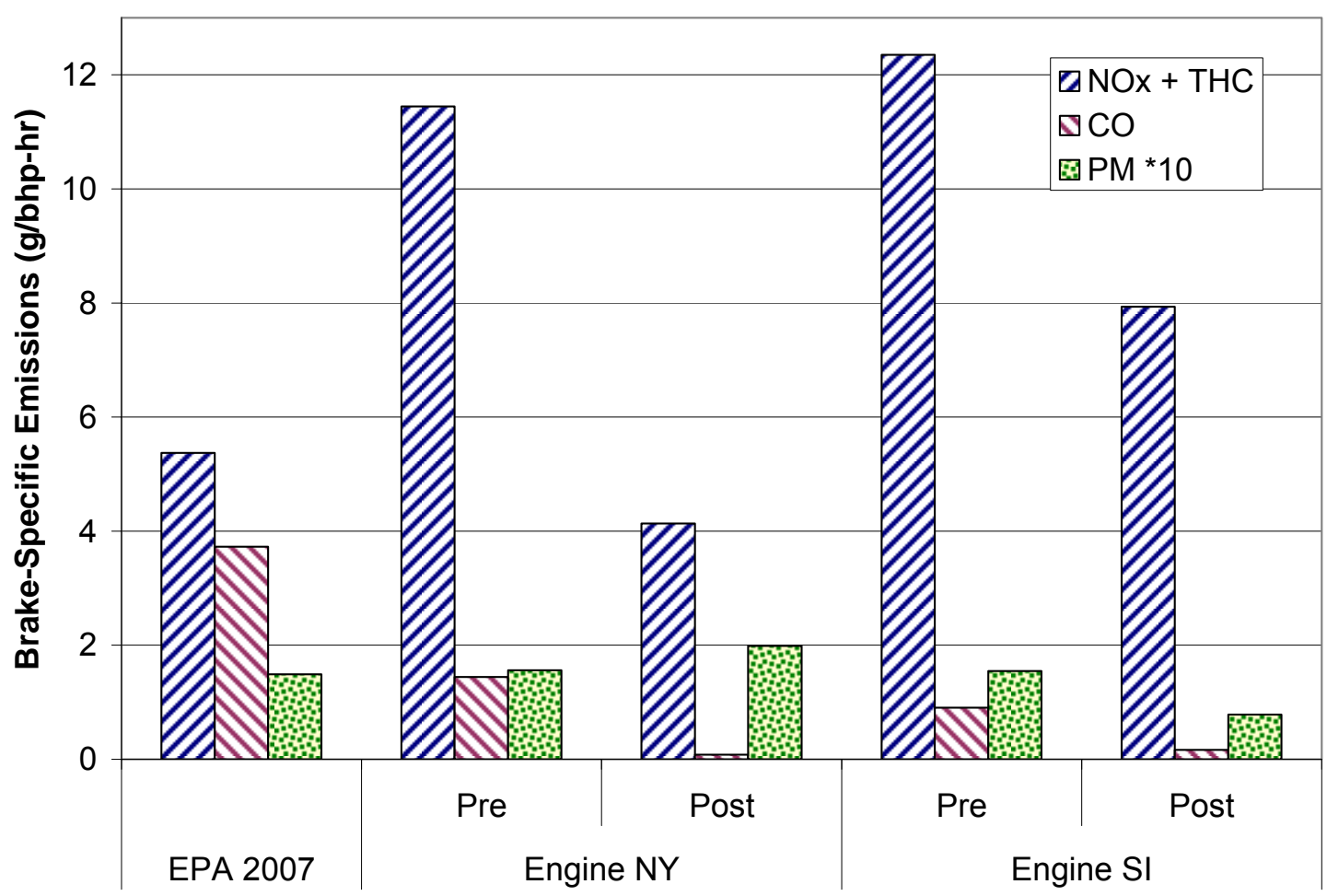

Figure 4-12 EPA 2007 Emission Requirements Compared to In-Use Emissions: Average Round-Trip Data Considering all Valid Runs

\subsubsection{Oxides of Nitrogen}

Figure 4-13 and Figure 4-14 provide examples of continuous NOx traces used to compute modal values. The difference in pre and post-aftertreatment NOx before urea injection was attributed to the accuracy of the analyzers. Pre-aftertreatment NOx was 
measured with the Horiba MEXA-720 and post-aftertreatment was measured with ECO Physics NOx analyzer. Exhaust manifold temperature is also displayed in Figure 4-13 and Figure 4-14. All other individual runs displaying NOx pre and post-aftertreatment are included in APPENDIX E. The plots show NOx output in a single direction along with exhaust manifold temperature and exhaust stack temperature for the engine displayed. The delay in urea injection relative to the start of acceleration modes is depicted.

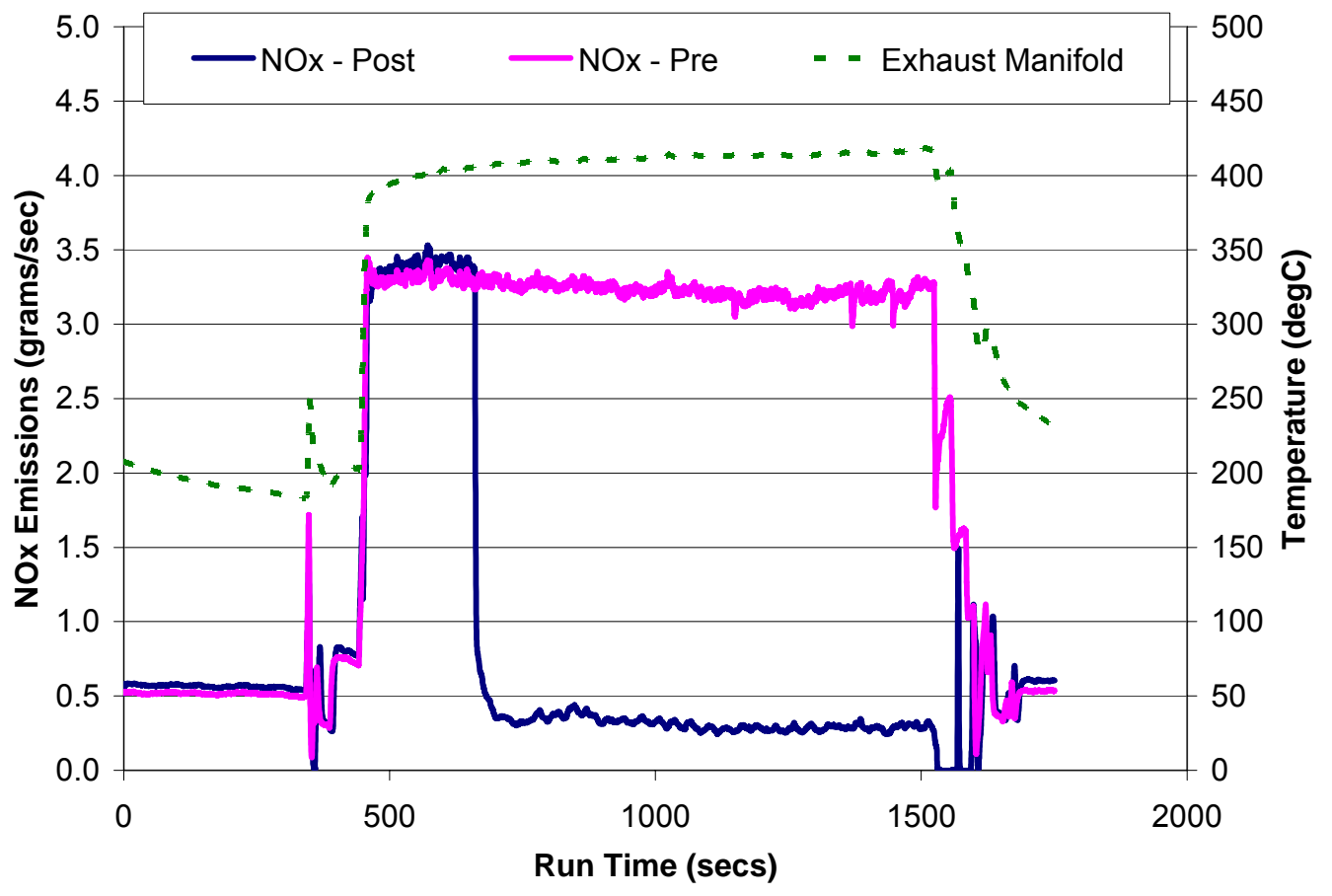

Figure 4-13 Engine NY, Staten Island to Manhattan, Run 2, 4/26/05 


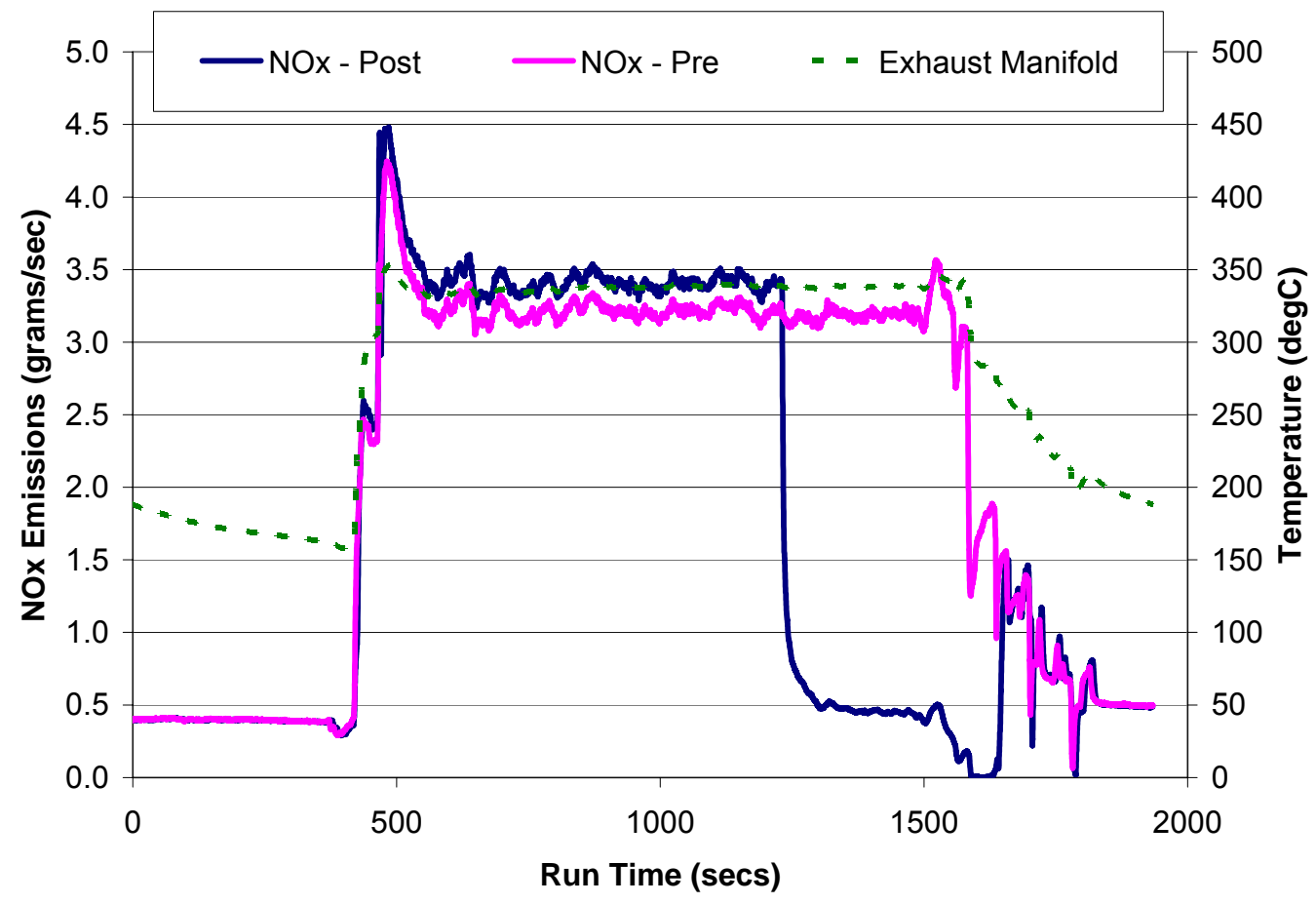

Figure 4-14 Engine SI, Manhattan to Staten Island, Run 1, 4/28/05

A modal analysis was done on the NOx emissions from the onboard measurement system. The results are displayed in Figure 4-15. The bars show one standard deviation from the mean. Each mode was tested approximately three times in each direction and sampling location. Many more tests would be needed to provide a better overall indication because of varying water conditions as well as changes in pilot behavior. The engine SI preaftertreatment from Manhattan to Staten Island cruise NOx value was much lower than the other cruise conditions. This was from the change in engine operating conditions indicated earlier. Overall, post-aftertreatment NOx was much lower during cruise for engine NY than engine SI. Acceleration and maneuvering mode produced varying results since these modes last approximately two minutes and were difficult to capture. Acceleration NOx was most variable from run to run because acceleration behavior was more variable than behavior for the other modes. 


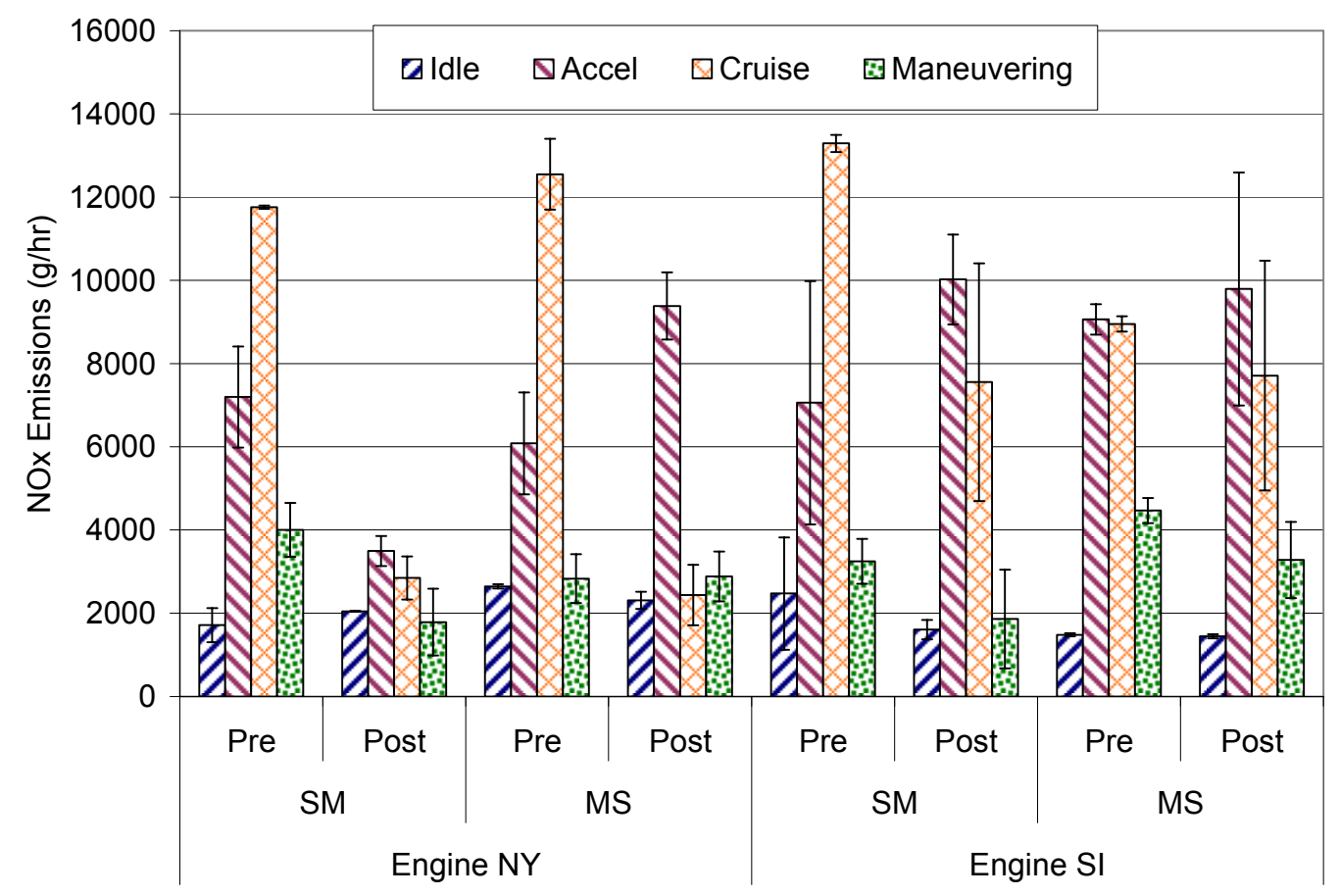

Figure 4-15 Onboard Pre and post-aftertreatment NOx Modal Test Results: Average Modal Data Considering all Valid Runs

The brake-specific NOx for each engine both pre and post-aftertreatment is displayed in Figure 4-16. The EPA tier I 2004 NOx standard, tier II 2007 NOx + THC standard, and the voluntary blue sky NOx + THC standard for a new engine of the same size used onboard the Alice Austen engine is also displayed. The test procedure used by the certification process to produce a NOx value was different from the value of NOx computed from an Alice Austen round trip. For comparison, the engine NY post-aftertreatment almost met the EPA Blue Sky value. The pre-aftertreatment was much greater than the 2004 EPA requirement. With the current aftertreatment control, the performance of engine SI, postaftertreatment, was approximately equivalent to the 2004 requirement. 


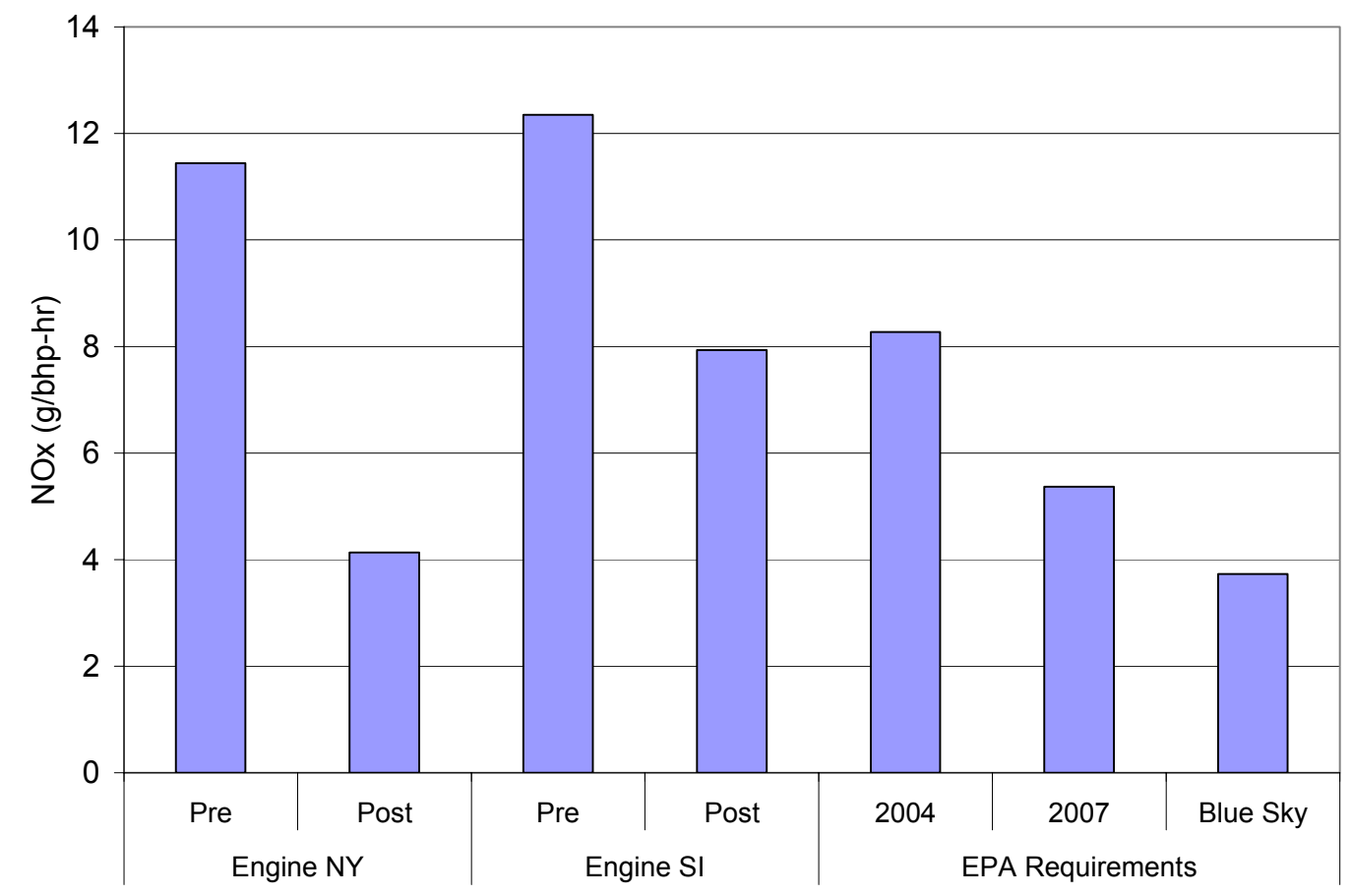

Figure 4-16 Pre and post-aftertreatment with EPA Standards: Average Round-Trip Data Considering all Valid Runs

\subsubsection{Carbon Monoxide}

The installed SCR system included both an SCR catalyst and an oxidation catalyst, which has the effect of oxidizing carbon monoxide and hydrocarbons. The continuous reduction of $\mathrm{CO}$ provided by the catalyst is provided in Figure 4-17. High concentrations and mass flow rates of $\mathrm{CO}$ emissions are seen during the acceleration mode. During testing, the carbon monoxide analyzer over ranged during the acceleration mode pre-aftertreatment and over ranged occasionally during acceleration post-aftertreatment. The $\mathrm{CO}$ for acceleration mode tests are invalid because of the over ranging of the analyzer, calibrated on a $1500 \mathrm{ppm}$ bottle. The modal analysis of the carbon monoxide produced by both engines in each direction is displayed in Figure 4-18 below. The bars show one standard deviation of the mean. The oxidation catalyst oxidized most of the carbon monoxide in the exhaust. The only significant contribution was during acceleration mode when a large spike in carbon 
monoxide could not be completely oxidized. Lower reduction of $\mathrm{CO}$ was seen from engine SI, possibly due to low operating temperature of the catalyst immediately following the idle period. Engine SI also ran cooler than engine NY due to its lighter load.

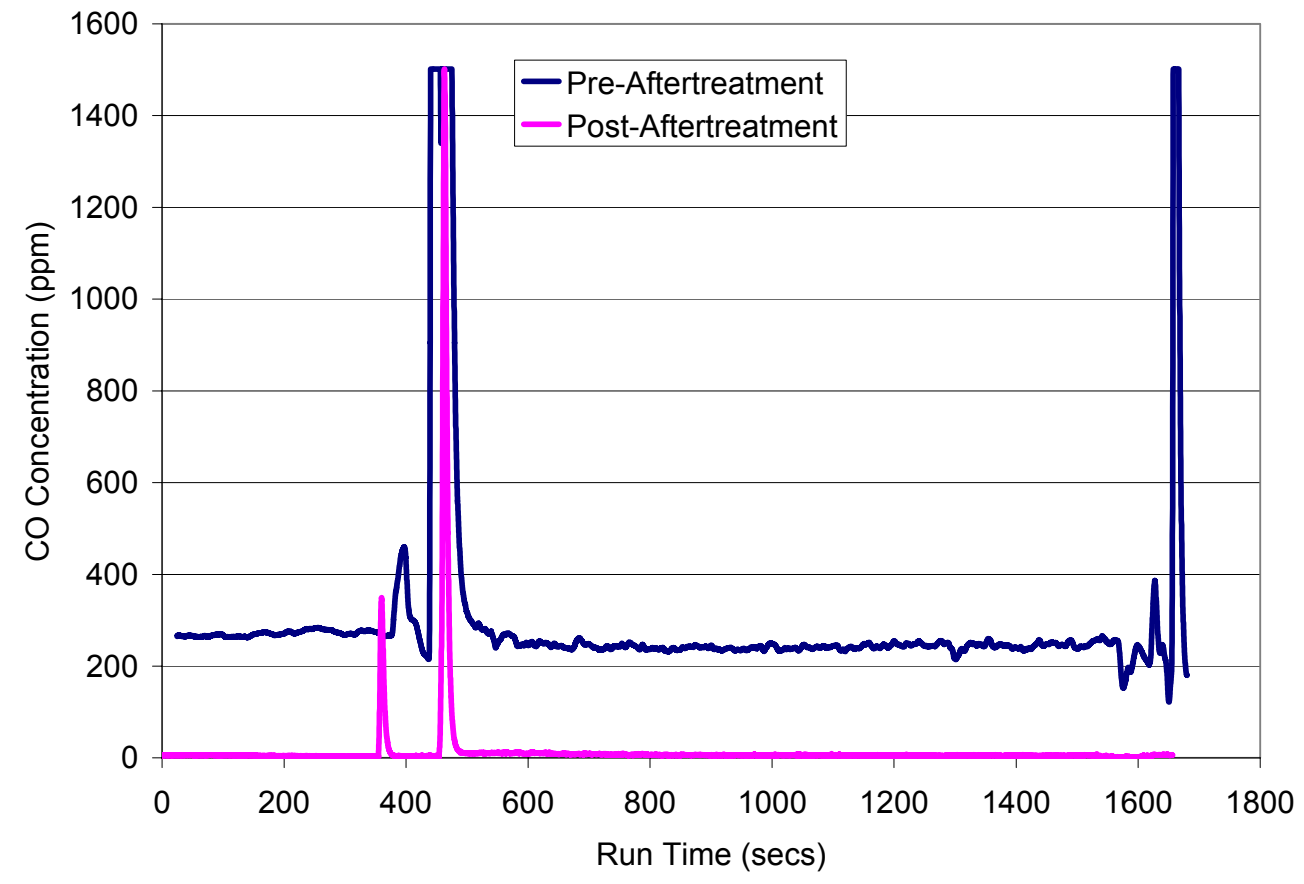

Figure 4-17 Concentration of CO in Engine NY from Staten Island to Manhattan Sampled Pre and post-aftertreatment from Two Separate One-Way Time-Aligned Trips (The exhaust gas may be rich overall for a brief period during acceleration) 


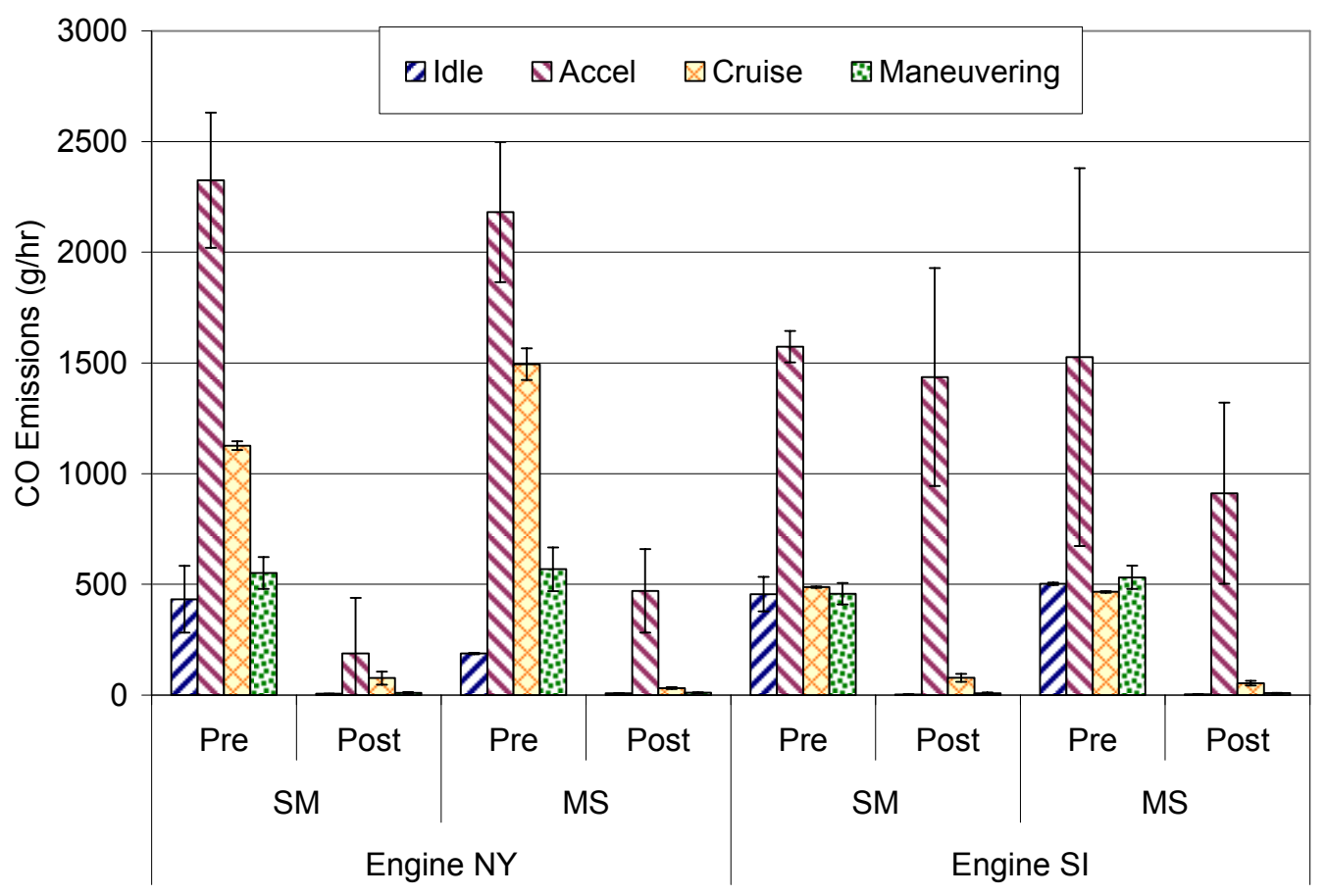

Figure 4-18 Onboard Pre and post-aftertreatment CO Modal Test Results: Average Modal Data Considering all Valid Runs

\subsubsection{Particulate Matter (as PM10)}

The modal particulate matter (Figure 4-19) depicts the PM10 at each mode for each engine and direction. The modes without a PM value indicate that PM data was not collected for this mode or the data was void. Each mode was collected either once or twice. To complete this modal analysis and provide a standard deviation for PM with one filter set collected at each mode, 32 and 96 valid modal sets would be required, respectively. Due to time constraints of the project, performing this number of tests was not possible. The idle and cruise PM provided the most reliable data since PM collection was for approximately 10 minutes instead of the one or two minutes for acceleration and maneuvering modes. Most modal post-aftertreatment PM decreased from the pre-aftertreatment, except engine NY acceleration and maneuvering from Manhattan to Staten Island. The decrease in PM over most modes can be an indication of the oxidation catalyst oxidizing the heavy hydrocarbons that would normally collect on the PM filter or the removal of the SOF fraction by the SCR 
catalyst [58]. The formation of sulfates by an oxidation catalyst can increase PM emissions [59] and might be the contribution during the two increasing modes. More tests onboard the Alice Austen would need to be done to determine the reasons for PM increase or decrease.

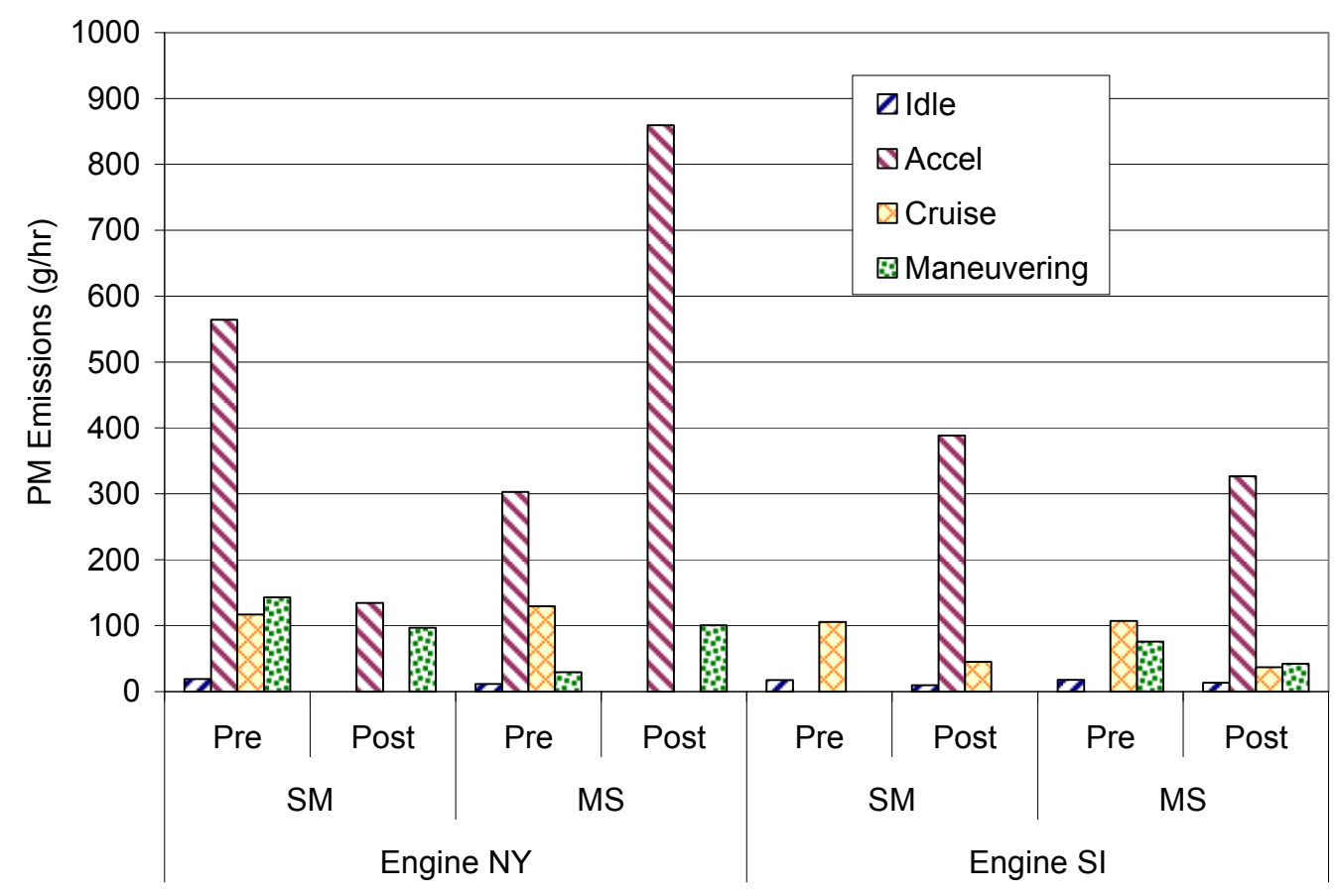

Figure 4-19 Onboard Pre and post-aftertreatment PM Modal Test Results: Average Modal Data Considering all Valid Runs

\subsubsection{Bag Analysis}

Ammonia and nitrous oxide was collected from a bag sample taken during every other mode. The ammonia had a tendency to holdup inside the analyzer. Sampling a bag of nitrogen after sampling an exhaust bag sample for 20 minutes, did not return the analyzer back to zero. Running a nitrogen bag sample for approximately an hour was required to remove completely any previous ammonia sampled in the analyzer. Time constraints and limited number of heated boxes reduced the time allotted for sampling. The value returned for ammonia after running a bag of nitrogen for ten minutes was subtracted from the returned value of ammonia from an exhaust sample. The modal analysis of ammonia pre- 
aftertreatment is displayed in Figure 4-20 and post-aftertreatment in Figure 4-21 below. The missing columns indicate that no bag sample was taken for that mode or the value was below $1 \mathrm{ppm}$. The ammonia value reduced from pre-to-post-aftertreatment sampling. The results showed only minimal slip with only acceleration and maneuvering mode above 10 ppm in the pre-aftertreatment location. The ammonia in the pre-aftertreatment location (see Figure 4-20) must be attributed to unwanted urea delivery when the SCR system was disabled.

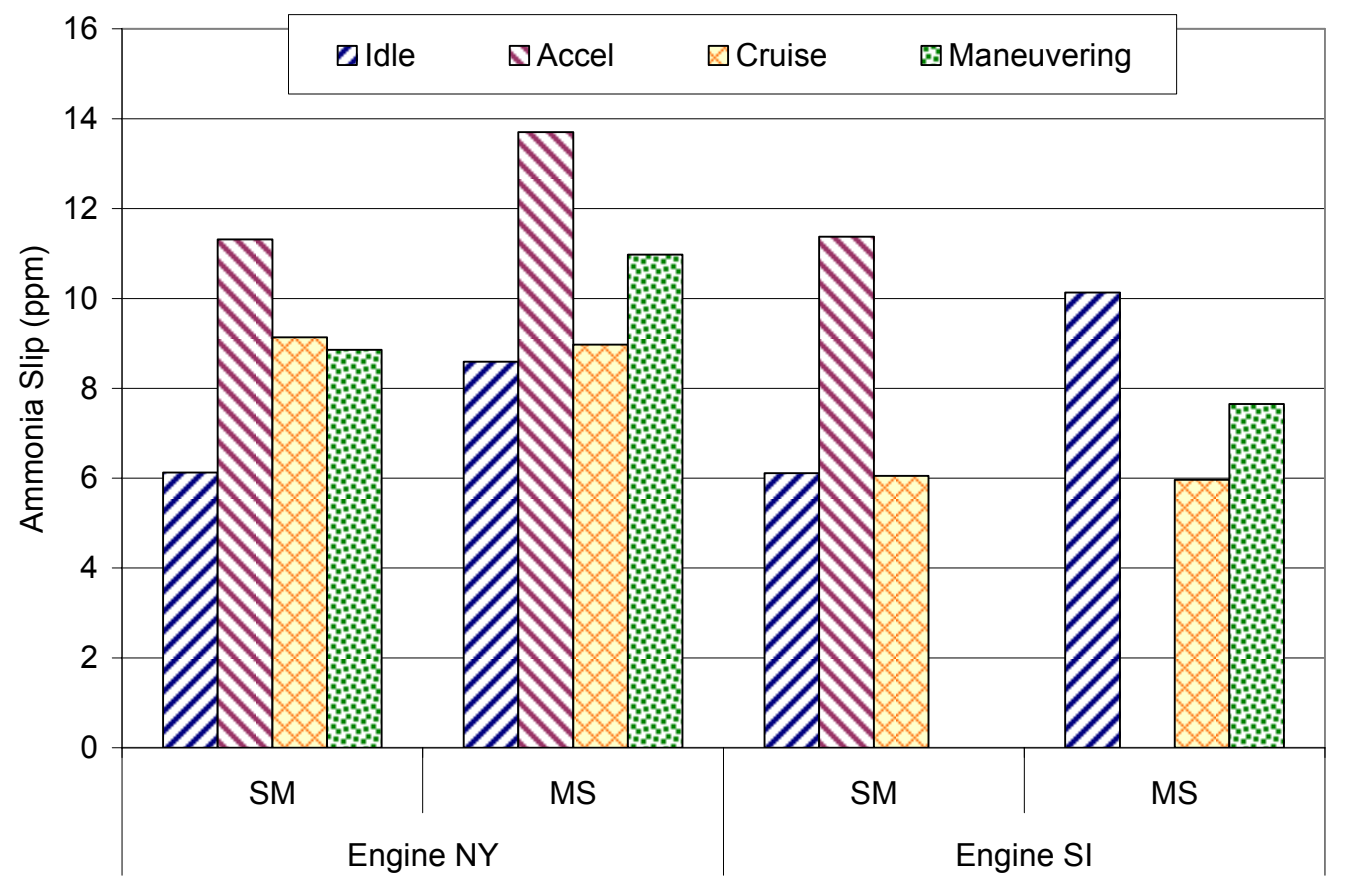

Figure 4-20 Onboard Pre-Aftertreatment $\mathrm{NH}_{3}$ Modal Test Results: Average Modal Data Considering all Valid Runs 


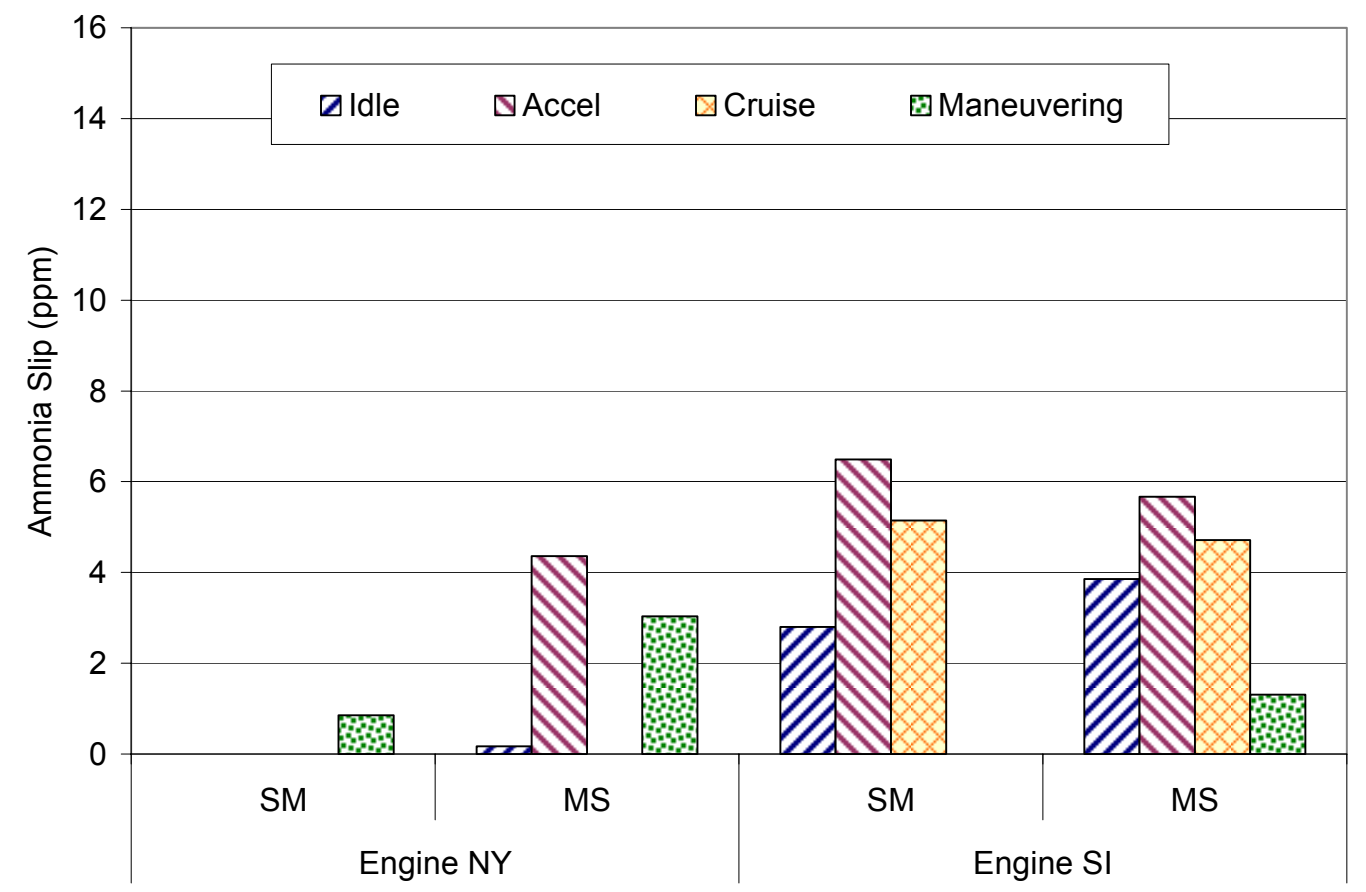

Figure 4-21 Onboard Post-Aftertreatment $\mathrm{NH}_{3}$ Modal Test Results: Average Modal Data Considering all Valid Runs

Nitrous oxide was determined to have interference from carbon monoxide in the exhaust. The 1302 analyzer did not have compensation setup for $\mathrm{CO}$, therefore the values of nitrous oxide were invalid.

\subsubsection{Fuel Flow}

The fuel flow was calculated by carbon balance from carbon dioxide and carbon monoxide. A modal analysis of the fuel flow (Figure 4-22), shows that idle and maneuvering modes are lowest with the maneuvering mode higher than idle. The bars designate one standard deviation from the mean. The fuel flow at cruise was lower for engine SI than engine NY. The fuel flow during acceleration varied over all situations from changing water conditions and driver variability. 


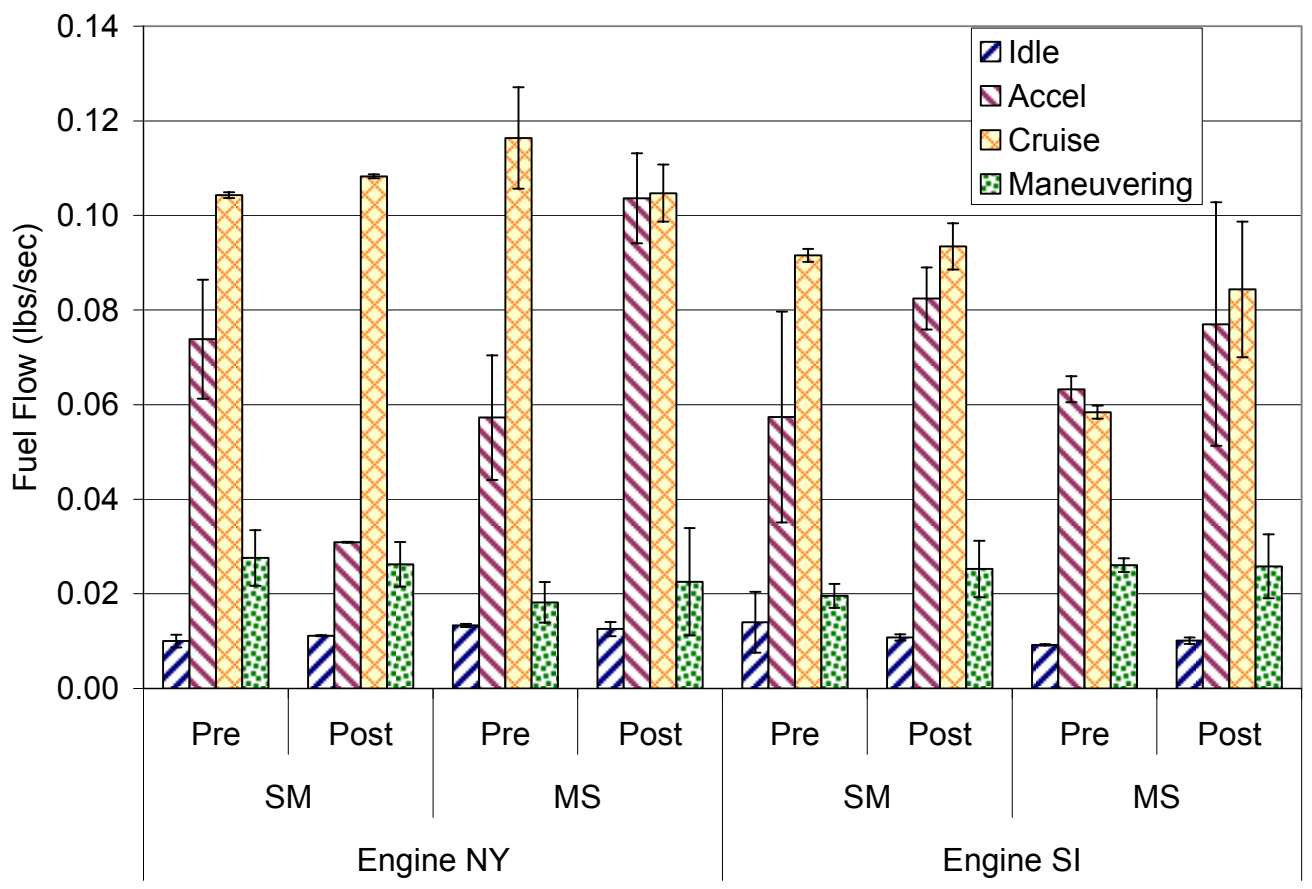

Figure 4-22 Onboard Pre and post-aftertreatment Fuel Flow Modal Test Results: Average Modal Data Considering all Valid Runs

\subsubsection{Percentage Reductions in Emissions due to SCR System}

The overall percent reduction in emissions from the brake-specific emission values of pre and post-aftertreatment showed that NOx was reduced $64 \%$ in engine NY and $36 \%$ in engine SI, displayed in Table 4-5. Carbon monoxide was reduced 80-95 \%. As discussed before the $17 \%$ change in $\mathrm{CO}_{2}$ and $\mathrm{BSFC}$ from mass emitted per round-trip based reductions (Table 4-6) indicated an engine operating change for engine SI. The brakespecific $\mathrm{CO}_{2}$ and $\mathrm{BSFC}$ showed less than $4 \%$ change from pre and post-aftertreatment.

Table 4-5 Percent Reduction in Emissions for Each Engine: Average Brake-Specific Round Trip Data Considering all Valid Runs

\begin{tabular}{|c|c|c|}
\hline Emission & Engine NY & Engine SI \\
\hline $\mathrm{NOx}$ & $63.9 \%$ & $35.7 \%$ \\
$\mathrm{CO}$ & $94.3 \%$ & $81.6 \%$ \\
$\mathrm{CO}_{2}$ & $-2.5 \%$ & $-3.6 \%$ \\
$\mathrm{BSFC}$ & $-2.0 \%$ & $-3.3 \%$ \\
\hline
\end{tabular}


Table 4-6 Percent Reduction in Emissions for Each Engine: Average Mass Emitted Per Round Trip Data Considering all Valid Runs

\begin{tabular}{|cc|c|}
\hline Emission & Engine NY & Engine SI \\
\hline $\mathrm{NOx}$ & $65.3 \%$ & $27.5 \%$ \\
$\mathrm{CO}$ & $94.6 \%$ & $79.2 \%$ \\
$\mathrm{CO}_{2}$ & $1.7 \%$ & $-16.9 \%$ \\
$\mathrm{BSFC}$ & $2.1 \%$ & $-16.6 \%$ \\
\hline
\end{tabular}

Table 4-7 shows details of the NOx percent reductions for a one-way trip, during cruise, and during cruise while urea injection was active. The SCR system was capable of over $94 \%$ NOx reductions during urea injection. During the MS2 run on engine SI, the urea injection never occurred due to low load.

Table 4-7 Percent Reduction in NOx Emissions for Each Engine when Pre and postaftertreatment was Measured

\begin{tabular}{|c|c|c|c|c|}
\hline Engine & $\begin{array}{c}\text { Direction / } \\
\text { Run }\end{array}$ & $\begin{array}{c}\% \text { reduction } \\
\text { one-way trip }\end{array}$ & $\begin{array}{c}\% \text { reduction } \\
\text { cruise }\end{array}$ & $\begin{array}{c}\% \text { reduction } \\
\text { cruise } \\
\text { (urea on) }\end{array}$ \\
\hline NY & SM2 & $64.1 \%$ & $72.4 \%$ & $90.5 \%$ \\
\hline NY & MS2 & $64.2 \%$ & $81.2 \%$ & $95.1 \%$ \\
\hline NY & MS4 & $57.7 \%$ & $73.9 \%$ & $94.1 \%$ \\
\hline NY & SM5 & $66.2 \%$ & $78.1 \%$ & $91.2 \%$ \\
\hline NY & MS5 & $51.8 \%$ & $68.6 \%$ & $95.4 \%$ \\
\hline SI & MS1 & $20.9 \%$ & $26.2 \%$ & $86.9 \%$ \\
\hline SI & SM2 & $38.0 \%$ & $44.0 \%$ & $94.1 \%$ \\
\hline SI & MS2 & $-6.0 \%$ & $-6.6 \%$ & - \\
\hline SI & SM3 & $39.0 \%$ & $44.8 \%$ & $94.6 \%$ \\
\hline SI & MS3 & $52.2 \%$ & $62.5 \%$ & $95.3 \%$ \\
\hline SI & SM4 & $49.7 \%$ & $57.0 \%$ & $95.1 \%$ \\
\hline SI & SM5 & $43.3 \%$ & $49.0 \%$ & $95.1 \%$ \\
\hline
\end{tabular}

The requirement of the SCR was to meet $70 \%$ reduction in NOx for a complete round trip. Engine NY provided a 50-70 \% reduction while engine SI provided 20-53\%. Argillon had a thermocouple pressed against the catalyst for catalyst temperature. During the testing, the threshold temperature (turn-on temperature) was set at $300{ }^{\circ} \mathrm{C}$. This turn-on temperature was the required temperature to be met before injection began. A urea injection delay occurred as the catalyst heated to the threshold temperature during acceleration and cruise and the time delay was a function of NOx reduction for a one-way trip, shown in 
Figure 4-23. The model line was based on the average percent reduction of NOx when urea injection was active. At zero injection delay, $75.5 \%$ reduction (average NOx reduction with urea injection active from Table 4-7) of NOx occurred and at a 966.3 second injection delay (average length of cruise), $0 \%$ reduction occurred. A best-fit line to the data points is also displayed.

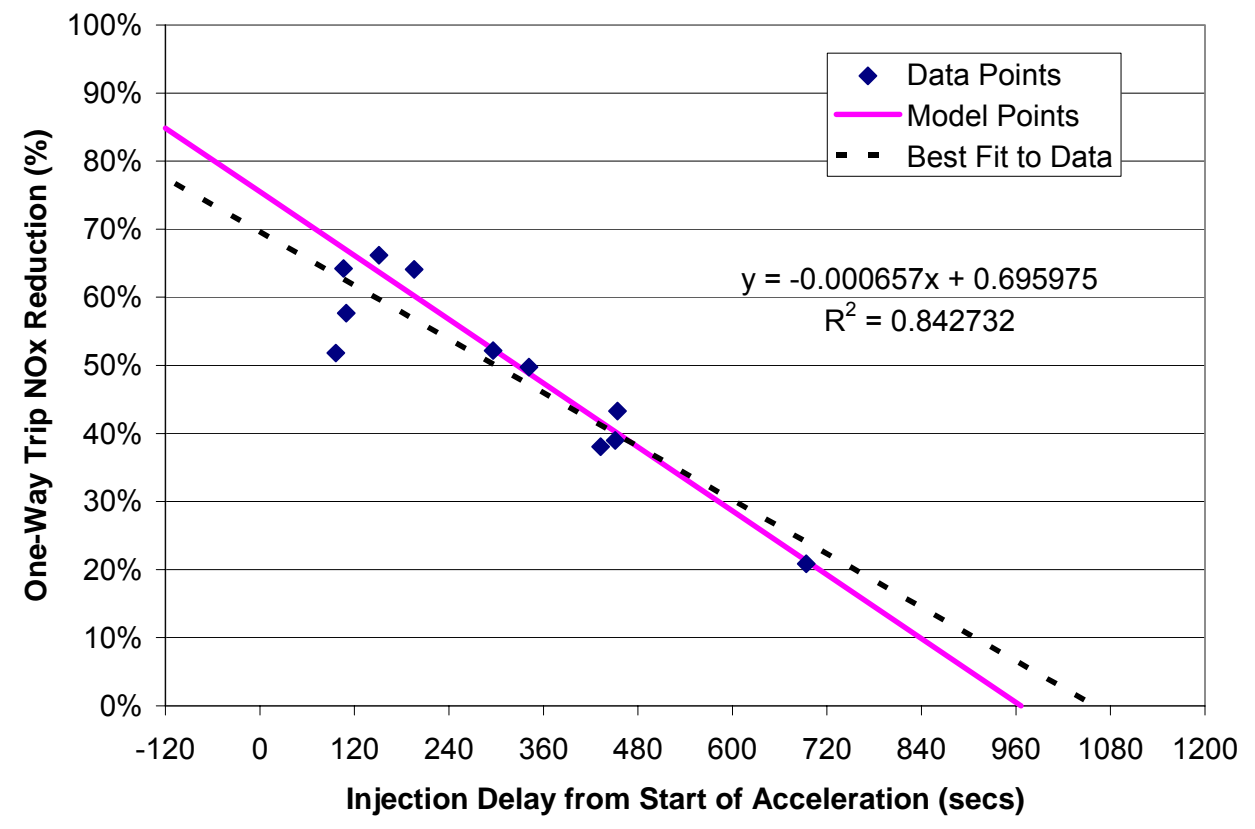

Figure 4-23 Percent Reduction of NOx during a One-Way Trip Based on Urea Injection Delay

A reduction of the threshold temperature would increase the NOx reduction, since the injection delay would be shorter. The threshold temperature subtracted from the manifold temperature at the start of urea injection as a function of NOx reduction from all the runs of engine NY and engine SI are displayed in Figure 4-24. A reduction of the threshold temperature from $300{ }^{\circ} \mathrm{C}$ to $270{ }^{\circ} \mathrm{C}$, which was suggested by Argillon, would make NOx reduction $70 \%$ for engine NY and $50 \%$ for engine SI. The contribution of NOx during idle, acceleration, and maneuvering requires the need to inject urea during the full cruise mode for both engines to reach an overall of $70 \%$ reduction. Using the linear fit line, 
threshold temperature is suggested to be lowered to $240^{\circ} \mathrm{C}$. This is a low temperature for an SCR catalyst to operate with efficient NOx reduction.

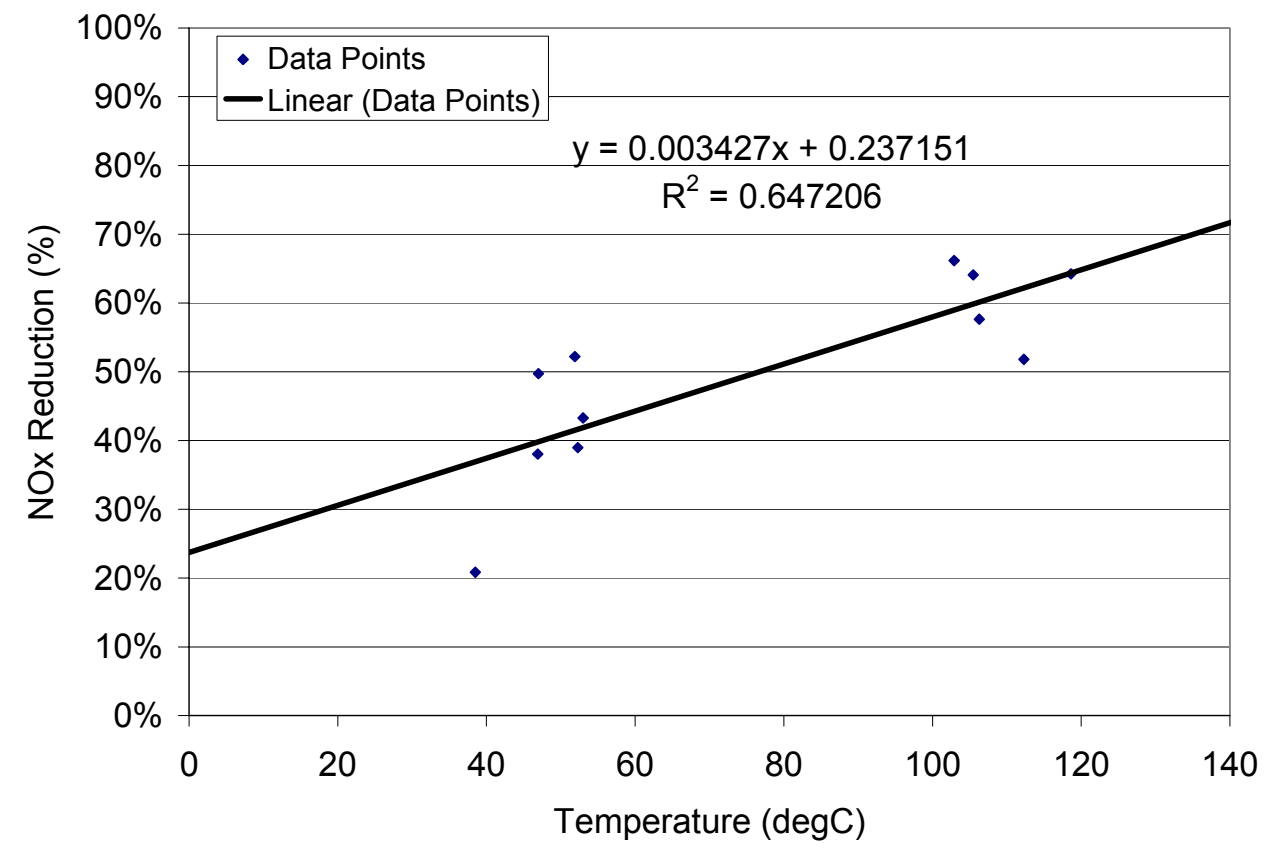

Figure 4-24 Percent Reduction of NOx Over One-Way Trip Based on Catalyst TurnOn Temperature Subtracted from Exhaust Manifold Temperature

The catalysts heated up slowly over the course of vessel operation, providing inconsistent results. The catalyst was cold at the start of the first trip, but was warmer for later trips. The catalyst brick temperature lagged the exhaust manifold temperature from thermal inertia. Extending urea injection past cruise mode into maneuvering mode and possibly idle mode might provide one solution to improved NOx reduction.

\subsection{Comparison of Modal Onboard NOx to Previous Datalogging NO}

The pre-aftertreatment NOx from onboard testing and the NO from previous datalogging show comparable results, as illustrated in Figure 4-25. The bars show one standard deviation from the mean. The idle mode for all directions and both engines was 
higher for the onboard testing. This higher value can be attributed to low sample flow in the NO boxes or a high concentration of $\mathrm{NO}_{2}$. The boxes only read the concentration of NO. The onboard testing also had higher values for the acceleration mode that was caused by the slow response time of the NO boxes. The cruise and maneuvering mode was comparable to within one standard deviation from the mean for the onboard and datalogging testing except for the low cruise mode NOx for engine SI from Manhattan to Staten Island during onboard testing. This low NOx value was attributed to load change or pilot variability during the onboard testing.

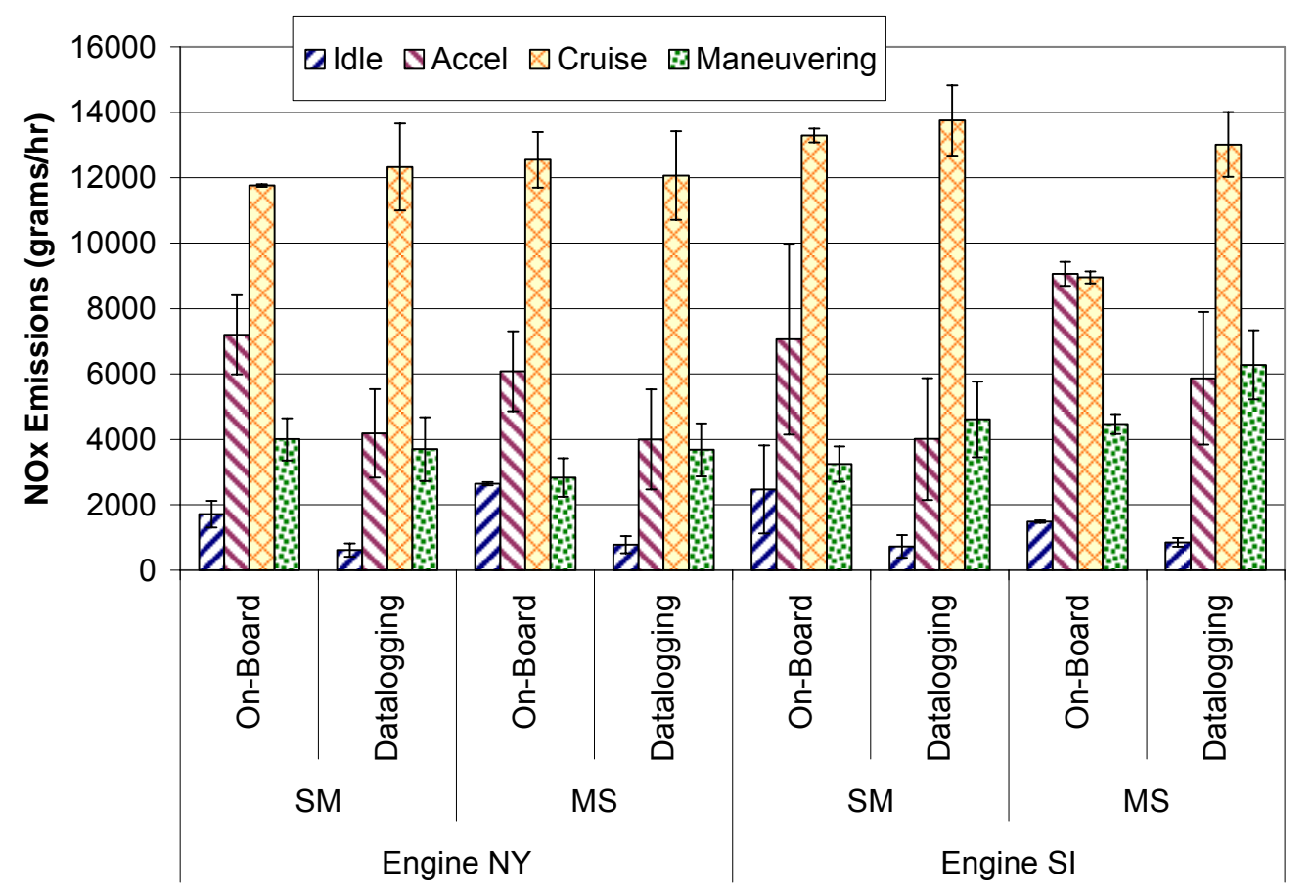

Figure 4-25 Comparison of Pre-Aftertreatment NOx from onboard testing and Datalogging 


\section{CONCLUSIONS AND RECOMMENDATIONS}

\subsection{Conclusions}

This study comprised onboard data logging to establish preliminary NO emissions. Repeatability of the vessel's normal operation, in addition to the results of the complete emissions using a full emission measurement system was tested. The data logging over two months provided a complete spectrum of the vessel and engine operation. The data logging provided a simple method of determining the characteristics of marine and mechanically controlled engines for analysis of an emissions reduction strategy. The full emission testing results of the newly installed SCR system provided information to determine if an SCR was a solution to NOx pollution in marine vessels and will provide the required $70 \% \mathrm{NOx}$ reduction to offset the dredging equipment emissions in the Port of NY \& NJ.

The vessel behavior was characterized into four modes of operations from datalogging data: idle, acceleration, cruise, and maneuvering from the GPS, engine operating levels, and NOx emissions. These modes were repeatable with the coefficient of variance for NO in mass rate being $32 \%$ for idle, $37 \%$ for acceleration, $9 \%$ for cruise, and $22 \%$ for maneuvering. The cruise mode had the greatest repeatability for NO. The exhaust flow and NO concentration were significantly higher where the NO sampling system was more accurate. The electrochemical sensor installed onboard for the data logging showed NO levels of 12000-14000 grams/hr (1500-1600 ppm) at cruise during normal operation.

With the current control strategy of the SCR, the SCR provided approximately $64 \%$ reduction of NOx for engine $\mathrm{NY}$ and $36 \%$ reduction for engine SI for a complete round trip with less than 8 ppm of ammonia slip. From modal analysis of onboard testing, $20 \%$ of the NOx was produced during idle, acceleration, and maneuvering. Cruise produced $80 \%$ of the NOx. A possibility to reach the goal of an overall $70 \%$ NOx reduction for a round trip, 
the SCR threshold temperature should be reduced. The SCR technology would provide much greater NOx reduction for vessels with longer trips or hotter exhaust temperatures. The oxidation catalyst reduces the CO production $95 \%$ for engine $\mathrm{NY}$ and $80 \%$ for engine SI. No clear conclusions can be made on the effects of the SCR on particulate matter without more testing. Hydrocarbons were not analyzed, though the hydrocarbons produced by the engine should be reduced by the oxidation catalyst.

The Alice Austen brake-specific NOx emissions for an average round-trip without the SCR were $11.45 \mathrm{~g} / \mathrm{bhp}-\mathrm{hr}$ and $12.35 \mathrm{~g} / \mathrm{bhp}$-hr for engine NY and engine SI, respectfully. This was above the EPA brake-specific NOx requirements of $8.27 \mathrm{~g} / \mathrm{bhp}$-hr for new engines built after 2004 with the Alice Austen's engine speed. The test cycle used by the EPA was different from the in-use emissions produced by the vessel. With the SCR for an average round-trip, engine NY (4.13 g/bhp-hr) met the NOx requirement of a new category I engine with a 4.375 liter per cylinder displacement for EPA Tier II regulations (5.37 g/bhp-hr). While Engine SI (7.94 g/bhp-hr) post-SCR did not meet the 2004 requirement for NOx.

\subsection{Recommendations}

With marine emissions contributions becoming more visible as on-board transportation sources are controlled, a way to perform onboard emission measurement needs to be established and performed. A data logging system similar to the system used in this study provides a valuable way of characterizing vessel and engine operation. The electrochemical NO sensor provides an inexpensive and simple measurement when $5 \%$ accuracy of full scale is needed.

One-liter gas cylinders provided by Scott Specialty Gas can be used for zero and span bottles. In a datalogging application, automated zero and span using solenoid valves would provide accurate and repeatable results for weeks. A small 1-2 lpm pump could also 
be installed inside the NO boxes. This would greatly increase the accuracy of the NO results at idle.

With the SCR system and oxidation catalyst installed, NO and CO emission levels were decreased $20-70 \%$ for NOx and $80-95 \%$ for CO. The limiting factor of the SCR was the need to reach a threshold temperature in the exhaust stream before injection. The required exhaust temperature of the SCR catalysts should be lowered or an SCR should only be used on vessels with longer cruise modes if greater NOx reduction is to be achieved. Better urea injection control is needed. Another possibility is to extend urea injection past cruise mode into maneuvering and possibly part of idle. Using the exhaust manifold temperature as a function of urea injection amount is a fast response control possibility. Since higher exhaust temperatures correspond to greater NOx from a diesel engine.

From an emissions testing standpoint, the Horiba MEXA-720 analyzers should only be used pre-and-post aftertreatment while the ECO Physics should be calibrated on a low concentration NOx bottle to read ammonia slip. Bag sampling of ammonia is a time consuming method. Research into the viable ammonia measurement techniques and analyzers should be conducted for future SCR work. Solenoid valves should be incorporated into the PM sampling for automatic control of the filter flow and ease of emissions calculations from a digital channel. Solenoid valves for zero and spanning analyzers in a mobile application can be incorporated to reduce time required between runs for analyzer adjustments. This might provide quicker zero and spanning so time is not wasted while the vessel is operating. 


\section{REFERENCES}

1. Corbett, J. and Farrell, A., "Mitigating Air Pollution Impacts of Passenger Ferries," Transportation Research, Vol. 7D No. 3, 2002.

2. Farrel, A., Redman, D., Corbett. J., and Winebrake, J., "Comparing Air Pollution from Ferry and Landside Commuting," Transportation Research, Vol. 8D No. 5, 2003.

3. Health Assessment Document for Diesel Engine Exhaust. U.S. Environmental Protection Agency, Office of Research and Development, National Center for Environmental Assessment, Washington Office, Washington, DC, EPA/600/890/057F, 2002.

4. "Harbor Air Management Plan for the New York and New Jersey Harbor Deepening Project," New York District United States Army Corps of Engineers, New York, NY, 2004.

5. Code of Federal Regulations, "Control of Emissions from Marine CompressionIgnition Engines," CFR Title 40 Part 94, Office of the Federal Register National Archives and Records Administration, Washington, DC, 2004.

6. International Organization for Standardization, "Reciprocating Internal Combustion Engines -- Exhaust Emission Measurement -- Parts 1 through 9," ISO 8178 (1996), Geneva, Switzerland, 1996.

7. “MARPOL 73/78," International Maritime Organization, London, United Kingdom, ISBN: 92-801-5125-8, 2002.

8. “Emission Standards: U.S.A. - Marine Diesel Engines," DieselNet, Ecopoint Inc, Brampton, ON, Canada, 2002. http://www.dieselnet.com/standards/us/marine.html

9. "Diesel Boats and Ships," Environmental Protection Agency, Washington, DC, 2004. http://www.epa.gov

10. Bentz, A.P. and Weaver, E., "Marine Diesel Exhaust Emissions Measured by Portable Instruments," Warrendale, PA, SAE Paper No. 941784, 1994.

11. "Marine Vehicles Exhaust Emissions Program: A Study of the Effects of Multiple Emissions Reduction Technologies on the Exhaust Emissions of Marine Diesel Engines," Emissions Research and Measurement Division, Environment Canada, Ottawa, ON, Canada, April 2003. http://www.tc.gc.ca/tdc/publication/pdf/14000/14099e.pdf

12. "Water Injection System for Emissions Reduction Tested on the MV Cabot: Test Plan and Test Results," Emissions Research and Measurement Division, Environment 
Canada, Ottawa, ON, Canada, June 2004.

http://www.tc.gc.ca/tdc/publication/pdf/14200/14272e.pdf

13. "M/V Oski Emissions Tests: Bio-diesel and Inlet Air Water Injection," Final Report to MARAD, Walther Engineering Services Inc., Washington, DC, June 26, 2002. http://www.marad.dot.gov/nmrec/energy technologies/images/Final\%20Report\%201. pdf

14. Thompson, G.J., Carder, D.K., Riddle, W.C., Gautam, M., and Lyons, D.W., "Evaluation of Exhaust Emissions from Elizabeth River Ferries," Final Report to MARAD, Department of Mechanical and Aerospace Engineering, West Virginia University, Morgantown, West Virginia, July, 2002.

15. George, S., "Characterization of In-use Emissions from Marine Engines," M.S. Thesis, Department of Mechanical and Aerospace Engineering, West Virginia University, Morgantown, WV, 2004.

16. Gautam, M., Clark, N.N., Thompson, G.J., and Lyons, D.W., "Assessment of Mobile Monitoring Technologies for Heavy-Duty Vehicle Emissions," Whitepaper Submitted to the Settling Heavy-Duty Diesel Engine Manufacturers, Department of Mechanical and Aerospace Engineering, West Virginia University, Morgantown, WV, 1999.

17. Gautam, M., Clark, N.N., Thompson, G.J., Carder, D.K., and Lyons, D.W., "Evaluation of Mobile Monitoring Technologies for Heavy-Duty Diesel-Powered Vehicle Emissions," Phase I Final Report Submitted to the Settling Heavy-Duty Diesel Engine Manufacturers, Department of Mechanical and Aerospace Engineering, West Virginia University, Morgantown, WV, 2000.

18. Gautam, M., Clark, N.N., Thompson, G.J., Carder, D.K., and Lyons, D.W., "Development of In-use Testing Procedures for Heavy-Duty Diesel-Powered Vehicle Emissions," Phase II Final Report Submitted to the Settling Heavy-Duty Diesel Engine Manufacturers, Department of Mechanical and Aerospace Engineering, West Virginia University, Morgantown, WV, 2000.

19. Gautam, M., Thompson, G.J., Carder, D.K., Clark, N.N., Shade, B.C., Riddle, W.C., and Lyons, D.W., "Measurement of In-Use, Onboard Emissions from Heavy-Duty Diesel Vehicles: Mobile Emissions Measurement System," Warrendale, PA, SAE Technical Paper No. 2001-01-3643, 2001.

20. Weaver, C.S., Chan, L., and Peety, L., "Measurement of Air Pollutant Emissions from In-service Passenger Ferries," Engine, Fuel and Emissions Engineering, Inc., Emissions Data Report Submitted to San Francisco Bay Area Water Transit Authority, San Francisco, CA, 2002.

21. Weaver, C.S. and Balam-Almanza, M.V., "Development of the "RAVEM" RideAlong Vehicle Emission Measurement System for Gaseous and Particulate Emissions," Warrendale, PA, SAE Paper No. 2001-01-3644, 2001. 
22. Basar, P., Duncan, and D., Langer, D., "Step Forward In Diesel Engine Emissions Reduction: System Incorporating a Novel Low Emission Diesel Fuel Combined With a Diesel Oxidation Catalyst," Warrendale, PA, SAE Paper No. 2001-01-2491, 2001.

23. Fanick, E.R., Schubert, P.F., Russell, B.J., and Freerks, R.L., "Comparison of Emission Characteristics of Conventional, Hydro treated, and Fischer-Tropsch Diesel Fuels in a Heavy-Duty Diesel Engine," Warrendale, PA, SAE Paper 2001-01-3519, 2001.

24. "Water in Diesel Combustion," DieselNet, Ecopoint Inc, Brampton, ON, Canada, 2002. http://www.dieselnet.com/tech/engine water.html

25. Langer, D., Petek, N., and Schiferl, E., "Maximizing the Effectiveness of Water Blended Fuel in Reducing Emissions by Varying Injection Timing or Using Aftertreatment Device," Warrendale, PA, SAE Paper No. 2001-01-0513, 2001.

26. Su, T.F., Chang, C., Reitz, R., Farrell, P., Pierpont, A., and Tow, T., "Effects of Injection Pressure and Nozzle Geometry on Spray SMD and D.I. Emissions," Warrendale, PA, SAE Paper 952360, 1995.

27. California Air Resources Board (CARB). The Carl Moyer Program. Sacremento, CA, 2004.

28. Grone, O., Aabo, K., and Skjoldager, P., "Enhanced Application and Emission Control Possibilities With Electronically Controlled Low Speed Diesels," New York, NY, ASME Paper No. ICEF2004-901, 2004.

29. Mello, J.P. and Mellor, A. M., "NOx Emissions from Direct Injection Diesel Engines with Water/Steam Dilution,” Warrendale, PA, SAE Paper No. 1999-01-0836, 1999.

30. Bedford, F., Rutland, C., Dittrich, P., Raab, A., and Wirbeleit, F. "Effects of Direct Water Injection on DI Diesel Engine Combustion," Warrendale, PA, SAE Paper No. 2000-01-2938, 2000.

31. Kegl, B. and Pehan, S., "Reduction of Diesel Engine Emissions by Water Injection," Warrendale, PA, SAE Paper No. 2001-01-3259, 2001.

32. Chandler, G., Cooper, B., Harris, J., Thoss, J., Uuslmaki, A., Walker, A., and Warren, J., "An Integrated SCR and Continuously Regenerating Trap System to Meet Future NOx and PM Legislation," Warrendale, PA, SAE Paper No. 2000-01-0188, 2000.

33. Gekas, I., Gabrielson, P., Johansen, K., Nvengaard, L., and Lund, T., "Urea-SCR Catalyst System Selection for Fuel and PM Optimized Engines and a Demonstration of a Novel Urea Injection System," Warrendale, PA, SAE Paper No. 2002-01-0289, 2002. 
34. Gleshoff, J., Schafer-Sindlinger, A, Spurk, P.C., van den Tillaart, J. A. A. and Garr, G., "Improved SCR Systems for Heavy Duty Applications," Warrendale, PA, SAE Paper No. 2000-01-0189, 2000.

35. Miller, W.R., Klein, J.T., Mueller, R., and Doelling, W., "The Development of UreaSCR Technology for US Heavy-duty Trucks," Warrendale, PA, SAE Paper No. 200101-0190, 2001.

36. Scarnegie, B., Miller, W.R., and Ballmert, B., "Recent DPF/SCR Results Targeting US2007 and Euro 4/5 HD Emissions," Warrendale, PA, SAE Paper No. 2003-010774, 2003.

37. Majewski, W., "Diesel Particulate Filters," DieselNet, Ecopoint Inc, Brampton, ON, Canada, 2001. http://www.dieselnet.com/tech/dpf top.html

38. McKinnon, D., "Seven Years Experience with Diesel Particulate Filter Systems in Non-road Applications," Warrendale, PA, SAE Paper No. 940234, 1994.

39. Lin, C.Y., "Reduction of Particulate Matter and Gaseous Emission from Marine Diesel Engines using a Catalyzed Particulate Filter," Ocean Engineering, Vol. 29 No. 11, New York, NY, 2002.

40. Chatterjee, S., McDonald, C., Conway, R., Vertin, K., LeTavec, C., Clark, N., and Gautam, M., "Emissions Reductions and Operational Experiences With Heavy Duty Diesel Fleet Vehicles Retrofitted With Continuously Regenerated Diesel Particulate Filters in Southern California," Warrendale, PA, SAE Paper No. 2001-01-0512, 2001.

41. Khair, M., Lemaire, J., and Fischer, S., "Integration of Exhaust Gas Recirculation, Selective Catalytic Reduction, Diesel Particulate Filters, and Fuel-Borne Catalyst for NOx/PM Reduction,” Warrendale, PA, SAE Paper No. 2000-01-1933, 2000.

42. "Diesel Particulate Filter CRT," Johnson Matthey Catalysts, Malvern, PA, 2004. http://www.jmcsd.com

43. Code of Federal Regulations, "Control of Emissions from New and In-Use Highway Vehicles and Engines," CFR Title 40 Part 86, Office of the Federal Register National Archives and Records Administration, Washington, DC, 2004.

44. Gibble, J., "Comparison of Heavy-Duty Diesel Engine Emissions Between an OnRoad Route and Engine Dynamometer Simulated On-Road Cycle," M.S. Thesis, Department of Mechanical and Aerospace Engineering, West Virginia University, Morgantown, WV, 2003.

45. Vellaisamy, R., "Assessment of NOx Destruction in Heavy-Duty Diesel Engines by Injecting Nitric Oxide into the Intake," M.S. Thesis, Department of Mechanical and Aerospace Engineering, West Virginia University, Morgantown, WV, 2005. 
46. Turner, T., "Alice Austen - Staten Island Ferry", Shipspotting.com, http://www.shipspotting.commodules/myalbum/photo.php?lid26835\&cid=9, 2005.

47. Jürgens, B. and Fork, W., "Faszination Voith-Schneider- Propeller: Geschichte und Technik," Koehlers Verlagsges, Hamburg, Germany, ISBN: 3-7822-0854-4, 2002.

48. West Virginia University and MJ Bradley \& Associates, "Protocol for Onboard Marine Vessel Data Logging for Implementing Emissions Reduction Strategies," Submitted to Port Authority of New York and New Jersey Dated October 15, 2003, New York City, NY.

49. Fritz N., Mathes, W., Mueller, R., and Zuerbig, J., "On-Road Demonstration of NOx Emission Control for Diesel Trucks with SiNOx Urea SCR System," Warrendale, PA, SAE Paper No. 1999-01-0111, 1999.

50. Code of Federal Regulations, "Control of Emissions from New and In-Use Non-road Compression-Ignition Engines," CFR Title 40 Part 89, Office of the Federal Register National Archives and Records Administration, Washington, DC, 2004.

51. Code of Federal Regulations, "Control of Air Pollution from Locomotives and Locomotive Engines," CFR Title 40 Part 92, Office of the Federal Register National Archives and Records Administration, Washington, DC, 2004.

52. "Measurement of Carbon Dioxide, Carbon Monoxide, and Oxides of Nitrogen in Diesel Exhaust," SAE Standard, Warrendale, PA, SAE J177, 2002.

53. Brettschneider, J. "Extension of the Equation for Calculation of the Air-Fuel Equivalence Ratio,” Warrendale, PA, SAE Paper No. 972989, 1997.

54. Clark, N., Nine, R., Daley, J., Atkinson, C., Tennant, C., Lyons, D., Peerenboom, W., and Suski, V., "Heavy Duty Truck Emissions: Driving Routes and $\mathrm{NO} / \mathrm{NO}_{2}$ Ratios," $8^{\text {th }}$ CRC On-Road Vehicle Emissions Workshop, San Diego, CA, April 1998.

55. U.S. Census Bureau, Census 1998, "generated by John Nuszkowski," using TIGER Mapping Service, <http://tiger.census.gov/cgi-bin/mapbrowse-tbl>, July 11, 2005.

56. Van Helden, R., Verbeek, R., Willems, F., and van der Welle, R., “Optimization of Urea SCR deNOx Systems for HD Engines," Warrendale, PA, SAE Paper No. 200401-0154, 2004.

57. Saito, S., Shinozaki, R., Suzuki, A., Jyoutaki, H., and Takeda, Y., "Development of Urea-SCR System for Commercial Vehicle - Basic Characteristics and Improvement of NOx Conversion at Low Load Operation," Warrendale, PA, SAE Paper No. 200301-3248, 2003.

58. Rusch, K., Hoffman, L., Zuerbig, J., and Scarnegie, B., 2003. "PM-Reduction by SCR-Catalyst,” Warrendale, PA, SAE Paper No. 2003-01-0777, 2003. 
59. Havenith, C. and R.P. Verbeek, "Transient Performance of a Urea DeNOx Catalyst for Low Emissions Heavy-Duty Diesel Engines,” Warrendale, PA, SAE Paper No. 970185, 1997. 


\section{APPENDIX A FUEL ANALYSIS \\ S O U T H W E T R E E A R C H I N T I T U T E \\ 6220 CULEBRA RD, 79238-5196 - P.O. DPAWER $2851079228-0510$ - SAN ANTONIO, TEXAS, USA - (210) 684-5111 * WWW.SWP!.OAG}

June 9,2005

Mr. Thomas K. Spencer

West Virginia University

Mechanical and Aerospace Engineering

Engineering Science Bldg. BM B39

Motgantown, WV 26506

Phone: (304) 293-2419

Re: Final Report

Fuel testing Request April 29, 2005

SwRI WO\#30005 [1.08.05.10959.01.145]

Page 1 of 2

Dear Mr. Spencer:

Analyses for various parameters are complete on your diesel samples. The gallon containers were received on May 20, 2005 in good condition. Testing took place from May 23 through June 6, 2005. Test methods and results obtained are shown on the attached summary table.

Testing was performed according to ASTM test methods with no deviations or modifications. Sample aliquots were taken in accordance with each ASTM test procedure. Precision should be consistent with those stated in the ASTM test procedures. These analyses pertain only to the samples received by Southwest Research Institute and represent only a sampling of each lot. This report shall not be reproduced except in full without the express written permission of Southwest Research Institute.

If there are any questions concerning these analyses or if you have further instructions please contact me at (210) 522-2181.

Sincerely,

$\cap \wedge \wedge \cap \wedge$,

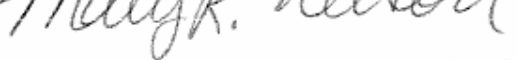

Mary R. Nelson, Senior Research Scientist

Fuels and Lubricants Section

Petroleum Products Research Department

Office of Automotive Engineering

OMRRAFI5

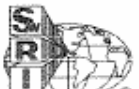

HOUSTON, TEXAS (713) 977-1377 - WASHINGTON, DC (301) 881-0226 


\section{DATA SUMMARY for WEST VIRGINIA UNIVERSITY \\ SwRI WO\#30005 [1.08.05.10959.01.145] \\ Page 2 of 2}

June 9,2005

\begin{tabular}{|l|c|c|c|}
\hline Test Parameter & $\begin{array}{c}\text { WVFUEL } \\
0065\end{array}$ & $\begin{array}{c}\text { WVFUEL } \\
0066\end{array}$ & $\begin{array}{c}\text { WVFUEL } \\
0067\end{array}$ \\
\hline SwRI Lab\# & 44697 & 44698 & 44699 \\
\hline ASTM D1319, Aromaticity (vol\%) & & & \\
Aromatics & 39.2 & 37.4 & 38.2 \\
Olefins & 1.9 & 1.5 & 1.4 \\
Sarurates & 58.9 & 61.1 & 60.4 \\
\hline ASTM D2622 Sulfur (ppm) & 873 & 944 & 919 \\
\hline ASTM D5186 Aromatics by SFC (wt $\%)$ & & & \\
Total Aromatics & 38.3 & 38.2 & 38.6 \\
Mono Aromatics & 18.8 & 18.7 & 19.0 \\
Polynuclear Aromatics & 19.4 & 19.5 & 19.7 \\
\hline
\end{tabular}

OMRRAFI5 


\section{S OUTHWEST RESEARCH INST IT U T E \\ 6220 CULEBRA RD. $78238-5166$ - P.O. DRAWEA 28510 76226-0510 - SANANTONIO. TEXAS, USA (210) 604-5111 - WWW.SWR!ORG}

June 9, 2005

Mr. Thomas K. Spencer

West Virginia University

Mechanical and Aerospace Engineering

Engineering Science Bldg. BM B39

Morgantown, WV 26506

Phone: (304) 293-2419

Re: $\quad$ Final Report

Fuel testing Request May 18, 2005

SwRI WO\#30006 [1.08.05.10959.01.145]

Page 1 of 2

Dear Mr. Spencer:

Analyses for various parameters are complete on your diesel sample. The gallon container was received on May 20, 2005 in good condition. Testing took place from May 22 through June 7,2005 . Test methods and results obtained are shown on the attached summary table.

Testing was performed according to ASTM test methods with no deviations or modifications. Sample aliquots were taken in accordance with each ASTM test procedure. Precision should be consistent with those stated in the ASTM test procedures. These analyses pertain only to the samples received by Southwest Research Institute and represent only a sampling of each lot. This report shall not be reproduced except in full without the express written permission of Southwest Research Institute.

If therc are any questions concerning these analyses or if you have further instructions please contact me at (210) 522-2181.

Sincerely,

$$
\text { m A } 1 . .0
$$

Mary R. Nelson, Senior Research Scientist Fuels and Lubricants Section

Petroleum Products Research Department

Offece of Automotive Engineering 


\section{DATA SUMMARY for WEST VIRGINIA UNIVERSITY}

SwRI WO\#30006 [1.08.05.10959.01.145]

Page 2 of 2

June 9, 2005

\begin{tabular}{|l|c|}
\hline Test Parameter & WVFUEL 0068 \\
\hline SwRI Lab\# & 44700 \\
\hline ASTM D2622 Sulfur (ppm) & 931 \\
\hline ASTM D287 API Gravity & 31.7 \\
\hline ASTM D445 Kinematic Viscosity @ $40^{\circ} \mathrm{C}(\mathrm{cSt})$ & 2.935 \\
\hline ASTM D5291 Elemental Analysis (wt $\%$ ) & 87.01 \\
Carbon & 12.34 \\
\hline Hydrogen & 43.6 \\
\hline ASTM D613 Cetane Numbers & $172 / 77.8$ \\
\hline ASTM D93 Flash Point $\left({ }^{\circ} \mathrm{F} /{ }^{\circ} \mathrm{C}\right)$ & \\
\hline ASTM D86 Distillation, ${ }^{\circ} \mathrm{F}$ & 365.5 \\
IBP & 422.0 \\
$5 \%$ & 445.4 \\
$10 \%$ & 459.9 \\
15\% & 470.9 \\
$20 \%$ & 489.4 \\
$30 \%$ & 504.2 \\
$40 \%$ & 520.0 \\
$50 \%$ & 536.5 \\
$60 \%$ & 555.3 \\
$70 \%$ & 579.1 \\
$80 \%$ & 613.5 \\
$90 \%$ & 640.0 \\
$95 \%$ & 662.7 \\
FBP & 98.4 \\
Recovered & 1.2 \\
Loss & 0.4 \\
Residue & \\
\hline & \\
\hline & \\
\hline
\end{tabular}

OMRRBFI5 


\title{
APPENDIX B DATALOGGER EXAMPLE PROGRAM
}

\author{
BEGIN"DAY1" \\ CATTN \\ 'Spans and polynomial declarations \\ $\mathrm{S} 1=0,2400,0,7320$ \\ $\mathrm{S} 2=0,1000,1.8,5008.34$ \\ $\mathrm{S} 3=0,1000,1.39,5005.93$ \\ $\mathrm{S} 4=0,1000,1.74,5005.28$ \\ $\mathrm{S} 5=0,1000,-0.27,5004.68$ \\ $\mathrm{S} 6=0,1000,0.35,5004.89$ \\ $\mathrm{S} 7=0,1000,2.45,5006.15$ \\ $\mathrm{S} 8=0,1000,0.02,5004.25$ \\ $\mathrm{S} 9=0,1000,2.8,5006.67$ \\ $\mathrm{S} 10=0,30,1013.499,4999.209$ \\ $\mathrm{S} 11=0,30,1013.795,5004.804$ \\ $\mathrm{S} 12=0,30,1009.9,5004.58$ \\ $\mathrm{S} 13=0,30,1005.19,5005.19$ \\ $\mathrm{S} 14=0,15,1006.886,5048.197$ \\ $\mathrm{S} 15=0,15,949.765,4952.197$ \\ $\mathrm{S} 16=0,15,1013.94,5013.94$ \\ $\mathrm{S} 17=0,15,1013.16,4991.94$ \\ $\mathrm{S} 18=0,2000,-1999.44,-653.81$ \\ $\mathrm{S} 19=0,2000,-1986.43,-703.64$ \\ $\mathrm{S} 20=0,2000,-1969.96,-709.49$ \\ S21 $=0,2000,-2009.9,-777.54$ \\ 'Parameter declarations \\ $\mathrm{P} 11=60$ \\ $\mathrm{P} 31=3$ \\ $\mathrm{P} 46=2$ \\ $\mathrm{P} 57=3$
}

'Global Schedule Runs Once

RS1S

'Sets up serial channel to communicate with Garmin Model 35/36 GPS

$\mathrm{PS}=4800, \mathrm{~N}, 8,1, \mathrm{NOFC}$

'Empties the serial channel input buffer

1SERIAL(RS232,"\\e",W)

'Program initial conditions for checking engine run status to set LOGON/LOGOFF

$91 \mathrm{CV}(\mathrm{W})=10$

$81 \mathrm{CV}(\mathrm{W})=10$

'Logs day number for $24 \mathrm{hr}$ logging

$15 \mathrm{SV}(=100 \mathrm{CV}, \mathrm{W})$

'Logs hour for $1 \mathrm{hr}$ logging

'3ST $(=100 \mathrm{CV}, \mathrm{W})$ 
'Schedule A Trigger by serial

RA LOGONA GA

'Serial channel text string trigger

RA1SERIAL"\$GPRMC"

'Delay state for filling buffer

$\operatorname{DELAY}(\mathrm{W})=500$

'Stores serial data into seperate variables: Header, Latitude, Direction, Longitude, Direction, Speed

1SERIAL(RS232,"\%15s[1\$],\%f[1CV],\%1s[2\$],\%f[2CV],\%1s[3\$],\%f[3CV],\%f[4CV],\%6s $[4 \$], \| \mathrm{le}, 2, \mathrm{~W})$

'Formats serial data

$1 \$(" H e a d e r: ")$

$1 \mathrm{CV}($ "Latitude =",FF4) $=1 \mathrm{CV} / 100$

$2 \$(" ')$

$2 \mathrm{CV}($ "Longitude $=$ ",FF4) $=2 \mathrm{CV} / 100$

$3 \$(" ')$

$3 \mathrm{CV}("$ Speed $=\sim$ Knots",FF1 $)=3 \mathrm{CV}$

$4 \mathrm{CV}(\mathrm{FF} 1)=4 \mathrm{CV}$

$4 \$(" ')$

'schedule definition

RB100T LOGONB GB

'Speeds

7C(R,RS,"Aux Eng 1 Speed",FF1)

8C(R,RS,"Aux Eng 2 Speed",FF1)

$11+\mathrm{F}(\#,=20 \mathrm{CV}$, ,Engine NY Speed",1000,FF1,S1)

11-F(\#,=21CV,"Engine SI Speed",1000,FF1,S1)

$11 * \mathrm{~F}(\#,=22 \mathrm{CV}$,"Engine 3 Speed",1000,FF1,S1)

11\#F(\#,=23CV,"Engine 4 Speed",1000,FF1,S1)

'Thermocouples

3+V(\#,"MAT Eng 1",FF1,S2)

3-V(\#,"Exh Eng 1",FF1,S3)

$3 * \mathrm{~V}(\#$, ,MAT Eng 2",FF1,S4)

3\#V(\#,"Exh Eng 2",FF1,S5)

4+V("MAT Eng 3",FF1,S6)

4-V("Exh Eng 3",FF1,S7)

4*V("MAT Eng 4",FF1,S8)

12+V("Exh Eng 4",FF1,S9)

5TK("Exh St 1",FF1)

5*TK("Exh St 2",FF1)

6TK("Exh St 3",FF1)

6*TK("Exh St 4",FF1)

7TK("Exh Gen 1",FF1)

7*TK("Exh Gen 2",FF1)

8TK("Ambient Temp",FF1)

REFT 


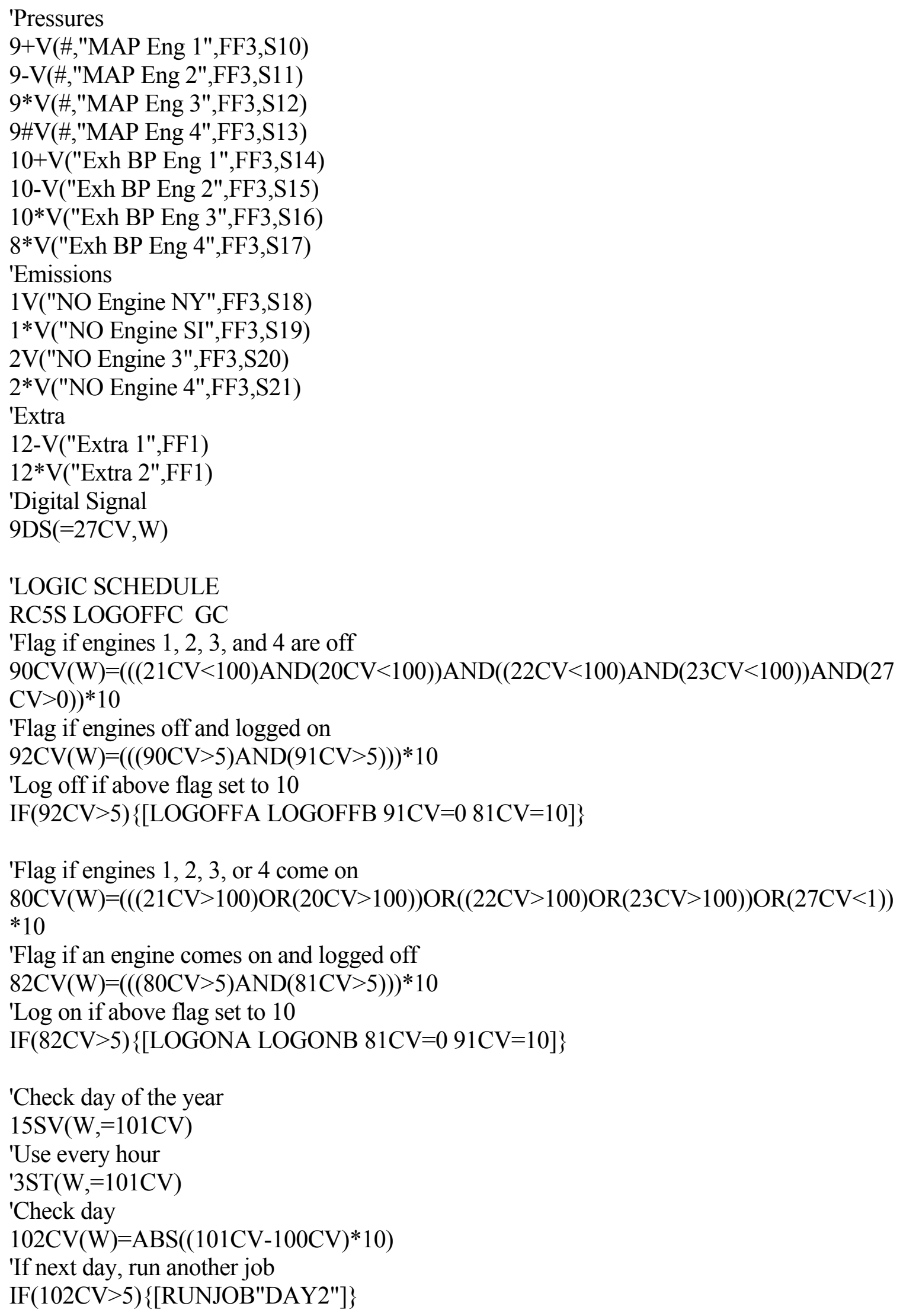

'Flag if engines 1, 2, 3, or 4 come on $80 \mathrm{CV}(\mathrm{W})=(((21 \mathrm{CV}>100) \mathrm{OR}(20 \mathrm{CV}>100)) \mathrm{OR}((22 \mathrm{CV}>100) \mathrm{OR}(23 \mathrm{CV}>100)) \mathrm{OR}(27 \mathrm{CV}<1))$ *10

'Flag if an engine comes on and logged off $82 \mathrm{CV}(\mathrm{W})=(((80 \mathrm{CV}>5) \mathrm{AND}(81 \mathrm{CV}>5))) * 10$

'Log on if above flag set to 10

$\mathrm{IF}(82 \mathrm{CV}>5)\{[\mathrm{LOGONA}$ LOGONB $81 \mathrm{CV}=0$ 91CV=10]\}

'Check day of the year

$15 \mathrm{SV}(\mathrm{W},=101 \mathrm{CV})$

'Use every hour

'3ST(W,=101CV)

'Check day

$102 \mathrm{CV}(\mathrm{W})=\mathrm{ABS}((101 \mathrm{CV}-100 \mathrm{CV}) * 10)$

'If next day, run another job

IF $(102 \mathrm{CV}>5)\{[$ RUNJOB"DAY2"]\} 
END 


\section{APPENDIX C GAS ANALYZER SPECIFICATIONS}

\begin{tabular}{|c|c|c|c|}
\hline Component & Manufacturer & Model Number & Accuracy \\
\hline MEMS EC NOx Analyzer & Sensors, Inc & AMBII & $\pm 4 \%$ \\
\hline MEMS ZrO ${ }_{2}$ NOx Analyzer & Horiba & MEXA-120 & $\pm 3 \%$ \\
\hline $\mathrm{EC} \mathrm{NO}$ Analyzer $_{2}$ & Sensors, Inc & AMBII & $\pm 4 \%$ \\
\hline $\mathrm{ZrO}_{2} \mathrm{NOx}$ Analyzer & Horiba & MEXA-720 & $\pm 3 \%$ \\
\hline $\mathrm{O}_{2}$ Analyzer & Horiba & MEXA-720 & $\pm 2 \%$ \\
\hline $\mathrm{CO}_{2}$ Analyzer & California Analytical & $300 \mathrm{NDIR}$ & $\pm 1 \%$ \\
\hline $\mathrm{CO}$ Analyzer & California Analytical & $300 \mathrm{NDIR}$ & $\pm 1 \%$ \\
\hline $\mathrm{CO}$ Analyzer & Horiba & AIA-210 & $\pm 1 \%$ \\
\hline $\mathrm{NOx}$ Analyzer & ECO Physics & CLD 844 CM h & $\pm 2 \%$ \\
\hline $\mathrm{NH}_{3}$ Analyzer & INNOVA & 1302 & $\pm 1 \%$ \\
\hline
\end{tabular}




\section{APPENDIX D CATERPILLAR ENGINE DATA}

Data for the engine configuration requested is not available with the correct engine hardware and/or settings. This estimate of emissions levels is based on measured data available for an engine with closest hardware and /or settings to the requested one. Emissions data measurement is consistant with those described in EPA CFR 40 Part 89 subpart D \& E and ISO 8178-1 for measuring $\mathrm{HC}, \mathrm{CO}, \mathrm{CO}$, and $\mathrm{NOx}$. These procedures are very similar to the methods described in EPA CFR 40 Part 60 Appendix A Method 25 A for hydrocarbons, Method 10 for $\mathrm{CO}$, Method $7 \mathrm{E}$ for NOx. Measured at standard conditions of 28.42 " $\mathrm{Hg}$ and number 2 diesel fuel with $35 \mathrm{API}$ and LHV of 18,390 BTU /Lb. If exact measurements are needed an emissions test will be required.

Provided data per this inquiry form represents NOMINAL engine emissions at rated power and rated speed at standard conditions and production injection timing and build conditions unless otherwise specified.

3516MUI marine rated 1156 BKW@1600 RPM using test spec 0rs\$13 at full load.

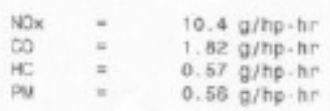

Nox to exceed data can be obtained by multipling the NOx value by 1.2 , the CO value by 1.8 , the $\mathrm{HC}$ value by 1.34 , and the PM value by 1.4

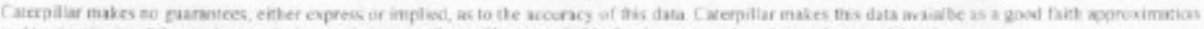

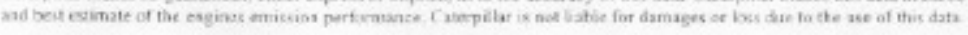

Figure D - 1 Engine Manufacture Emission Values Based on Similar Engine

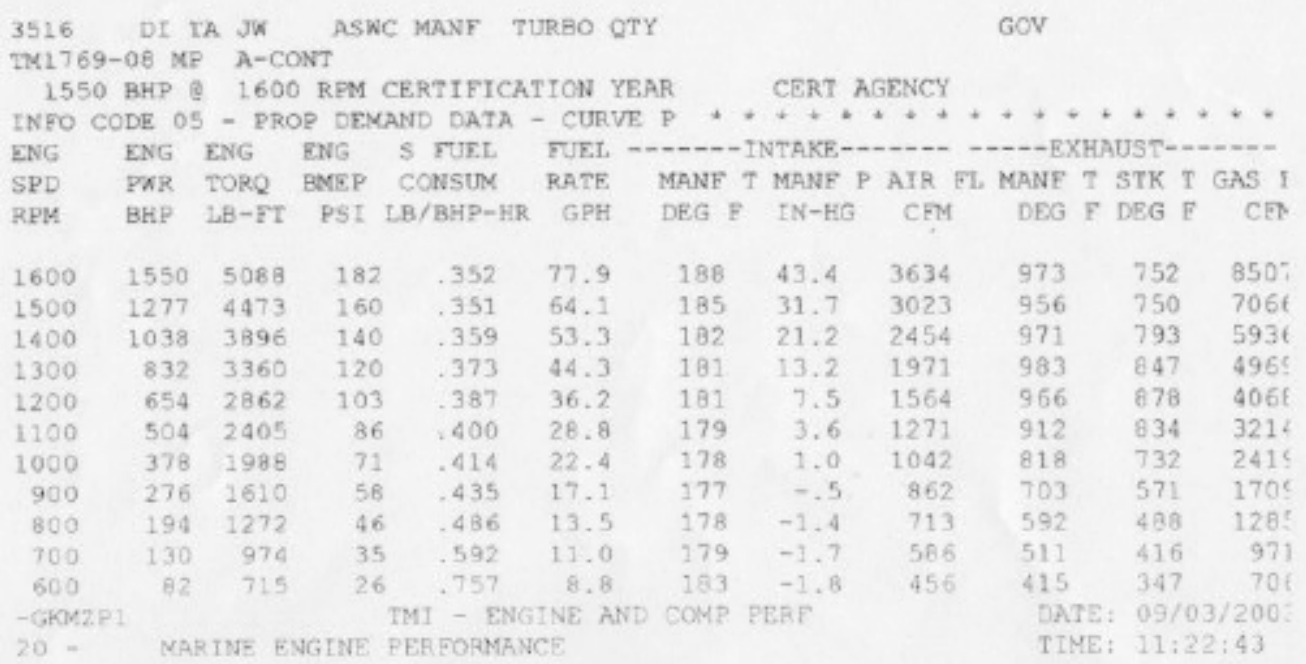

Figure D - 2 Engine Manufacture Data 


\section{APPENDIX E INDIVIDUAL RUN RESULTS}

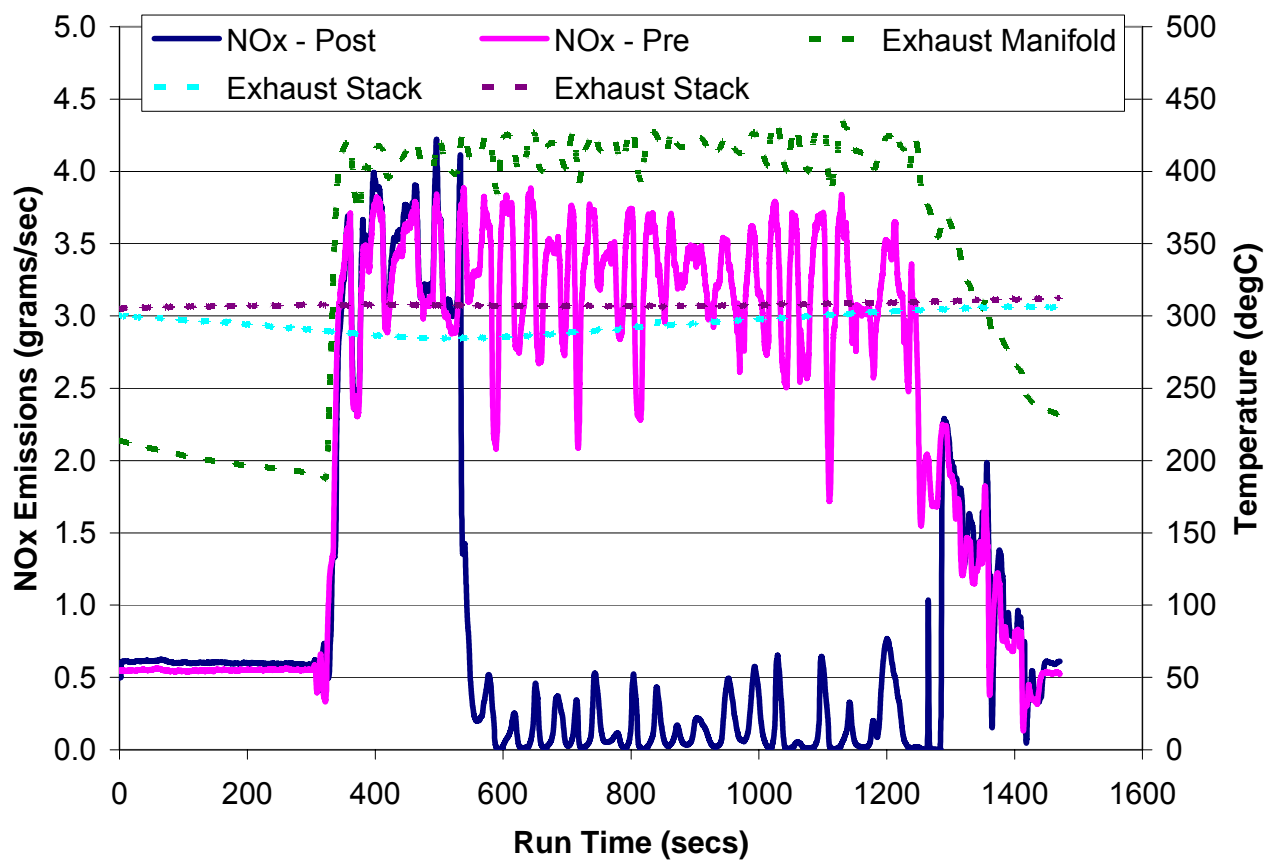

Figure E - 1 Engine NY, Manhattan to Staten Island, Run 2, 4/26/05

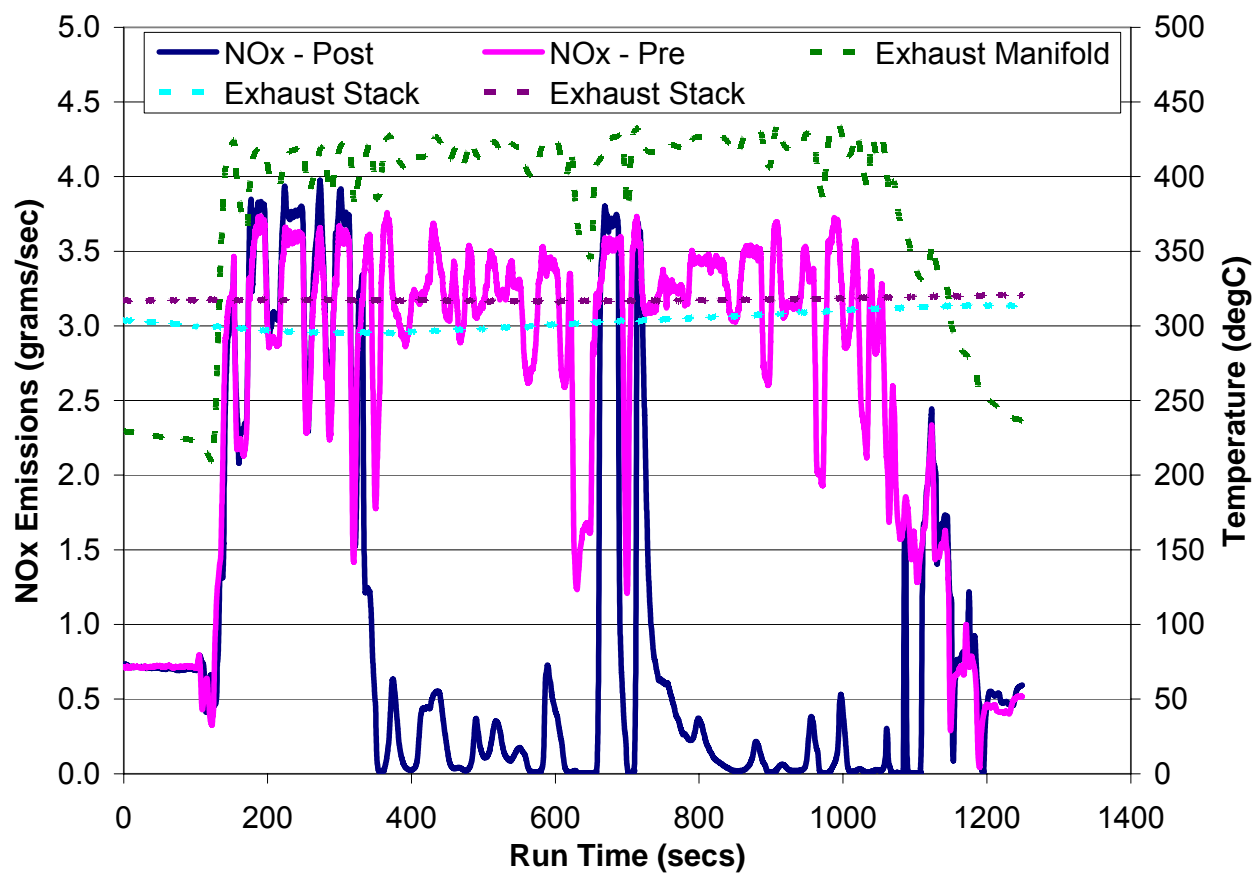

Figure E - 2 Engine NY, Manhattan to Staten Island, Run 4, 4/26/05 


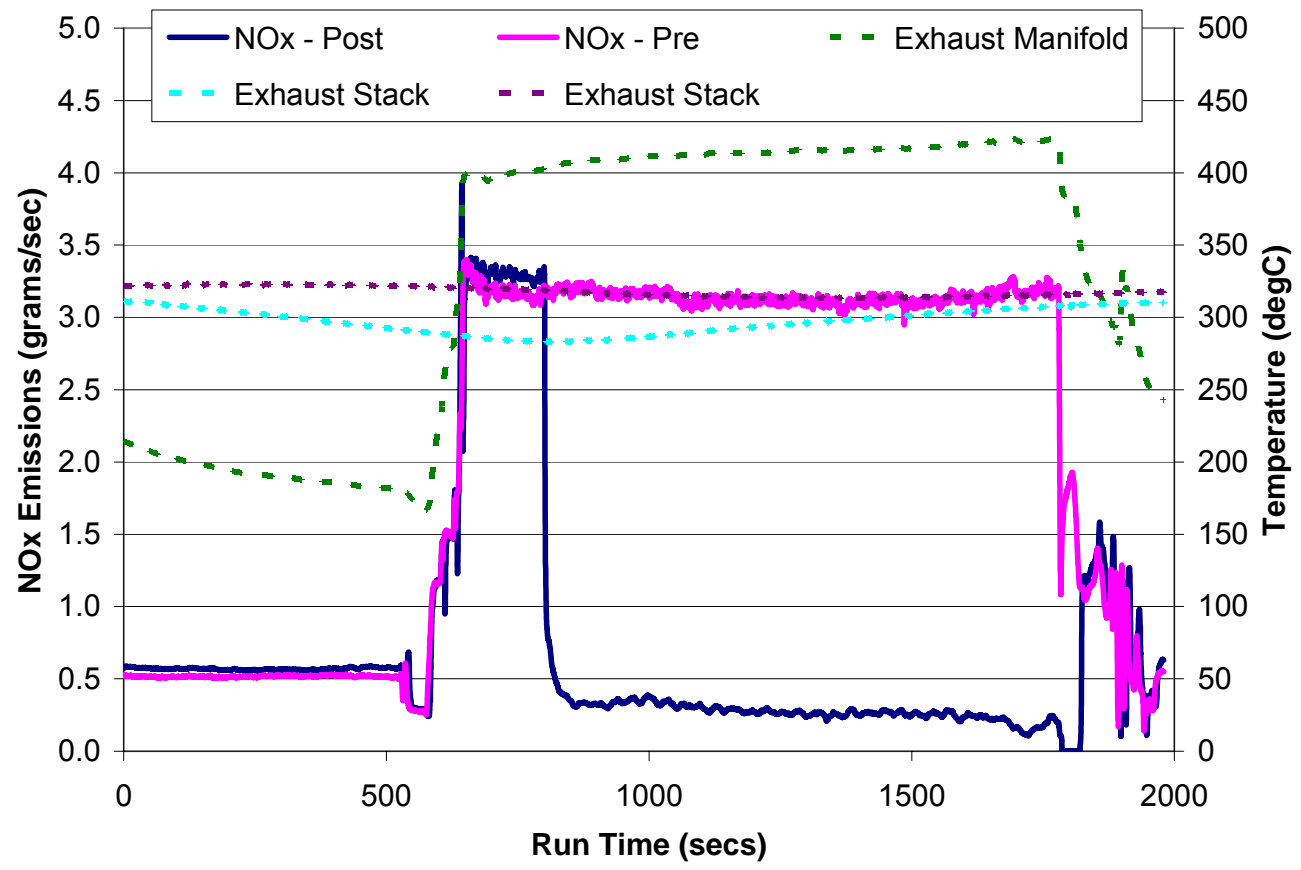

Figure E - 3 Engine NY, Staten Island to Manhattan, Run 5, 4/26/05

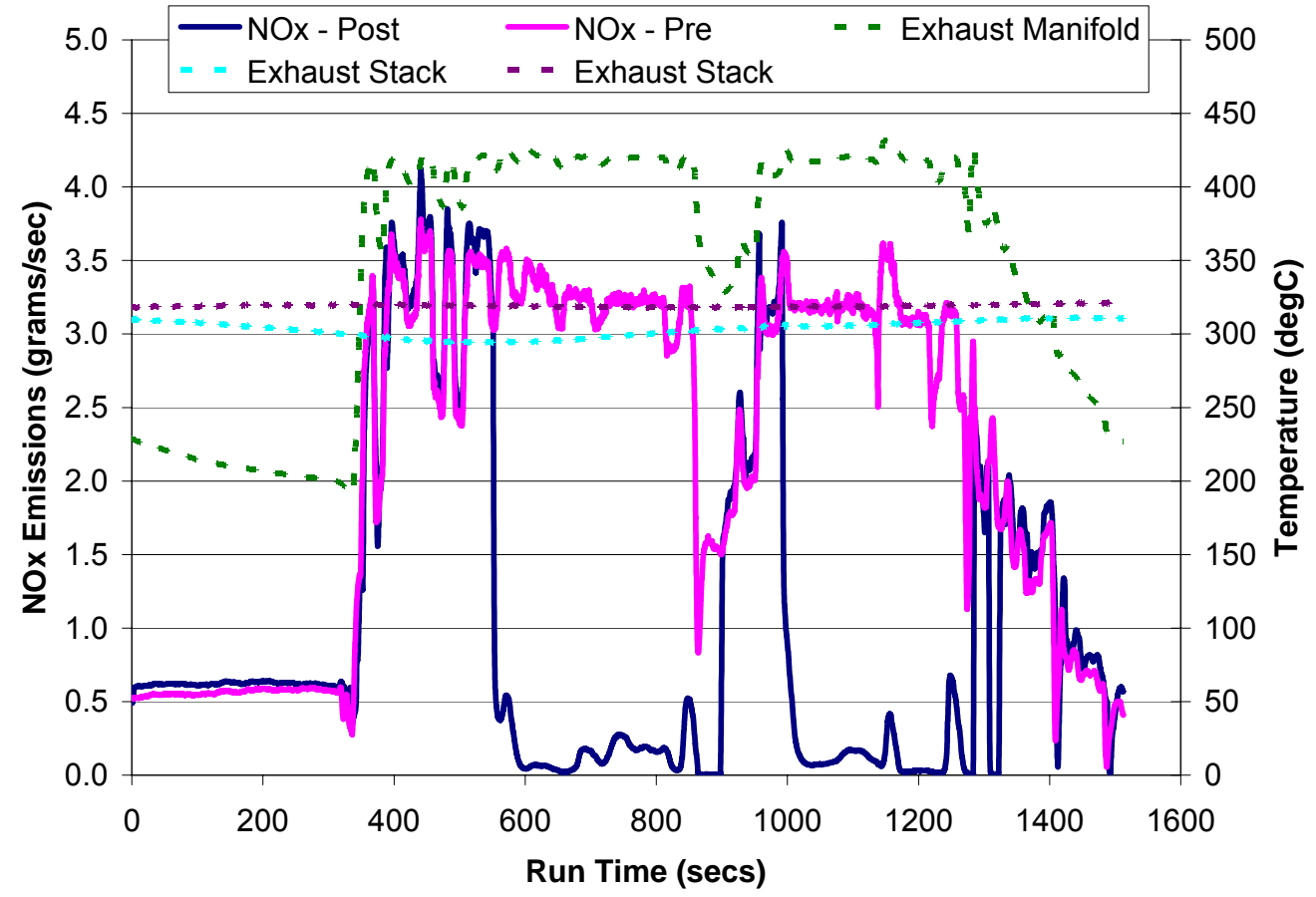

Figure E - 4 Engine NY, Manhattan to Staten Island, Run 5, 4/26/05 


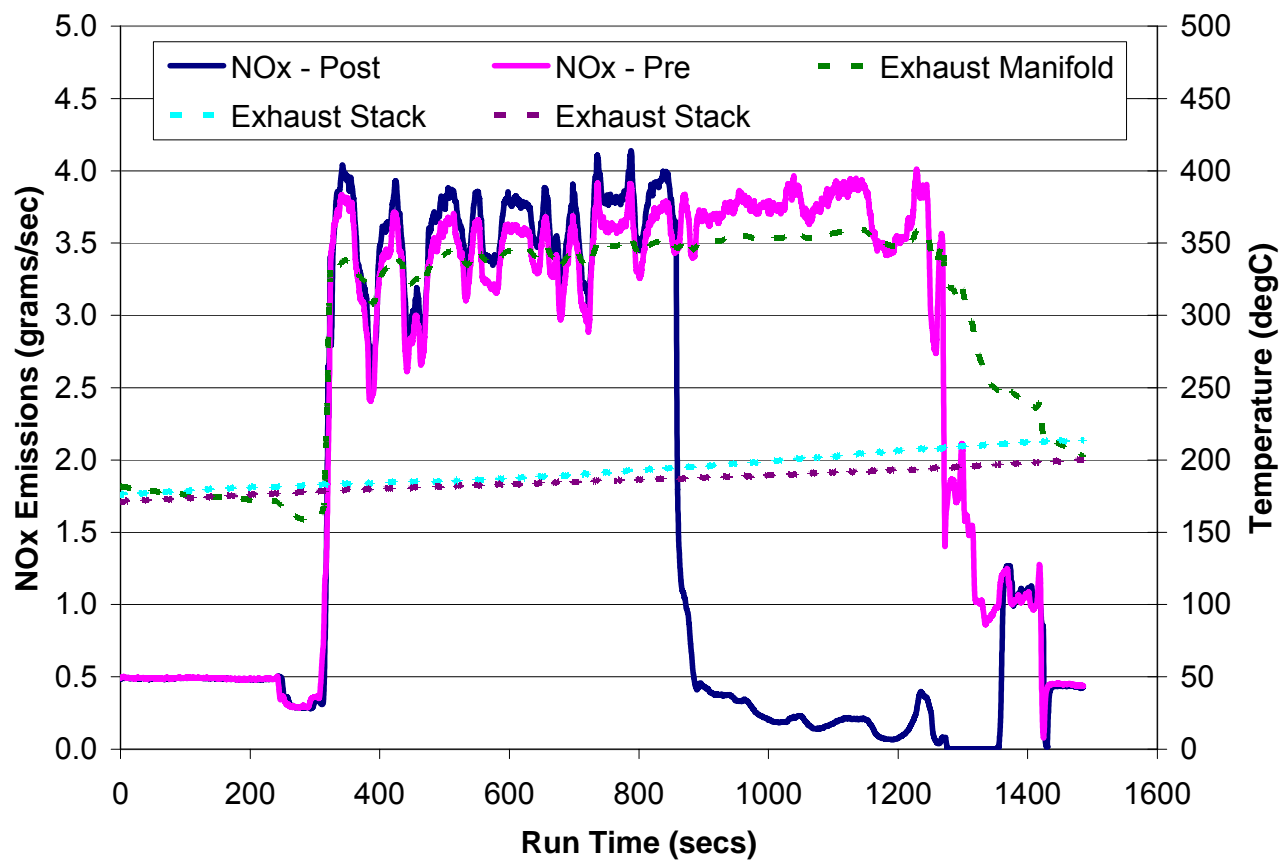

Figure E - 5 Engine SI, Staten Island to Manhattan, Run 2, 4/28/05

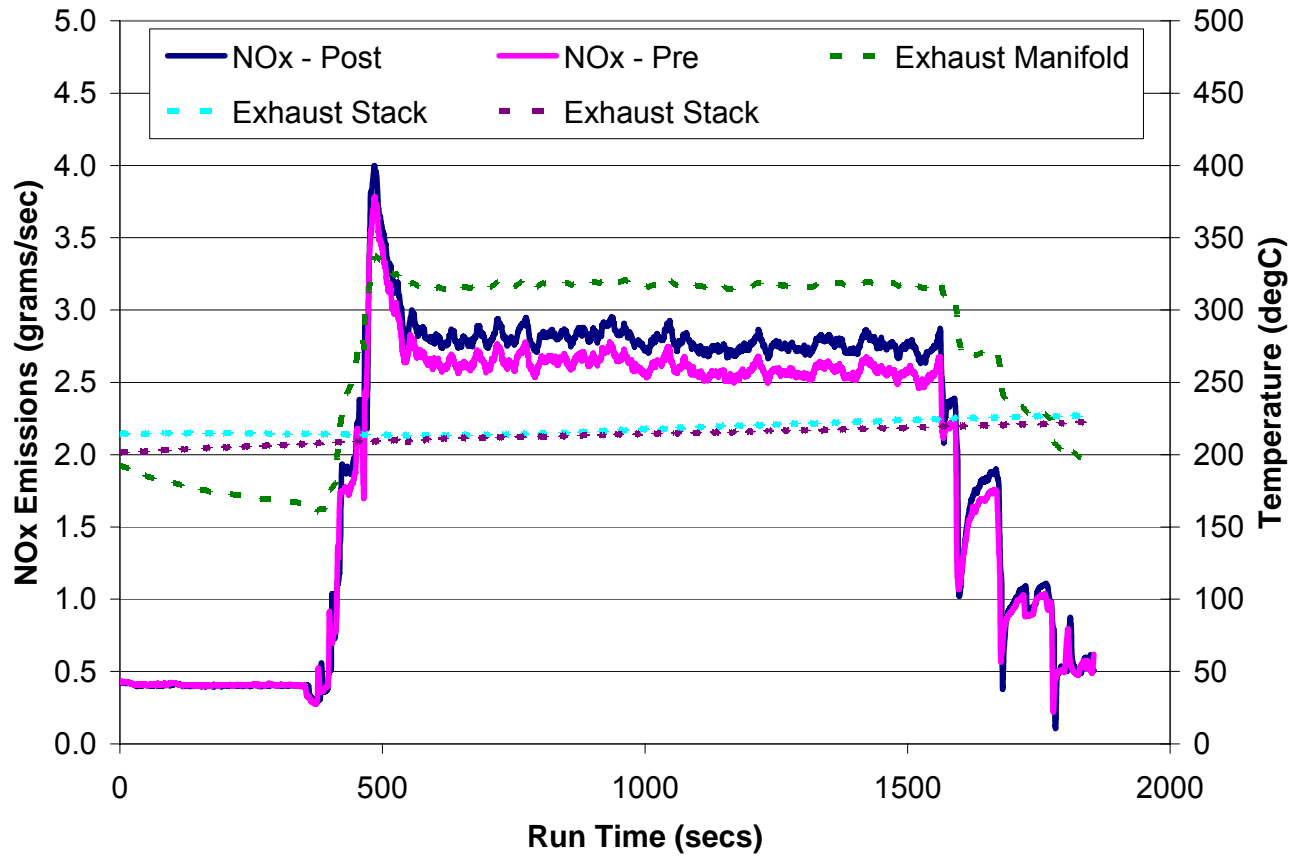

Figure E - 6 Engine SI, Manhattan to Staten Island, Run 2, 4/28/05 


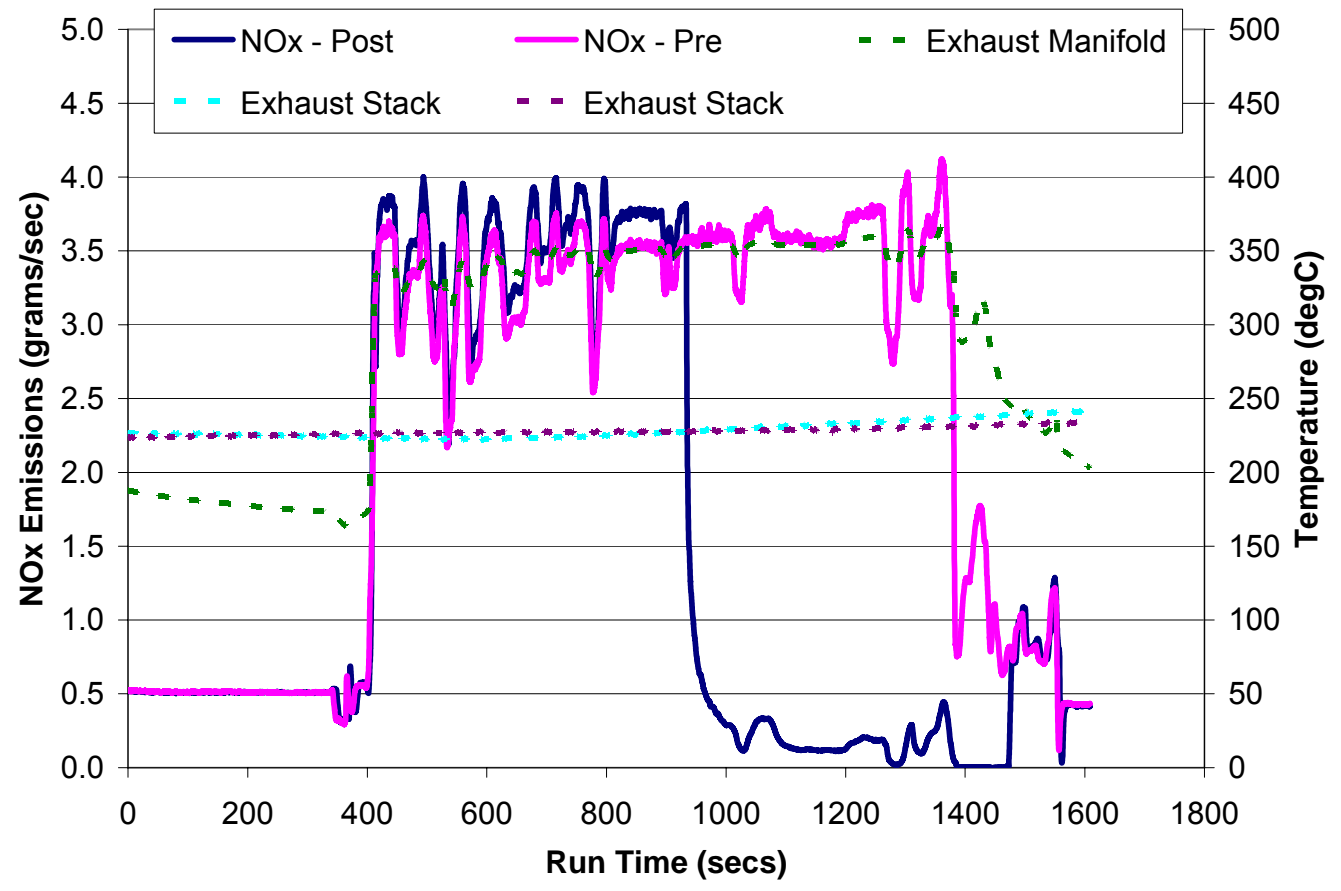

Figure E - 7 Engine SI, Staten Island to Manhattan, Run 3, 4/28/05

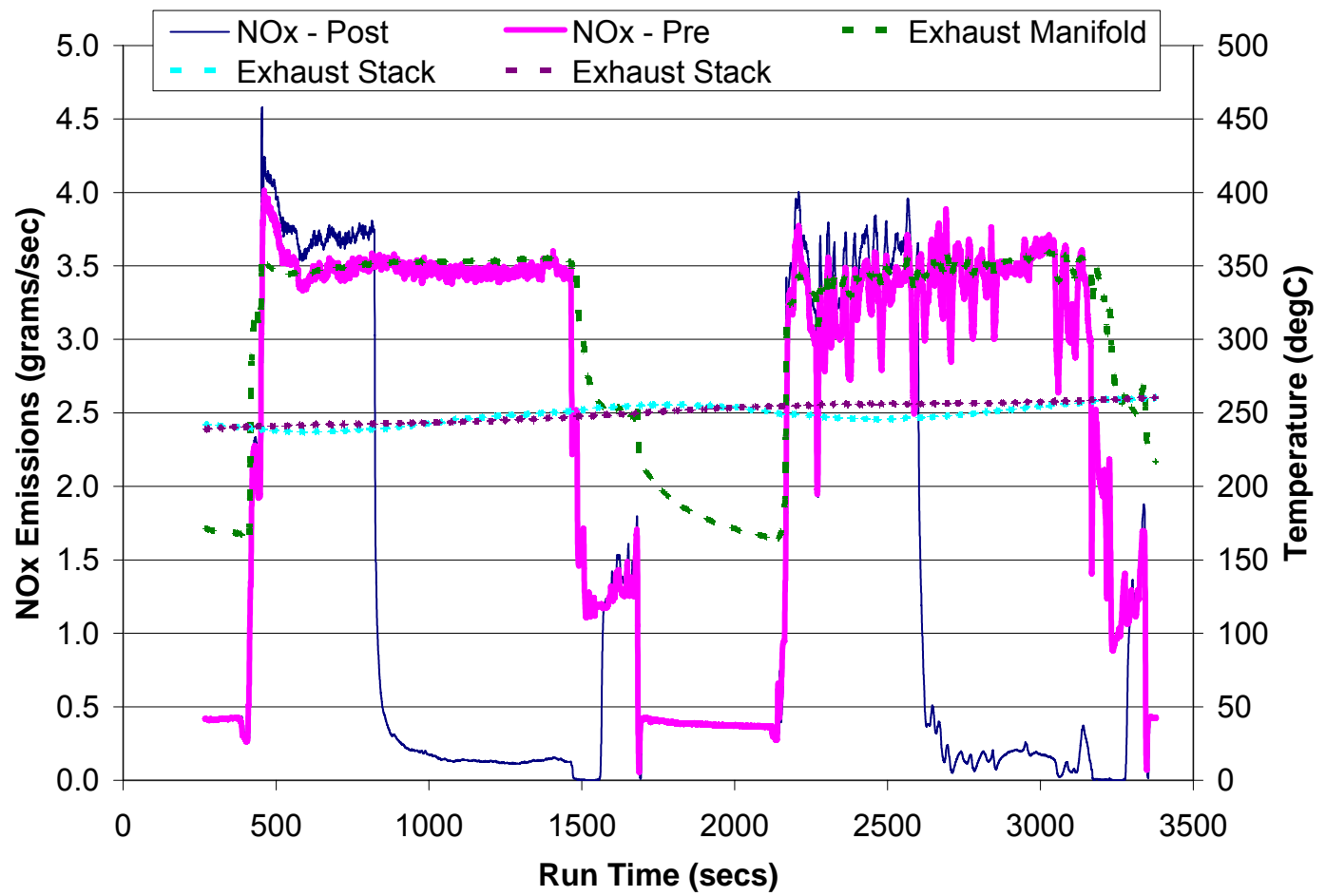

Figure E - 8 Engine SI, Manhattan to Staten Island and back, Run 3-4, 4/28/05 


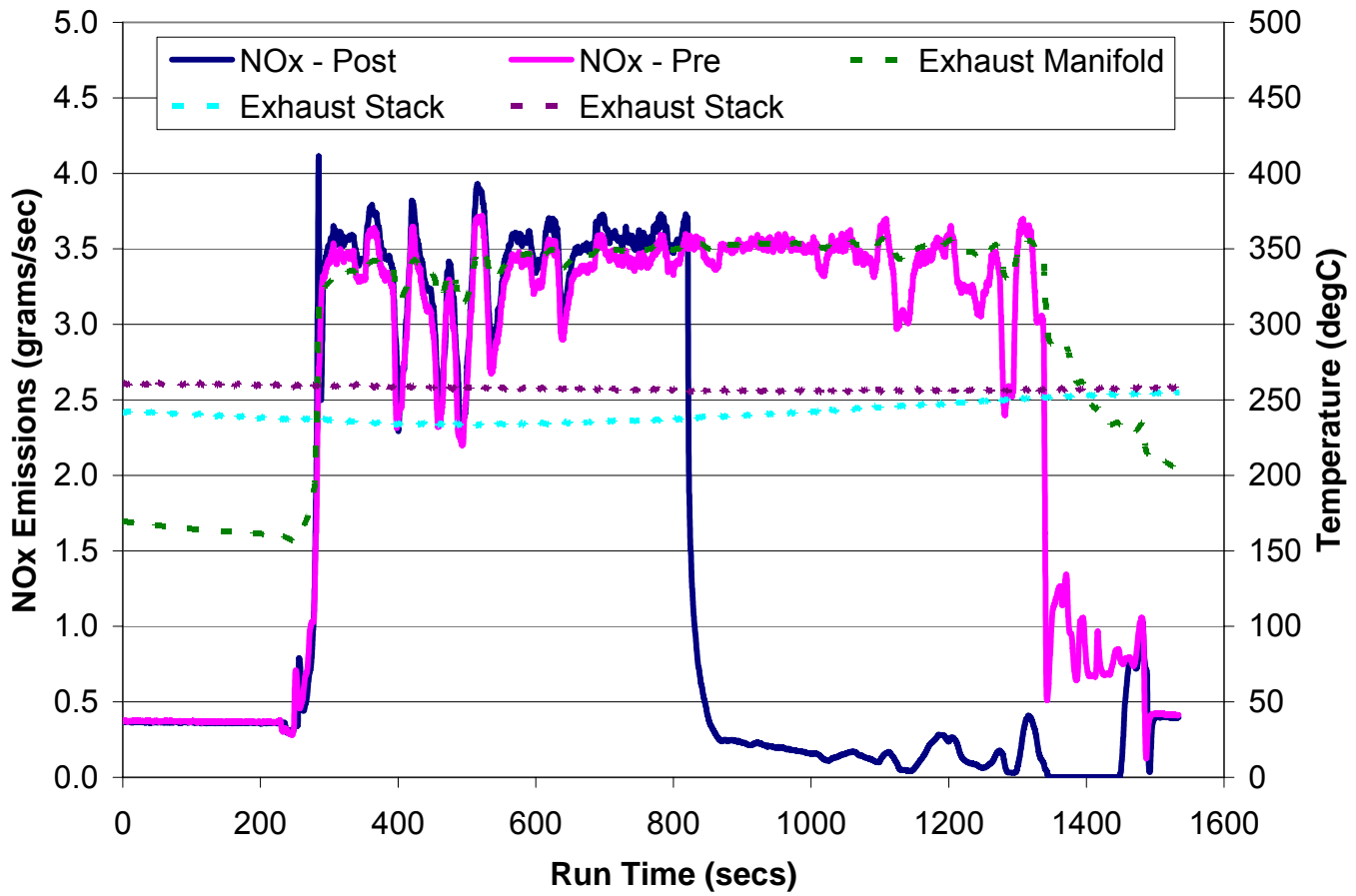

Figure E - 9 Engine SI, Staten Island to Manhattan, Run 4, 4/28/05 